\title{
THE PLANNING AND IMPLEMENTATION PROCESS OF PROGRAMMATIC ADVERTISING CAMPAIGNS IN EMERGING MARKETS
}

\author{
Jyväskylä University \\ School of Business and Economics \\ Master's Thesis \\ Spring 2020
}

Author: Thanh Tiet Subject: Digital Marketing and Corporate Communication Supervisors: Heikki Karjaluoto \& Aijaz A. Shaikh

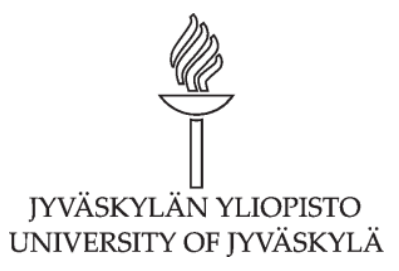




\section{ABSTRACT}

\begin{tabular}{|c|c|}
\hline $\begin{array}{l}\text { Author: } \\
\text { Thanh Tiet }\end{array}$ & \\
\hline $\begin{array}{l}\text { Title: } \\
\text { The planning and implementation process of prog } \\
\text { campaigns in emerging markets }\end{array}$ & tic advertising \\
\hline $\begin{array}{l}\text { Subject: } \\
\text { Digital Marketing and Corporate Communication }\end{array}$ & $\begin{array}{l}\text { Type of work: } \\
\text { Master's thesis }\end{array}$ \\
\hline $\begin{array}{l}\text { Date: } \\
\text { May } 2020\end{array}$ & $\begin{array}{l}\text { Number of pages: } \\
85+3 \text { (appendices) }\end{array}$ \\
\hline $\begin{array}{l}\text { Abstract: } \\
\text { Programmatic advertising has developed rapidly } \\
\text { the driver of the exponential growth of online ad } \\
\text { vertising initially involved with programmatic bu } \\
\text { to include programmatic creative. While program } \\
\text { back from the 2000s and already developed, prog } \\
\text { phenomenon in recent years and still developing } \\
\text { vertising is the combination of technology and a } \\
\text { brands to deliver personalised ads to the right ta } \\
\text { thesis studies the situation of programmatic adve } \\
\text { implementation process in emerging countries, est } \\
\text { The study results suggest that programmatic } \\
\text { both long-term brand building campaigns and sho } \\
\text { paigns for different reasons. And each campaign } \\
\text { ning and implementation process. In brief, the ac } \\
\text { term direct response campaigns is a non-linear pr } \\
\text { phase and implementation phase are integrated w } \\
\text { vertising process for long-term brand building ca } \\
\text { linear spectrum and the two phases are clearly sepa } \\
\text { grammatic advertising process is data-driven beca } \\
\text { steps of the advertising process. Lastly, the advert } \\
\text { anced combination between system automation an } \\
\text { ment to be effective. }\end{array}$ & $\begin{array}{l}\text { cent years and become } \\
\text { ing. Programmatic ad- } \\
\text { and gradually evolved } \\
\text { buying could be dated } \\
\text { natic creative is a new } \\
\text { rief, programmatic ad- } \\
\text { ce data, which allows } \\
\text { audience at scale. This } \\
\text { g and its planning and } \\
\text { ly Vietnam market. } \\
\text { rtising is leveraged for } \\
\text { m direct response cam- } \\
\text { ive has different plan- } \\
\text { sing process for short- } \\
\text { in which the planning } \\
\text { ch other, while the ad- } \\
\text { gns skews toward the } \\
\text { Furthermore, the pro- } \\
\text { ata are leveraged in all } \\
\text { process requires a bal- } \\
\text { ital specialists' involve- }\end{array}$ \\
\hline $\begin{array}{l}\text { Keywords } \\
\text { online advertising, programmatic advertising, ad } \\
\text { campaign management }\end{array}$ & process, advertising \\
\hline $\begin{array}{l}\text { Place of storage } \\
\text { Jyväskylä University Library }\end{array}$ & \\
\hline
\end{tabular}




\section{CONTENTS}

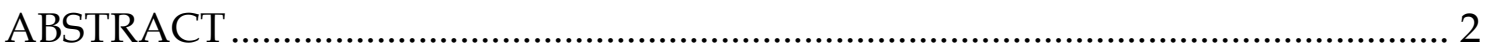

LISTS OF FIGURES, TABLES, APPENDICES, ABBREVIATIONS ....................... 5

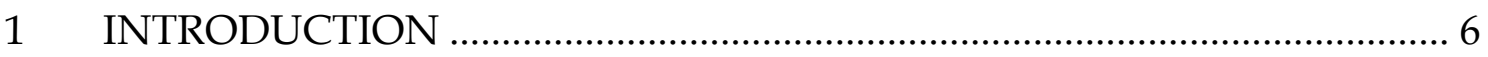

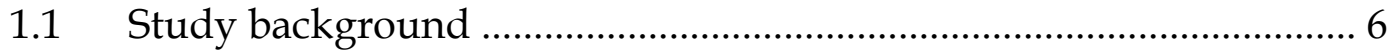

1.1.1 Programmatic advertising and research gap .......................... 6

1.1.2 The potential of emerging markets ...................................... 7

1.2 Study objective and research questions.......................................... 7

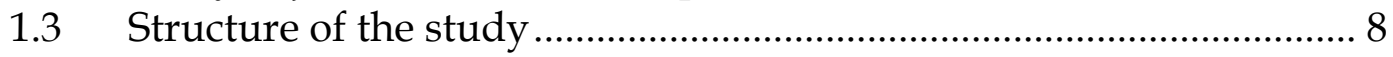

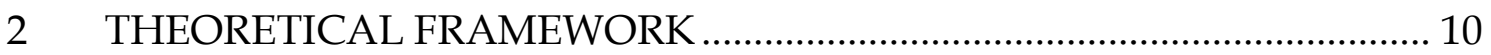

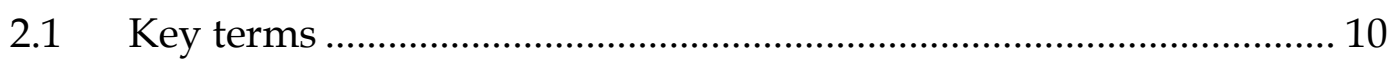

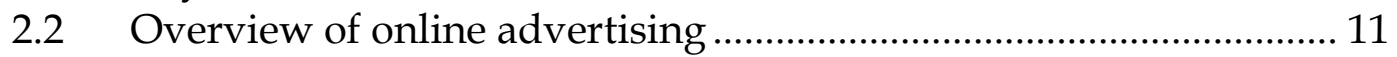

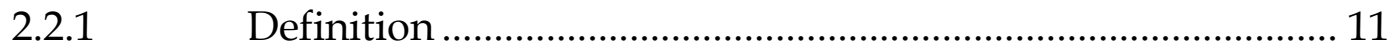

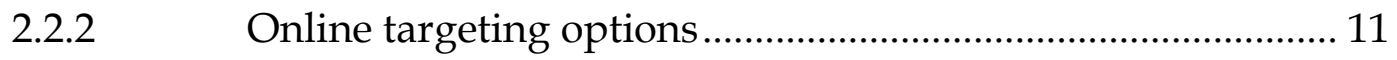

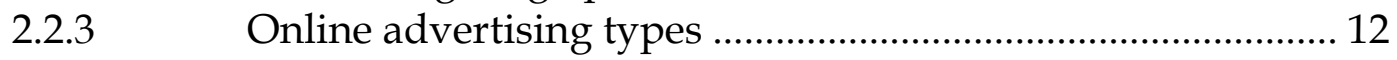

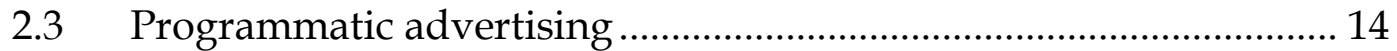

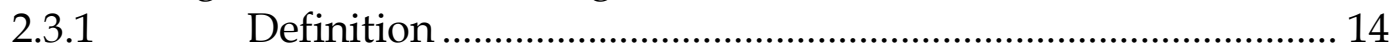

2.3.2 Programmatic buying ........................................................ 16

2.3.3 Programmatic creative ....................................................... 21

2.4 Online advertising planning and implementation process ............. 23

2.4.1 Setting campaign objectives and effectiveness metrics.......... 23

2.4.2 Campaign insight discovery ................................................. 24

2.4.3 Strategic advertising planning ............................................... 25

2.4.4 Message strategy and ad creation ........................................... 27

2.4.5 Media planning and buying................................................. 27

2.4.6 Campaign optimisation and evaluation................................. 29

2.5 Impact of programmatic advertising on the advertising process.... 31

2.5.1 New online advertising process .............................................. 31

2.5.2 Challenges of programmatic advertising................................ 34

2.6 Summary of the literature review …............................................... 36

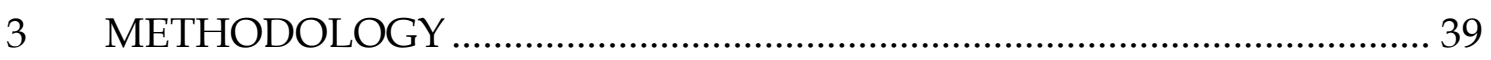

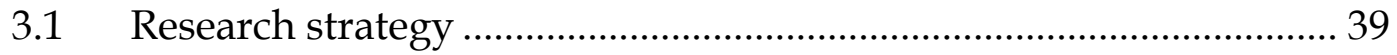

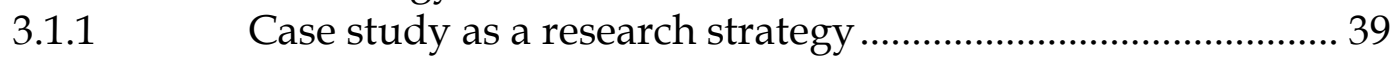

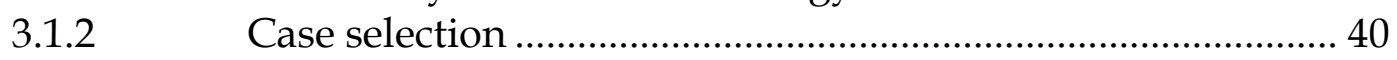

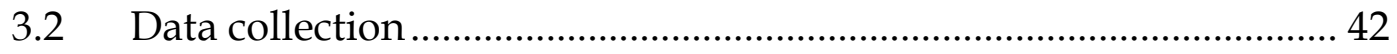

3.2.1 Interview as a data collection method .................................. 42

3.2.2 Recruiting study participants ............................................ 43

3.2.3 Conducting semi-structured interviews .............................. 43

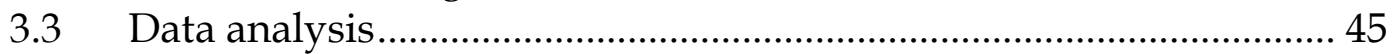

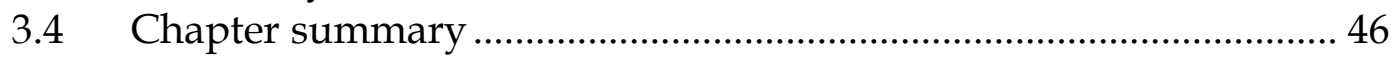




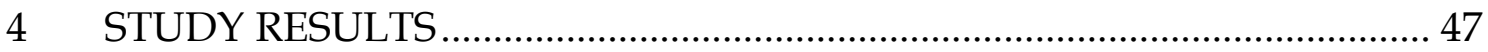

4.1 Campaign objectives and effectiveness metrics .............................. 47

4.2 Campaign insights discovery .................................................... 49

$4.3 \quad$ Strategic advertising planning ........................................................... 51

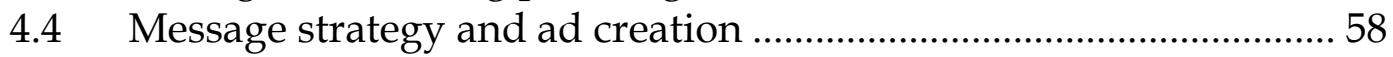

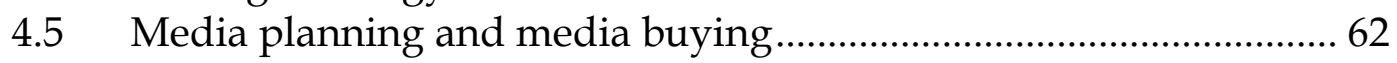

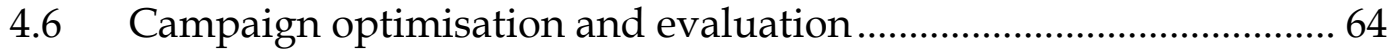

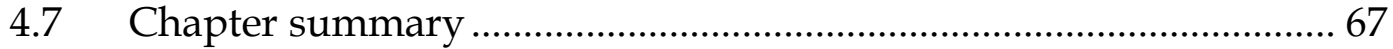

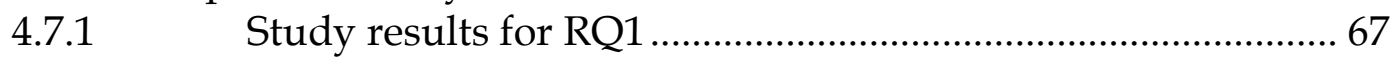

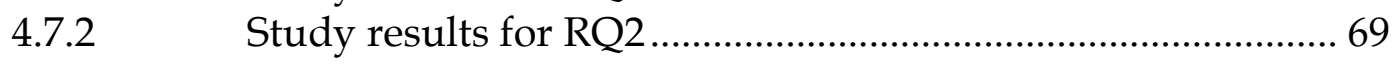

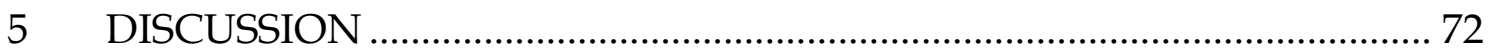

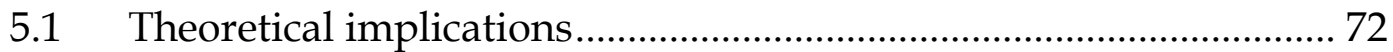

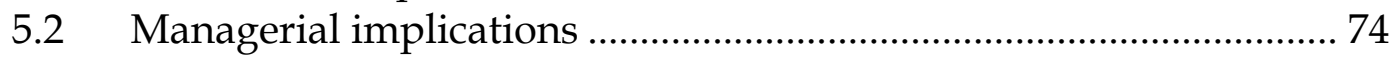

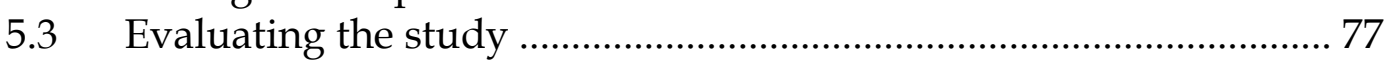

5.4 Limitations of the study and ideas for future research ................... 79

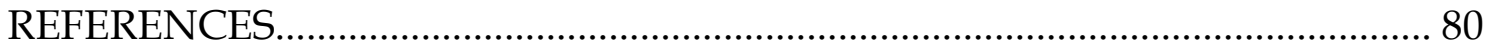

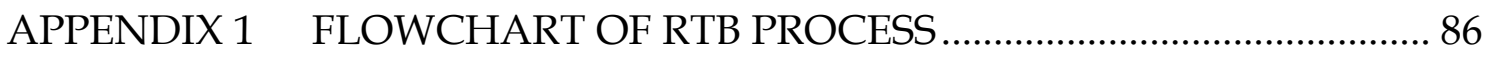

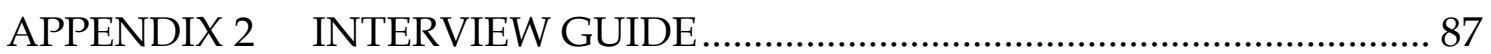




\title{
LISTS OF FIGURES, TABLES, APPENDICES, ABBREVIATIONS
}

\author{
FIGURES \\ FIGURE 1 Online advertising quaterly revenue 1996-2018 \\ FIGURE 2 Study objective and research questions \\ FIGURE 3 Structure of the study \\ FIGURE 4 Display of paid search ads versus an organic search results on Google \\ search engine result page \\ FIGURE 5 The model of programmatic advertising \\ FIGURE 6 Four types of programmatic buying transaction \\ FIGURE 7 Multiplatform Advertising Strategy \\ FIGURE 8 The transition from tradition advertising process to programmatic \\ advertising process \\ FIGURE 9 Research design of this study \\ FIGURE 10 Programmatic advertising process of long-term brand building campaign \\ FIGURE 11 Programmatic advertising process of short-term direct response campaign
}

\section{TABLES}

TABLE 1 Summary of key literature

TABLE 2 Details of semi-structured interviews

\section{APPENDICES \\ APPENDIX 1 Flowchart of RTB process \\ APPENDIX 2 Interview guide}

$\begin{array}{ll}\text { ABBREVIATIONS } \\ \text { CMP } & \text { Content management platform } \\ \text { CPA } & \text { Cost per action } \\ \text { CPAS } & \text { Collaborative performance advertising solution } \\ \text { CPC } & \text { Cost per click } \\ \text { CPM } & \text { Cost per thousand impressions } \\ \text { CTR } & \text { Click-through rate } \\ \text { DCO } & \text { Dynamic creative optimisation } \\ \text { DMP } & \text { Data-management platform } \\ \text { DSP } & \text { Demand-side platform } \\ \text { DV360 } & \text { Display \& Video 360 } \\ \text { KPIs } & \text { Key performance indicators } \\ \text { PAC } & \text { Programmatic advertisement creation } \\ \text { PCP } & \text { Programmatic creative platform } \\ \text { RTB } & \text { Real-time bidding } \\ \text { SSP } & \text { Supply-side platform }\end{array}$




\section{INTRODUCTION}

This chapter includes three parts which are study background (Section 1.1), study objective and research questions (Section 1.2), and study structure (Section 1.3). The study background provides an overview of programmatic advertising and identifies the research gap. Then, study objective and research questions to address the research gap are formed. Lastly, study structure outlines the main content of the rest chapters of this thesis.

\subsection{Study background}

\subsubsection{Programmatic advertising and research gap}

The year 1994 marked the beginning of online advertising with the introduction of the first online banner ( $\mathrm{Li} 2019$ ). Since then, online advertising has grown exponentially and accounted for the significant share of total advertising spends. Global online advertising spent in 2018 was $\$ 107.5$ billion, contributing to around $38 \%$ of all advertising share, and surpassed TV advertising (IAB 2019a). Figure 1 demonstrates the rapid growth of online advertising spend from 1996 to 2018.

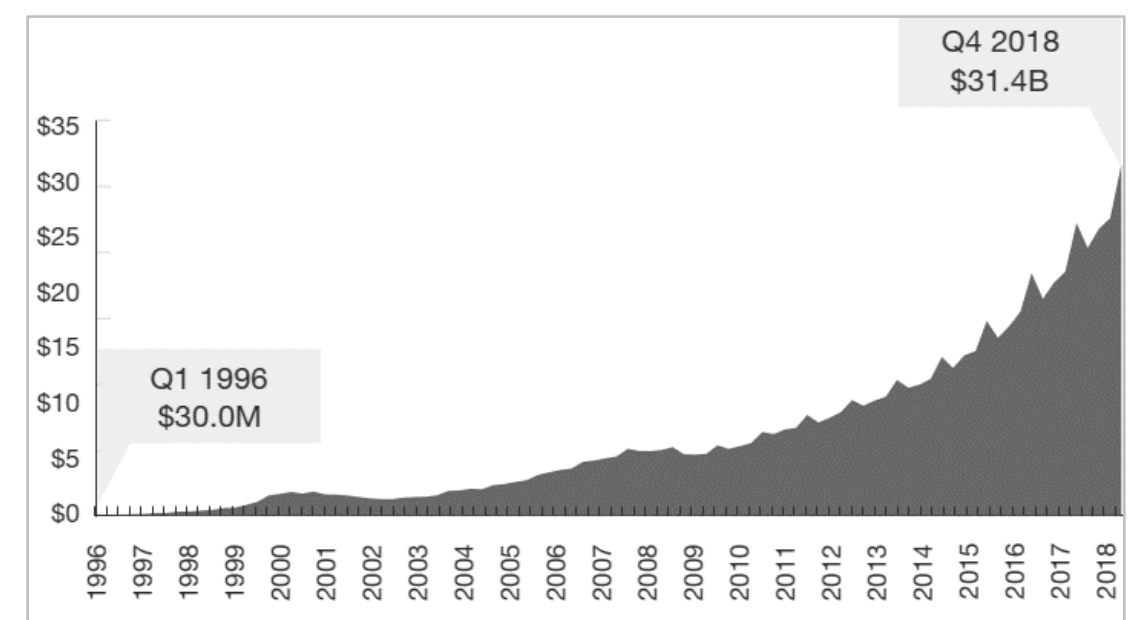

FIGURE 1 Online advertising quarterly revenue 1996-2018 (IAB 2019a)

Online advertising has evolved dramatically from a banner advertisement (ad) to different ad forms. There are three main forms of online advertising, namely display advertising (such as banner ads, video ads), search ad and classified ad (Goldfarb 2014). According to IAB (2019a), in 2018 display advertising accounted for the highest share (i.e. $46 \%$ ) as well as the highest growth rate (i.e. approximately $23 \%$ ) among the three advertising forms. And the driver of display advertising's exponential growth is programmatic advertising (BCG 2018; Choi \& Mela 2019; Qin \& Jiang 2019). Furthermore, BCG (2018) projects that programmatic 
buying ad spend will account for $63 \%$ of global display advertising spend, leaving $37 \%$ ad spend share for direct buy (i.e. advertisers and or agencies manually choose individual ad placements and book them directly with the publishers).

The rapid advancement of programmatic advertising has gained the attention of both the advertising industry and the academic community. In fact, there have been many research papers on the topic. Several popular research areas under this topic are (i) RTB optimisation algorithms (e.g. Balseiro, Feldman, Mirrokni \& Muthukrishnan 2014; Cai et al. 2017; Choi \& Mela 2019; Qin, Yuan \& Wang 2017; Zhang, Yuan \& Wang 2014), (ii) RTB advertising revenue maximisation for publishers (e.g. Chen 2017; Sayedi 2018), and (iii) the impact of programmatic advertising on consumer data privacy (e.g. Estrada-Jiménez, Parra-Arnau, Rodríguez-Hoyos \& Forné 2017; Palos-Sancheza, Saurab \& Martin-Veliciaa 2019). Based on the publication date of these articles, the articles related to RTB can be dated back to 2014 or earlier while the other topics were not researched until 2017.

Despite the richness in the literature of programmatic advertising, there is a disciplinary gap between the advertising industry and academic research mostly because of the technical nature of the subject (Li 2017; Yang, Yang, Jansen \& Lalmas 2017). The field has been led by technology companies and computer scientists rather than the advertising academia (Yang et al. 2017). This also explains why most of the articles were published in computer science journals or software engineering proceedings, which caused a "research gap in the social science of the subject" (Li 2017,4). Qin and Jiang (2019) complement this view by arguing that the existing studies overemphasise the technologies of programmatic advertising itself and lack the discussion on how these technologies affect and transform the traditional advertising process and practices.

\subsubsection{The potential of emerging markets}

Statistics show that emerging markets (e.g. China, India, Indonesia, Brazil) have a significant contribution to the global advertising landscape in terms of ad spend volume and growth rate. According to Zenith's advertising forecast, seven out of the top ten contributors to global ad spend growth from 2017 to 2020 are emerging markets (The Drum 2019). Also, the growth rate of digital ad spends in emerging markets, especially the South East Asia region is double-digital growth (Digiday 2017). Despite that, there are limited studies about online advertising and its dynamics at these markets.

\subsection{Study objective and research questions}

Based on the identified research gap of programmatic advertising topic and the interest in digital advertising practices in emerging markets, this thesis aims at studying how programmatic advertising is planned and implemented in these markets. Figure 2 outlines the study objectives and the two research questions. 
The first research question (RQ) seeks to understand the situation of programmatic advertising in these markets. For example, to which extend programmatic advertising is leveraged in online advertising campaigns, the advantages and disadvantages of leveraging programmatic advertising. The first $R Q$ establishes the context for the next question. The second RQ concerns with the planning and implementation process of programmatic advertising campaigns. Programmatic advertising involves automation and the integration of different technologies, which may require a different advertising process to be effective.

\section{Study objective}

To understand the planning and implementation process of programmatic advertising in emerging markets.

\section{Research questions}

RQ1: How is programmatic advertising being used in online advertising campaigns in emerging markets?

RQ2: What is the planning and implementation process of programmatic advertising campaigns?

FIGURE 2 Study objective and research questions

This thesis makes two contributions to research and practice of online advertising. First, in terms of theoretical contribution, the thesis fills the disciplinary gap as it studies the programmatic advertising phenomenon from the perspective of marketing communications. The study also presents the findings from the perspective of emerging markets, which is currently missing in academic research. Next, in terms of managerial contribution, the study discovers two distinctive planning and implementation processes of programmatic advertising campaigns, depending on the campaign's objectives. The study also pinpoints the good practices and bad practices of the programmatic advertising processes. These findings help advertisers manage effectively and efficiently their programmatic ad campaigns.

\subsection{Structure of the study}

Figure 3 outlines the study structure. Chapter 2 discusses the theoretical background of the study. The chapter starts with providing overview of online advertising to guide the context. Then, the chapter moves on discussing the concept of programmatic advertising, the different steps in the online advertising process, and the impact of programmatic advertising on the online advertising process. After that, chapter 3 explains the research methodology, case selection, data collection and analysis method. Next, chapter 4 reports the study results. Finally, 
chapter 5 discusses the study results, as well as acknowledges the study's limitations and proposes ideas for future research.

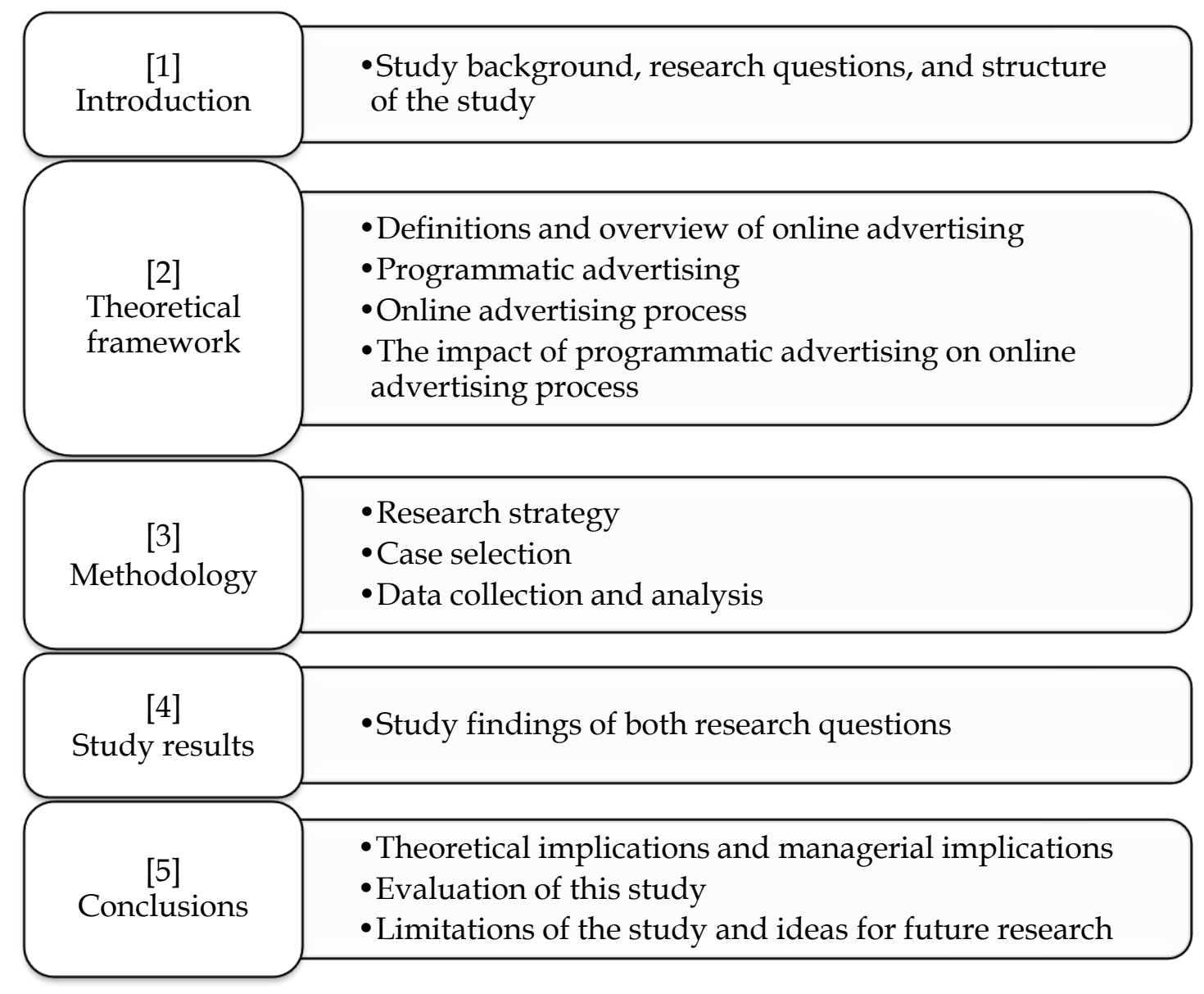

FIGURE 3 Structure of the study 


\section{THEORETICAL FRAMEWORK}

This chapter discusses the research literature related to the thesis topic. It starts by introducing the key terms used in the literature review (Section 2.1). Then, the chapter moves on defining online advertising, different targeting options and online ad forms (Section 2.2). After that, programmatic advertising and its impact on the advertising process are studied (Section 2.3 and 2.4, respectively).

\subsection{Key terms}

Advertisers are companies buying advertisements (ads).

Advertising agencies/ Agencies are companies contracted by an advertiser to develop campaign concepts, produce ads, and find placements to place ads.

Publishers are individuals or organisations who own and disseminate online content. Publishers also own and sell ad inventory.

Target audience is defined as the desired audience for an ad. Target audience is usually defined in terms of demographics such as age and gender, or purchase behaviours.

Ad inventory is defined as an opportunity when the advertiser can show ad within or near the publisher's content on a webpage.

Impression is a single appearance of an ad on a webpage.

Click is an interaction between the online user and the ad. By default, the user will be landed to the advertising campaign's webpage after clicking the ad.

Reach is the total number of unique users exposed to an ad. In this thesis, reach is usually referred to as a campaign's reach, which indicates the total number of unique users exposed to different ads belongs to an advertising campaign.

Frequency is the number of times that an ad is exposed to a user during a specific period. In this thesis, the frequency is usually referred to as a campaign's average frequency which indicates the average number of times that a user was exposed to the campaign's ads during the campaign period.

Cost per thousand impressions (CPM): this is one type of pricing model in which advertisers pay to publishers each time an ad is served. 
Cost per click (CPC): this is one type of pricing model in which advertisers only pay publishers when their ads are clicked by the users.

Cost per action (CPA): this is one type of pricing model in which advertisers only pay publishers when their ads lead to a completion of the desired action. Examples of desired actions are viewing a video, downloading a whitepaper, purchasing a product or service.

\subsection{Overview of online advertising}

\subsubsection{Definition}

While there are various definitions of online advertising, marketing scholars generally agree that online advertising comprises online activities taken by a brand to promote its products. Ha (2008) defines online advertising as ads that advertisers place on third-party websites, search engines and directories for promotional purposes. Klapdor $(2013,16)$ stipulates that brands' online activities classified under online advertising should fulfil four criteria which are "(1) paid by the advertiser, (2) non-personal communication, (3) presentation of promotion of ideas, goods or services, (4) advertiser can be identified as a sponsor". Ha (2008) also emphasises online advertising is not interactive advertising because it does not require interactions between advertisers and consumers via an online ad.

Then, Goldfarb (2014) extends the definition of online advertising by pinpointing the fundamental difference between online advertising and offline advertising. It is precise targeting. Thanks to the underlying technologies, online advertising is capable of various online targeting options which are demographic targeting, contextual targeting, and behavioural targeting. The next section 2.2.2 will discuss the three targeting options in detail. Goldfarb (2014) states that these targeting options allow advertisers to send communication messages to the target audience more precisely than offline advertising. This helps reduce the waste of advertising spend on the undesired audience. Hence, Goldfarb (2014) affirms it is the critical factor distinguishing online advertising and offline advertising.

\subsubsection{Online targeting options}

Goldfarb (2014) identifies three online targeting options which are demographic targeting, contextual targeting, and behavioural targeting. First, demographic targeting allows advertisers to send brand messages to target audience based on their gender, age, income range and so on. Over time, this targeting option has been more diversified and granular, thanks to the availability of online users' data. For example, Facebook has users' personally identifiable information (PII), so the platform offers advertisers possibilities to target their consumers based on languages, locations or internet IP, email address marital status, or even religion 
(Ali et al. 2019). Next, contextual targeting means advertisers place their ads relevant to the surrounding context (Goldfarb 2014). For example, clothing ads are placed on lifestyles and fashion websites. Finally, behavioural targeting means advertisers show ads to target audience based on their previous online behaviours using clickstream data (Choi, Mela, Balseiro \& Leary 2019; Evans 2009; Goldfarb 2014). For instance, when a user clicks an ad or interacts with a piece of content on social platforms, that might indicate the user is interested in that specific piece of content. Since different users are interested in different topics, advertisers can utilise such data to generate tailormade messages to the different target audience.

Among the three targeting options, behavioural targeting is the most advanced. However, when this method was first introduced back in the 2000s, marketing scholars like Evans (2009) criticises this method for its narrow approach. The author argues that behavioural targeting overly focuses on those ultimately purchasing the products soon and ignore a larger group of consumers. Such narrow targeting can hurt the brand's profitability in the long run. Therefore, the advertisers need to justify the cost and benefit of targeting a smaller group of purchasers versus reaching a larger group of audience. Given the data availability and predictive technique of that period, this argument was reasonable. Though, recent developments in data collection methods and predictive techniques have not only improved the precision of behavioural targeting but also extended the audience scale of this targeting method. For example, online profilebuilding or lookalike audience techniques have allowed advertisers to look for online users displaying behaviours similar to those desired by advertisers (IAB $2019 b$ ). Hence, behavioural targeting is no longer subject to the weaknesses according to the arguments of Evans (2009).

\subsubsection{Online advertising types}

There have been many new advertising formats and channels introduced. Yet, there is no universal source listing all available advertising types. And there are many opinions on online advertising types within the research community. For example, Goldfarb (2014) identified three general categories of online advertising which are search advertising, classified advertising, and display advertising. On the other hand, Klapdor $(2013,17)$ lists several forms of online advertising, such as search advertising, display advertising, lead generation, affiliate marketing, classifieds/directories, sponsorships. IAB (2019a) also includes audio advertising and other unspecified formats in its 2018 advertising revenue report. However, according to the report, search advertising and display advertising accounted for more than $90 \%$ of global advertising revenue in 2018 (IAB 2019a). Given the scale of each advertising type and for simplicity, this section focuses on discussing search advertising and display advertising only. 


\section{Search advertising}

Search advertising has many different names such as search engine marketing (SEM), Pay-per-click (PPC) ads, sponsored search ads or paid search ads to differentiate with the organic search results on a search engine. Search advertising is defined as a text ad that an advertiser pays for so that the ad can be displayed on top of non-paid results on the search engine result pages. A search ad is triggered when the keywords in the text ad match with the search terms are entered into the search engine by a user (Chaffey \& Ellis-Chadwick 2016, 32-33; Ghose \& Yang 2009). Figure 4 illustrates how Google search engine displays search ads versus organic search result.

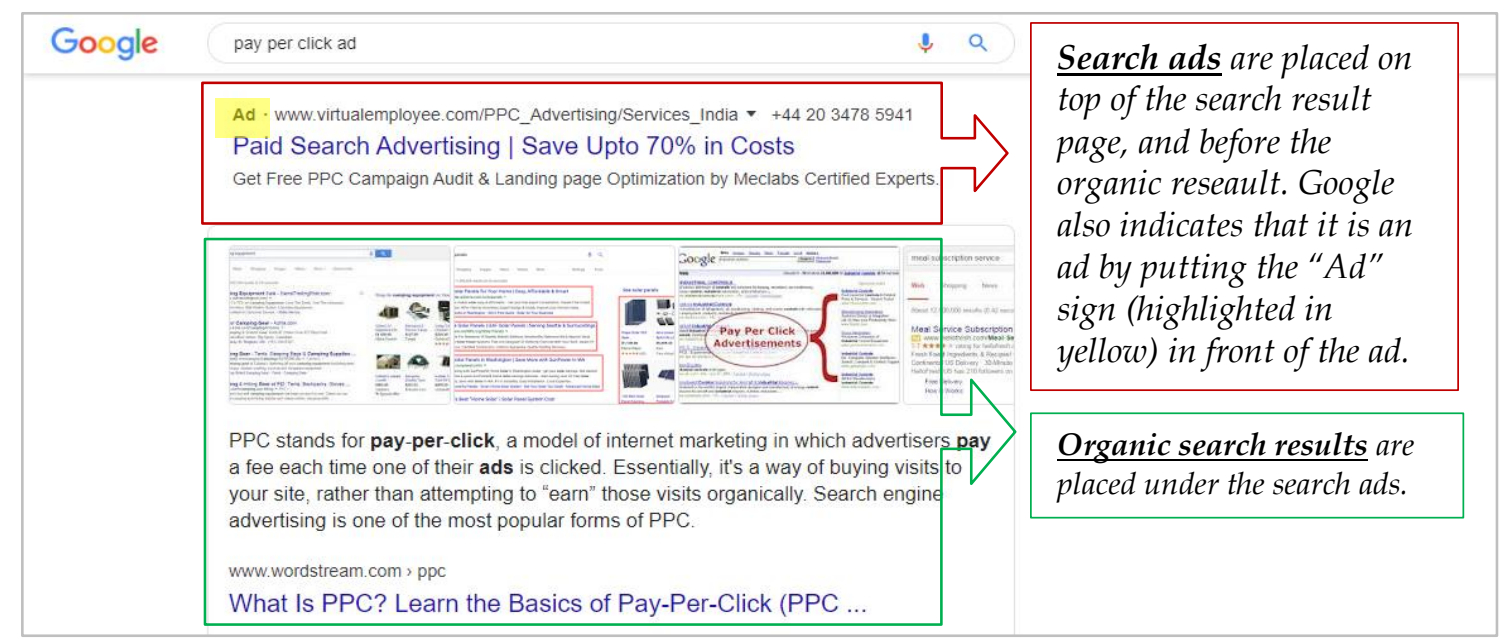

FIGURE 4 Display of paid search ads versus organic search results on Google search engine result page. (The screenshot was taken on 13.02.2020)

Regarding the pricing models of search ad, there are two main models which are cost per click (CPC) and cost per action (CPA). In other words, the search engines do not charge advertisers any fee by displaying their ads on the search engine. Thus, search ads are especially suitable for lower marketing funnel tasks like lead generation or purchase (Choi et al. 2019).

\section{Display advertising}

Display advertising is the umbrella term for many advertising formats, including a simple banner ad, dynamic banner ad, video ad, social network ad. These ads are normally shown to online users when they are browsing websites (Chaffey \& Ellis-Chadwick 2016, 33; Goldfarb 2014). While search ads are triggered by users' search terms, display ads are triggered depending on the targeting options (Choi et al. 2019). For example, if an advertiser wants to target consumers who locate at a specific region and/or possess certain online behaviours, then only those web page users qualifying these criteria can be exposed to the advertiser's ads. In contrast, if no targeting option is selected, anyone browsing the website during the advertising period have an equal chance to be exposed to the ads.

Regarding the pricing models of display ads, there are cost per thousand impressions (CPM), cost per click (CPC) and cost per action (CPA). CPM is the 
original pricing model. Over time, CPC and CPA are introduced to the market because advertisers demand performance-oriented advertising (Chaffey \& EllisChadwick 2016, 103). The desired actions could be viewing videos, registering for a webinar and so on. Thus, display ads can be used throughout the marketing funnel: building and maintaining brand awareness at the higher funnel and converting to purchase at the lower funnel (Choi et al. 2019).

\subsection{Programmatic advertising}

Programmatic advertising belongs to display advertising. Before programmatic advertising was introduced, display ads were bought and delivered manually. The advertisers or their agencies would manually choose individual ad placements and book them directly with the publishers (i.e. direct buy). However, as the internet grows, there have been thousands of websites offering millions of ad placements, which make it inefficient to buy and sell all ad placements manually. Furthermore, the internet also makes consumer journeys increasingly fragmented and sophisticated. For example, in the past, an advertiser could easily communicate its brand message to most of its target audience by displaying ads on several top websites. However, that approach is ineffective in today's context. Therefore, programmatic advertising leveraging data and technologies is in place to help advertisers address these issues. (IAB UK 2017.)

\subsubsection{Definition}

Generally, programmatic advertising comprises a range of technologies allowing online ads to be sold and bought automatically, which helps advertisers offer the right message, to the right person, at the right time at scale (Choi et al. 2019). There are various definitions of programmatic advertising. On the one the hand, Chen, Xie, Dong and Wang (2019), and Sven and Owens (2016, 123-130) propose that programmatic advertising comprises two components which are programmatic buying and programmatic creative. Figure 5 outlines the model of programmatic advertising by Chen et al. (2019). The authors define programmatic buying as a range of technologies automating the process of selling and buying ads in real-time. On the other hand, programmatic creative is a range of technologies optimising and generating ad content in real-time so that the ads are relevant to the users (i.e. personalised ads). While the two components have different functions, both rely on massive data (e.g. consumer data, ad inventory data), optimisation algorithms and intermediaries so that relevant ads can be delivered to the right target audience at scale ( $\mathrm{Li}$ 2017).

One the other hand, IAB defines programmatic advertising as programmatic buying only. IAB (2020) defines programmatic as "media or ad buying that uses technology to automate and optimise, in real-time, the ad buying process. 
On the back end, algorithms filter ad impressions derived from consumer behavioural data, which allows advertisers to define budget, goal, and attribution and optimise for reduced risk while increasing ROI". According to this definition, the programmatic buying component is evident in the definition, while the creative optimisation component seems to be lacking. In fact, Chen et al. (2019) also recognise and list a few studies defining programmatic advertising narrowly.
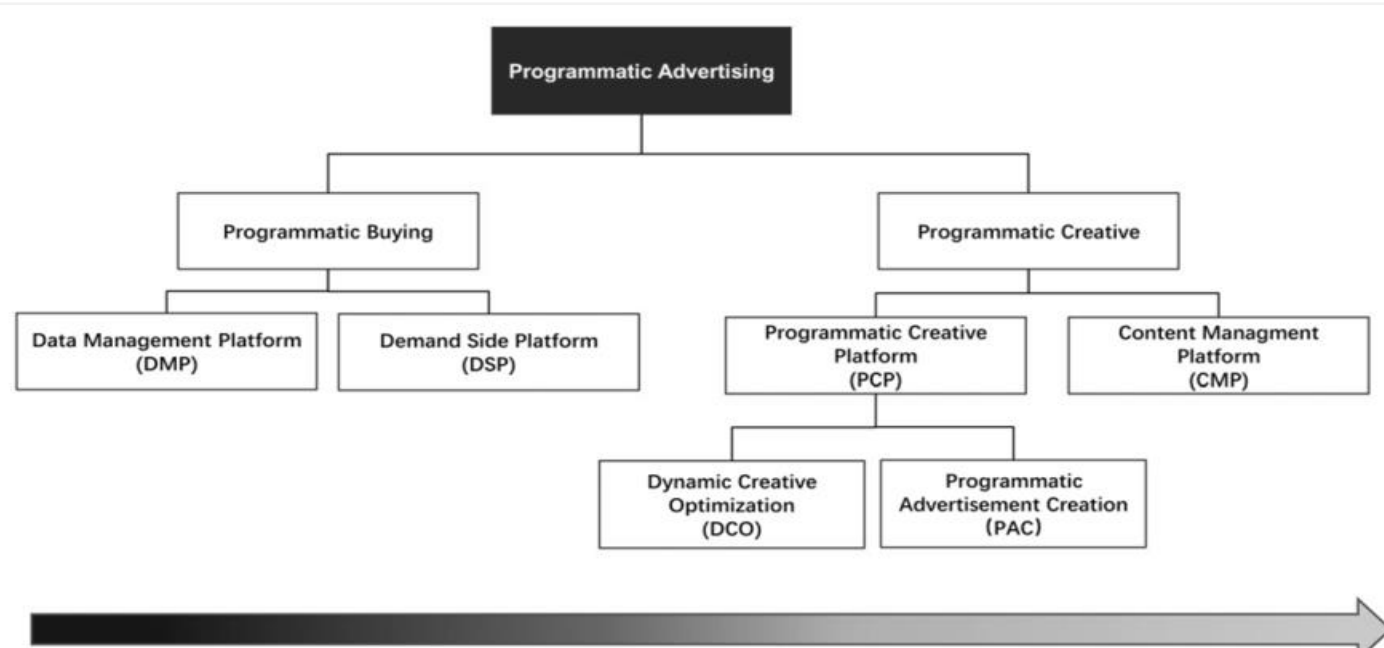

Developed

Developing

FIGURE 5 The model of programmatic advertising (Chen et al. 2019)

The inconsistency of programmatic definitions could be explained by the gap in the development stage of programmatic buying and programmatic creative. Per the illustration in Figure 5, programmatic buying has reached a developed stage while programmatic creative is still developing. Programmatic buying can be dated back to 2005 (Wang, Zhang \& Yuan 2017), and then the giant tech companies, Yahoo!, and Google introduced programmatic buying in their advertising ecosystem in 2007 (Disruptor Daily 2017). Since then, programmatic buying has developed rapidly. In contrast, programmatic creative is slow to be picked up by the market. Even though programmatic creative was predicted to boom in 2016 (Qin \& Jiang 2019), only 1\% of digital ads served to consumers utilising creative programmatic technologies (Mediacom 2018). Because programmatic creative is newer and less popular than programmatic buying, the terms programmatic advertising and programmatic buying interchangeably. This is especially true when perusing papers published before 2016. However, programmatic creative started to gain popularity from 2018 after Facebook and Google introduced dynamic creative ads (i.e. a form of programmatic creative) for online campaigns in 2017 (Tinuiti 2018). Therefore, it is reasonable to use the definition of programmatic advertising by Chen et al. (2019) because it reflects the reality and is updated. 
The next two sections discuss programmatic buying and programmatic creative, respectively. Each section includes three main parts including overview, intermediaries and technologies, and the working mechanism of each component.

\subsubsection{Programmatic buying}

\section{Overview}

Programmatic buying uses data and technologies to automate and optimise the process of selling and buying ads in real-time. Nevertheless, programmatic buying is not a fully automatic process because human intervention is still required to guide the system (Chen et al. 2019, Choi et al. 2019; IAB 2020; Li 2017; Qin \& Jiang 2019). Additionally, it can be implied from these research papers that data and technologies are equally important to the success of programmatic buying. Without data, there is no input for the technologies to process and optimise. Similarly, without the technologies, the automatic ad procuring process is not feasible, and advertisers cannot leverage the potential of data because human beings are not capable of analysing such a significant amount in real-time.

\section{The development of programmatic buying:}

Gertz and McGlashan $(2016,56)$ argue that programmatic buying has developed "from a performance channel only to a method to buy a broad range of digital media". The authors observe that programmatic buying has gone through three development stages from programmatic 1.0 (i.e. retargeting), programmatic 2.0 (i.e. audience buying) to programmatic 3.0 (i.e. consumer-centric advertising).

The very first programmatic buying technology is retargeting. According to Lambrecht and Tucker (2013), Gertz and McGlashan (2016, 56), retargeting helps an advertiser re-engage with the consumers who previously interacted with the ads (e.g. click on the banner, watch a TV commercial) but did not take the desired action (e.g. make a purchase). Retargeting ads show them personalised ads based on their historical browsing activities on the advertiser's website. Therefore, retargeting is also called behavioural targeting (Goldfarb 2014). The goal of retargeting is to nudge the consumers to complete the desired actions by the advertisers, so it is perceived to be performance-oriented. Furthermore, because retargeting only works with consumers who show interest in the brand, it is not suitable for upper marketing funnel, i.e. brand awareness (Gertz \& McGlashan 2016, 57).

Programmatic 2.0 (i.e. audience buying) was introduced to overcome the shortfall of programmatic 1.0 (Gertz \& McGlashan 2016, 57). The authors define audience buying as reaching the right audience by using data and technologies, rather than buying media space contextually like the traditional direct buy. This results in the increase in the efficiency of advertising spend because advertisers no longer book fixed ads slots which uncertainly be seen by the target audience. Unlike retargeting focusing on lower marketing funnel, audience buying is more effective at helping brands to discover and reach new consumers (Gertz \& McGlashan 2016, 57). Thanks to the advancement in audience buying technology, 
programmatic buying becomes a powerful tool for advertisers throughout the marketing funnel.

Finally, programmatic 3.0 (i.e. consumer-centric advertising) arrived to overcome the challenges of programmatic 2.0 and enhance the efficiency and effectiveness of audience buying (Gertz \& McGlashan 2016, 57). The authors state that there are more sophisticated technologies being introduced to the media buying process to filter out low quality and inappropriate ad inventories. Therefore, brand safety (i.e. the advertisers' ads were misplaced next to or inside the inappropriate or violent content) and viewability (i.e. the wasted ad impressions caused by ads being shown in ad slots that were not seen by the consumers) issues are mitigated. While these challenges persist, improvements are recognised (Campaign US 2019; IAB UK 2019). Furthermore, the technologies of combining and processing data from various sources have also advanced, which provides more holistic and in-depth consumer profiles. Accordingly, advertisers can better segment their consumers and target them with highly relevant ads (Gertz \& McGlashan 2016, 57).

\section{Four types of the programmatic buying transaction}

Programmatic buying and RTB are strongly associated with each other; as a result, the terms are often used interchangeably (IAB 2014). However, RTB and programmatic should be distinguished with each other because RTB is only a subset of programmatic buying. IAB (2014) explains that advertisers can buy programmatic inventories via either auction-based options or fixed-rate options. With auction-based options, there are open auction and invitation-only auction. With fixed-price options, there are automated guaranteed (i.e. reserved fixed rate) and unreserved fixed rate. Figure 6 maps out four transaction types.

First, regarding the fixed-rate programmatic buying, all inventories under this category have their prices negotiated between a publisher and an advertiser before an advertising campaign start. Moreover, the ad inventories bought via fixed-rate transactions are of premium quality compared to auction-based transactions (IAB 2014). Therefore, advertisers demanding for high-quality inventories and sophisticated targeting technologies (e.g. luxury brands) would be interested in buying fixed-rate programmatic inventories (Choi et al. 2019).

In terms of automatic guaranteed programmatic buying, this option also has other name variations such as programmatic guaranteed or programmatic reserved. This option is similar to the traditional online direct buy-in which a publisher and an advertiser negotiate the impression volumes and prices in advance, except that the ad impressions will be delivered via programmatic platforms (IAB 2014). Next, in terms of unreserved fixed rate programmatic buying, this option also has other name variations such as preferred deals or first right of refusal. The unreserved fixed price programmatic buying operates similarly with the automatic guaranteed, except that the advertisers have the right not to buy the ad impression when it is offered in real-time. This also explains why the ad 
delivery under this option is non-guaranteed. The unsold ad inventories will be then transferred to auction-based programmatic buying (IAB 2014).

Second, regarding the auction-based programmatic buying (i.e. RTB), according to Agrawal, Najafi-Asadolahi and Smith (2020, 99-146) and Choi et al. (2019), the inventories bought via RTB involves selling and buying ads in realtime. In other words, the decision whether to buy and sell an ad impression is made within milliseconds once a user arrives at the webpage. Thus, the price is also determined in real-time. Furthermore, because an advertiser's ads will only be shown if the advertiser wins the bid, there is no commitment on the number of total ad delivery between a publisher and an advertiser. Hence, ad impressions bought via RTB are unreserved.

In terms of the invitation-only auction, this option also has other name variations such as private auction or private marketplace. The names imply that only several invited advertisers have the right to access to these ad inventories and bid for them. If the ad impressions cannot be sold, they will be available in the open auction where hundreds or thousands of advertisers can bid for them. Because of such a mechanism, the quality of ad impressions sold via open auction is of the lowest quality among the four transaction types. (IAB 2014.)

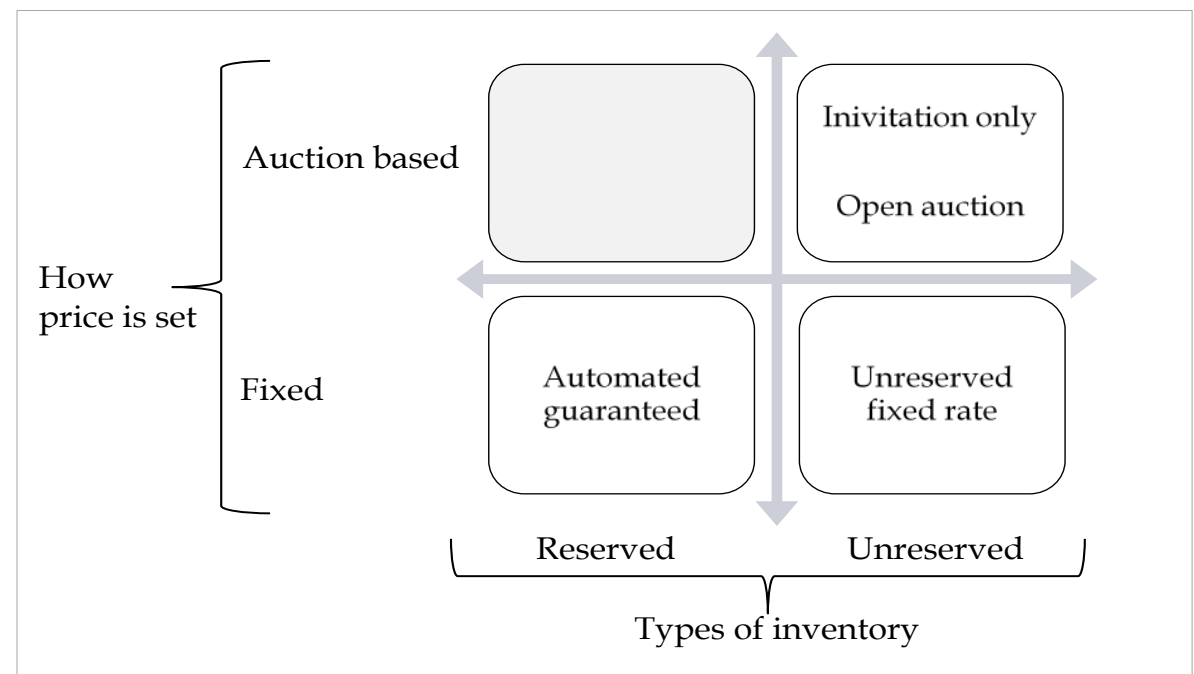

FIGURE 6 Four types of programmatic buying transaction (IAB 2014)

\section{Intermediaries}

Choi et al. (2019) define the intermediaries of programmatic buying as platforms that provid technologies to match the advertisers with publishers. The authors give examples of these technologies, such as data collection and analysis, RTB, real-time ad serving, and optimisation tools. According to Choi et al. (2019) and Chen (2020, 299-308), main intermediaries in programmatic buying are demandside platform (DSP), data management platform (DMP), supply-side platform (SSP), an ad exchange. The next paragraphs explain each intermediary in detail. 


\section{Demand-side platform (DSP)}

DSP is a platform serving advertisers or their agencies who are the buyers of ad inventories to manage programmatic buying campaigns. Examples of DSPs are MediaMath, AOL, Rocket Fuel, and Google Display and Video 360 (DV360). The main tasks of DSP include (i) analysing audience attributes of a potential ad impression to ensure the audience attributes match with the advertiser's target audience, (ii) deciding whether to purchase the ad impression in real-time, and (iii) connecting with creative programmatic platforms to serve the personalised ads to the right audience.

Regarding the second task, the system will make different decision types depending on the corresponding programmatic buying transaction (Agrawal et al. 2020, 99-146). The authors explain that if the advertiser is in fixed-rate programmatic buying deal, the DSP will purchase the ad impression based on the agreed price. If the advertiser is in unreserved fixed rate programmatic buying deal, the system will decide whether to buy the ad impression based on the advertiser's predefined criteria. In contrast, if the advertiser is in RTB deals, the system will conduct a bid process in real-time. That is, whether to bid for ad placement (i.e. ad auction) and how much to bid has there is no bid process. Chen et al. (2019) also mention that for DSP to make these two decisions, it will first analyse the potential of each ad impression based on the data provided by DMP. The potential is defined by the user's interest in the ad, which is inferred based on the user's online attribute and historical behaviours. If the ad impression is potential, the system will predict CTR of the ad impression, upon which the bid would be calculated and submitted for auction. The higher the CTR, the higher the bid. In contrast, if the ad impression is perceived to be of no potential, the system will not bid (Chen et al. 2019; Choi et al. 2019).

\section{Data management platform (DMP)}

According to Chen (2020, 299-308), DMP is an important intermediary because it is layered on top of DSP to provide data for the system. The role of DSP is collecting and integrating data from different sources, analysing the data to build comprehensive audience profiles, and feeding data to DSPs. DMPs can collect data from both online and offline sources, such as data from company's websites, social network platforms, behavioural and demographic data, and so on (Chen 2020, 299-308; Choi et al. 2019). Examples of DMPs are Lotame, Nielsen DMP (Mopinion 2019).

Chen et al. (2019) assert three main advantages of DMPs. First, the data are classified into tags to infer a user's attributes, such as their age, gender, location, lifestyles, and interests. Thus, DMPs offer a holistic view of the target audience. Second, by organising data into tags, DMPs are capable of segmenting and targeting users flexibly and granularly. Advertisers can choose to segment, and target users based on a combination of different tags. Furthermore, the data in DMPs keeps increasing and updated on a real-time basis as the users browsing 
websites and doing other online activities. The continuous data update is important because the user's information such as interests are temporal. Finally, substantial data volume allows precise inference of online user attributes. Due to these advantages, DMPs are the driving force of precision targeting.

\section{Supply-side platform (SSP)}

SSP is a platform serving the suppliers of advertising inventories. Examples of SSPs are PubMatic, AppNexus, OpenX, AOL, and Google's AdX (Agrawal et al. 2020, 99-146). SSP helps publishers manage ad inventories, optimise prices of an ad impression, and receive revenue (Chen 2020, 299-308; Choi et al. 2019).

\section{Ad exchange}

The analogy of ad exchange is a stock exchange. The ad exchange is a centralised platform where DSPs (buyer) and SSP (sellers) buy and sell ad inventories in realtime. SSPs list their ad inventories on ad exchanges so that DSPs can bid (Agrawal et al. 2020, 99-146; Chen 2020, 299-308; Choi \& Mela 2019). According to Chen (2020, 299-308), the winning DSP is the one who offered the highest bid. In addition to facilitating RTB between DSPs and SSPs, ad exchange also supports payments from DSPs to SSPs. Examples of ad exchanges are Google DV360, AppN (Agrawal et al. 2020, 99-146).

\section{How does programmatic buying work?}

Programmatic buying mechanisms vary depending on different programmatic buying types. Yet, most research literature only discusses the mechanism of RTB.

\section{Fixed-rate programmatic buying}

Implying from the paper of Choi et al. (2019), the mechanism of programmatic buying of fixed-rate buying and RTB options are almost similar except that fixedrate buying option does not involve the bidding procedure but apply the predetermined rate. In that sense, the mechanism of fixed-rate buying should be similar to the mechanism of RTB, except that there is no auction being taken place and the Ad Exchange is eliminated out of the ecosystem.

\section{RTB programmatic buying}

A standard RTB programmatic buying process comprises eight steps (Appendix 1 illustrates this process step by step). Firstly, right after a user visiting a webpage or a mobile application, the publisher's SSP will make bid request(s) to one or many ad exchanges, by sending the information of the available ad impression (e.g. the website that the ad impression belongs to, the minimum bid for that impression) and the user attributes (e.g. demographics, locations, historical web browsing activities, and so on). After receiving the information from SSP, the ad exchanges will forward it to DSPs. Then, the DSPs can consult DMP to map the user attributes provided by the SSPs as well as layer more attributes if possible. Next, the DSPs will evaluate the ad impression based on available data and then 
submit bid responses (e.g. whether to bid and bid value) to the ad exchanges. Fifthly, each ad exchange will choose the DSP with the highest bid as the winner, and submit the ad's mark-up and the price to the SSP. The final winning DSP is decided by the SSP, especially when the SSP sends bid requests to more than one ad exchange. In the sixth step, the winning DSP will be sent a winning notice and final price, depending on the auction types discussed in the next paragraph. Then, the publisher will display the advertiser's ad in the designated ad placement. Finally, DMP will collect the user's feedback on the ad, for example, whether the user clicks the ad or whether the ad results in a purchase. The feedback is useful data for DSPs to evaluate the ad impressions and optimise bid in the future. The constant feedback loop is the unique benefit offered by programmatic advertising. (Agrawal et al. 2020, 99-146; Chen 2020, 299-308; IAB 2016; Wang et al. 2017.)

\subsubsection{Programmatic creative}

\section{Overview}

If programmatic buying is to find the right person, then programmatic creative is to show that person personalised ads. According to Kumar and Gupta (2016), consumers increasingly expect to see personalised ads that are relevant to them and able to address their needs. The most important benefits of personalised ads are "accelerating a consumer's decision-making process and increasing the likelihood of response and purchase" (Kumar \& Gupta 2016, 303).

Chen et al. (2019) define programmatic creative is defined as a set of technologies and data to generate personalised and contextualised ads automatically in real-time and at scale. Inferring from the definition, programmatic creative possesses four main characteristics which are personalisation, contextualisation, scalability, and real-time. Personalised ads are ads resonating with each consumer. Therefore, consumers interested in the same brand but having different online attributes will be likely to be exposed to different ad versions (Deng, Tan, Wang \& Pan 2019). Furthermore, personalised ads are highly contextual, which implies that the same consumer could be exposed to different ad versions on different occasions and locations. The context-sensitive characteristic also explains the real-time characteristics of programmatic creative because the consumer's location and the situation can change quickly. Finally, since it is impossible to create hundreds or thousands of personalised ads within a second manually, programmatic creative is created to achieve this task automatically and at scale. (Chen et al. 2019; Deng et al. 2019.)

Similar to programmatic buying, programmatic creative is not a fully automatic process yet, so human intervention is required to ensure the appropriateness of system-generated ads ( $\mathrm{Li} 2019$ ). The author also states that programmatic creative has gone through two development phases. In the first phase, programmatic creative was only capable of choosing suitable premade ads to serve the target audience. In the second phase, the system can generate personalised ads based on data such as user attributes, audience segments, contexts (e.g. weather, locations). Advertisers/agencies just need to input required attributes for the ads; 
then the systems will automatically combine various creative elements to generate personalised ads. Thus, ads created by creative programmatic technologies are also called dynamic ads. Dynamic ads in this context refer to the dynamic nature in the ad's creation mechanism rather than the ad formats (i.e. static ad format versus dynamic ad formats). The ads are dynamic because the outcome of the ads (i.e. size, layout, copy, photos, etc.) varies depending on the users and the contexts (Chen et al. 2019).

\section{Intermediaries and how they work with each other}

According to Chen et al. (2019), the technologies of programmatic creative includes programmatic creation platform (PCP) and content management platform $(\mathrm{CMP})$. The subsequent paragraphs explain each platform in detail.

\section{Programmatic creation platform (PCP)}

Chen et al. (2019) define programmatic creation platform (PCP) as a platform generating mass personalised and contextualised ads in real-time. PCP consists of programmatic advertisement creation (PAC) and dynamic creative optimisation (DCO). PAC is like the ad factory, which creates multiple ad versions. DCO is the optimisation platform which is responsible for testing different creative versions to a different audience and in a different context to see which version works with whom and in which context. Then, DCO feedbacks the real-time performance of these ad versions to PAC so that PAC can adjust the content of the ad accordingly. In certain extend, DCO is similar to the traditional A/B testing but better because DCO executes the testing process automatically and it can test different ad version at the same time and at scale. (Chen et al. 2019.)

\section{Content management platform (CMP)}

CMP is a stock photography database capable of recognising individual objects in a photo automatically. Thanks to this capability, CMP can decompose all the components of a picture and assign them tags. Then, when CMP is connected to PCP, PCP will rely on these tags to extract the suitable components and create personalised ads automatically. Because there are thousands and millions of photos in the database, it is essential that CMP can recognise and tag the visual components on its own. The underlying technologies enabling this outcome are artificial intelligence (AI) technologies. However, because the underlying AI technologies are not mature yet, CMP is subject to many limitations. (Chen et al. 2019.)

Lastly, it is worth acknowledging that the main reference source of this discussion is the paper by Chen et al. (2019) because no other academic paper could be found. Hence, the discussion on the intermediaries of programmatic creative could be incomplete. First, referring to Figure 5, the model of programmatic advertising, Chen et al. (2019) only mention DSP and DMP under programmatic buying, so SSP and Ad exchange is missing. This raises the concern if the model 
focuses on the advertiser's perspective, explaining why only intermediaries representing the advertisers are included. If that is the case, then it is likely that intermediaries in programmatic creative are not limited to PCP and CMP. Second, because Chen et al. (2019) developed the framework based on the technologies of China market, there could be variation in how these intermediary platforms work. And since there is no other academic reference to compare, the level of variation is unknown.

\subsection{Online advertising planning and implementation process}

Overall, the online advertising process comprises a series of eight steps which are (1) Setting campaign objectives and effectiveness metrics, (2) Campaign insights discovery, (3) Strategic advertising planning, (4) Message strategy, (5) Ads creation, (6) Media planning, (7) Media buying, and (8) Campaign optimisation and evaluation (Chaffey \& Ellis-Chadwick 2016, 418-475; De Pelsmacker, Geuens \& Van den Bergh 2017, 125-199; Qin \& Jiang 2019). It can be implied from the research literature that these eight steps make up a linear online advertising process. The subsequent sections will discuss these steps in detail.

\subsubsection{Setting campaign objectives and effectiveness metrics}

According to De Pelsmacker et al. (2017, 148), "campaign objectives and campaign effectiveness are two sides of the same coin. An effective campaign is a campaign that reaches its objectives". Thus, it is crucial that an advertiser set clear objectives and measurement to evaluate its effectiveness in advance. Two main objective types are long-term brand building and short-term direct responses (Gordon et al. 2019; Zhu \& Wilbur 2011). Each type has a corresponding set of key performance indicators (KPIs) to measure its effectiveness. For example, KPIs of long-term brand building campaigns suggested by the authors is uplift in awareness, consumer's attitude, or perception towards brands; KPIs of shortterm direct response campaigns include clicks, visits, or purchases.

However, defining a campaign's effectiveness metrics is not as straightforward as it seems. There are two schools of thought regarding measuring the effectiveness of online advertising. On the the one hand, marketing scholars assure that online advertising allows advertisers to design sophisticated measuring system to measure the campaign effectiveness with higher accuracy and more indepth (e.g. lower marketing funnel metrics such as purchases, customer calls), which increases the accountability of online advertising (Klapdor 2013, 14-15; Schultz 2016). On the other hand, marketing scholars argue that developing relevant metrics and measurement system to evaluate ad effectiveness remains difficult (Braun \& Moe 2013; Gordon et al. 2019; Schultz 2016).

The data collected from advertising campaigns are behavioural. This implies that only if the target audience takes action (i.e. click the ad banner, watch 
the video), can the data be recorded. Behavioural data can be problematic because it only indicates the audience's immediate response to an ad, yet it fails to recognise the audience's potential attitudinal change leading to future purchases (Braun \& Moe 2013). There are studies (e.g. Drèze \& Hussherr 2003; Manchanda, Dubé, Goh \& Chintagunta 2006) proving that the consumers still make future purchases after seeing an ad without taking any interaction with it. In other words, a low CTR banner is not necessarily ineffective. Hence, pure relying on behavioural data can lead to inaccurate measurement of ad effects. Also, behavioural data do not allow the advertiser to measure long-term brand metrics such as uplift in awareness, consumer's perception towards the brand.

Lewis, Rao and Reiley (2015), Johnson, Lewis and Nubbemeyer (2017) and Gordon et al. (2019) elaborate this notion when arguing the online advertising environment has shifted advertisers' focus away from the true campaign goal. Instead, advertisers tend to measure and optimise for intermediate metrics such as CTR. For example, instead of focusing on growing brand awareness, the advertisers can be trapped into CTR. However, because intermediate metrics can be obtained easily and provide rapid feedback for the campaign, advertisers find it easier to optimise the campaign based on these metrics. Still, intermediate metrics are only the means for advertisers to optimise brand's communication objectives and do not necessarily reflect the true ad effect, overreliance on them can lead to suboptimal spending decisions (i.e. over- or under-invest).

\subsubsection{Campaign insight discovery}

Discovering campaign insight consists of two main tasks which are discovering insights into the brand's target audience and understanding competitors' communication activities (Chaffey \& Ellis-Chadwick 2016, 441-443).

First, in terms of target audience understanding, the authors state that understanding the products usage occasions is helpful for audience segmentation in the next step. Sharp $(2013,35-36)$ elaborate that a brand needs to gain insight into who buy the product, where and when they buy it, and how much. These insights help advertisers identify and understand different factors affecting the consumers' buying behaviours. In practice, advertisers can hire market research firms such as Nielsen and Kantar to help them conduct such research. Given the strategic nature of this step, Sharp (2013,35-36) argues that advertisers should invest proper effort and resources in understanding consumers' buying behaviour instead of simply relying on "one's intuition or asking colleagues". After understanding consumers' buying behaviours, a brand also needs to understand the target audience's media consumption behaviours such as their favourite content types, which activities they usually do online, which websites that they usually do shopping, and so on (Chaffey \& Ellis-Chadwick 2016, 441-443).

Next, in terms of reviewing competitors' communication activities, insights into competitors' online activities, media mix, tactics, and their performance (i.e. campaign reach, conversions) are valuable for brands in the planning stage (Chaffey \& Ellis-Chadwick 2016, 442-443). For instance, rough estimation 
of competitors' yearly communication budget would be helpful for advertisers to allocate adequate budget as per discussion in the subsequent section. Additionally, De Pelsmacker et al. $(2017,128)$ explain that understanding and analysing the competitors' strengths and weaknesses in terms of their communication strategies are essential. This knowledge certainly strengthens the brands' strategies. While it is not recommended a brand should follow its competitors, monitoring competitors helps brand refine its strategies and tactics over time (Chaffey \& Ellis-Chadwick 2016, 442-443; De Pelsmacker et al. 2017, 129).

\subsubsection{Strategic advertising planning}

This step involves two main tasks which are a budget estimation and customer segmentation.

\section{Budget estimation}

There are several budgeting approaches that advertisers can choose from. They are affordability, percentage-of-sales, competitive parity, and objective and task method (Chaffey \& Ellis-Chadwick 2016, 451; De Pelsmacker et al. 2017, 169-174). Each approach has its advantages and disadvantages. First, affordability method suggests advertising budget can be the 'leftover' budget after the advertiser subtracts all costs (e.g. manufacturing costs, operational costs, financial costs and so on) from the anticipated revenue. This approach is the least recommended because it assumes advertising as a cost rather than a strategic investment for brands. Next, the percentages-of-sale method implies that the advertising budget is set as a fixed percentage of next year's forecasted sales. While this approach is easy to apply, it can lead to overspend if sales forecast is overestimated and vice versa. This approach is flawed because it assumes that sales and advertising have a direct short-term relationship yet advertising also affect long-term sales (Tellis 2009). Third, the competitive parity method suggests a brand to set budget similar to its competitors. On the the one hand, this approach helps brand ensure comparable advertising activities with its competitors. On the other hand, this method is unreasonable because brands with different market shares should maintain different advertising spend to grow in the long term (Jones 1990 as cited in De Pelsmacker et al. 2017, 172). Finally, objectives and task method suggest that a brand should estimate the budget based on estimating how much each advertising activity costs to help the brand achieve its campaign objective. In other words, this method is a bottom-up method, while the other three are topdown methods. While this method is the most recommended because it is brandspecific, the method is difficult to apply because it requires a rigorous understanding of all advertising tactics as well as historical data to calculate their costs. (De Pelsmacker et al. 2017, 169-174.)

\section{Customer segmentation}

According to Chaffey and Ellis-Chadwick (2016, 443-445) and De Pelsmacker et al. $(2017,129-130)$, customer segmentation belongs to strategic planning because 
it will define the type of people that will be reached by the advertiser's advertising campaign. Advertisers need to first divide their potential customers into different segments. After that, the advertisers need to decide which segments to focus on, because budget constraint may hinder targeting the whole market. After finalising the desired target audience, advertisers can reach the target audience via various targeting options discussed previously.

Regarding customer segmentation, a company's customers can be segmented based on different variations such as their relationship with the company, demographic characteristics (e.g. age, gender, social group), psychographic or attitudinal segmentation (e.g. early adopter), or their behaviours (e.g. online search behaviour, responsiveness to an online ad, purchase history, and so on) (Chaffey \& Ellis-Chadwick 2016, 444-445; De Pelsmacker et al. 2017, 130144). De Pelsmacker et al. $(2017,144)$ also propose four criteria to achieve effective segmentation. These are measurability, attainability, difference, and scale. The measurability criterion refers to the concrete information related to the segments, for example, segment's sizes, the purchasing power of the segments and so on. Next, the attainability criterion suggests that the segments must be realistic and attainable. Then, the difference criterion means that the segments should be distinguishable from each other. Finally, the scale criterion suggests that a segment's size should be large enough to be meaning; however, the authors did not recommend a specific minimum size.

In the next step, advertisers need to choose their prioritised customer segments. Marketing scholars have discussed different approaches. First, De Pelsmacker et al. $(2017,147)$ advise that an advertiser can consider several aspects such as the growth and profitability of the segments, company's internal resources to target that segment effectively when choosing a customer segment. In other words, advertisers need to justify the costs to reach a segment and the profitability it will bring (Chaffey \& Ellis-Chadwick 2016, 444; Evans 2009). Another approach is to choose the desired segments either based on immediate profitability or based on long-term value (Choi et al. 2019). The authors explain that because the online environment allows advertisers to recognise and target online users. The latter are going to make purchases soon, targeting this segment can bring immediate profits to the advertisers. Otherwise, advertisers can target online users that will become valuable customers in the long term.

\section{Targeting}

Per discussion in section 2.2.2, there are three main targeting methods which are demographic, contextual, and behavioural targeting. Advertisers can leverage each targeting method on its own or combine different methods to achieve precision targeting. For example, an advertiser selling clothing can combine demographic (e.g. Female with age from 18 to 25 ) with contextual targeting (e.g. browsing lifestyle websites). While combined targeting makes sense in theory, Goldfarb and Tucker (2011) doubt its effectiveness in practice. The authors find that combining contextual targeting and behavioural targeting causes obtrusiveness 
to consumers, and they are more likely to ignore the ad as a result. The authors elaborate that consumers are more tolerant of contextual targeting ads because even though such ads signify privacy obtrusiveness, the obtrusiveness level is within their tolerant threshold. On the other hand, if the consumers realise that the ads are tailormade for them, implying that their privacy is threatened, they will raise their guard and choose to avoid the ads. This explains why hyper-targeting ads (e.g. combining contextual and behavioural targeting) are ineffective (Goldfarb \& Tucker 2011). Thus, such a targeting approach is not encouraged.

\subsubsection{Message strategy and ad creation}

Advertising message of an advertising campaign is the answer to the question of why a consumer should purchase the product or service from a particular brand. As there could be too many brands on the market for consumers to choose from, an advertiser has to position its brand so that the consumers can differentiate the brand with its competitors. Furthermore, brand positioning should signify the brand's unique selling point (USP), which helps consumers to solve problems and achieve their goals. All in all, the message strategy must resonate with target audience insights and brand positioning. The message strategy lays the foundation for ads design and creation. (Pelsmacker et al. 2017, 176)

There are three decisions related to ad design and creation that advertisers need to make, which are ad content, ad format, and ad size (Bruce, Murthi \& Rao 2017). Bruce et al. (2017) observe that ad content can generally be divided into two main themes which are price-based versus product-based message, and emotional-based versus argument-based message. Next, ad formats are diversified, for example, static banner and dynamic banner, video, social advertising ads (Bruce et al. 2017). Finally, ad sizes also vary, but they can be classified into two groups which are standard and non-standard size (Goldfarb \& Tucker 2015). While the decision concerning ad content is in the advertisers' full control, the decisions concerning ad formats and sizes are influenced by an ad placement's characteristics (Choi et al. 2019). For instance, several ad placements only accommodate static banners with a standard size. In such cases, the advertisers can only either follow the required ad specifications or choose another ad placement. Choi et al. (2019) add that while advertisers have abundant options to choose from, they also face budget constraint when producing too many ads with different formats and sizes. Therefore, advertisers need to balance the cost and benefits of producing additional ads towards achieving the campaign's objectives.

\subsubsection{Media planning and buying}

According to Sharp (2013, 387-388), as the media landscape is increasingly complex, fragmented together with the audience's changing of media habit, so is the role of media planning and buying in the advertising process. The author points out that several advertisers even perceive media strategy to be more important 
and should be preceded before creative strategy because the media budget can account for up to $70 \%$ of advertising budget.

\section{Media planning}

Media planning involves selecting the right mix of digital media channels. In other words, advertisers need to select different digital channels and allocate budget for each channel. An effective media mix means it can help advertisers achieve campaign objectives (Sharp 2013, 388) in a way that the cost of customer acquisition is minimised (Chaffey \& Ellis-Chadwick 2016, 454-456). In that sense, the media mix is influenced by the campaign objectives and budget. Regarding campaign objective affecting the media mix, short-term direct response campaigns may prioritise performance-driven channels such as affiliate and search marketing while long-term brand building campaigns may prioritise display advertising channels (Chaffey \& Ellis-Chadwick 2016, 455). However, the authors also encourage that the media mix should be improvised on a campaign basis based on the learning of good practices and bad practices from the previous campaigns. Regarding campaign budget affecting the media mix, the campaign budget will affect the percentage of budget allocated to each channel and the duration of the campaign. As Chaffey and Ellis-Chadwick $(2016,455)$ demonstrate that a lower budget results in fewer number of channels and shorter campaign period and vice versa for a higher budget.

\section{Media buying}

Media buying comprises four components which are whether to buy guaranteed or non-guaranteed inventories, price settlement, and campaign scheduling (Choi et al. 2019).

First, regarding buying guaranteed versus non-guaranteed inventories, the discussion on guaranteed and non-guaranteed ad inventories is in section 2.3.2 of this thesis. While the previous discussion mentions the ad inventory types in the context of programmatic advertising, advertisers can also book guaranteed ad inventories via direct buy. In general, advertisers have the flexibility to buy guaranteed inventories or non-guaranteed inventories or mix both types in a campaign - the decision on buying which ad inventory types will affect rest components. Even so, it is unclear why advertisers would favour one type of ad inventories over the others in practice (Choi et al. 2019).

Next, in terms of price settlement, per previous discussion, advertisers and publishers need to negotiate a fixed price in advance for all ad inventories if the advertisers are buying guaranteed inventories. Otherwise, advertisers will participate in a bidding process in real-time (i.e. RTB) for each single ad impression if they are buying non-guaranteed inventories. Because the bidding process is a competition among advertisers, one needs to bid rigorously enough to win the bid, yet the bid should still be optimal at the same time. The bid calculation has become more complex because it is influenced by four factors which are campaign budget constraint, a total number of impressions to be acquired, advertiser's valuation for each bid, and the budget pacing options so that the campaign 
budget is smoothly allocated through the campaign period (Choi et al. 2019; Wang et al. 2017). Failure to consider these factors may lead to overbid or underbid, which make the advertisers overpay for impressions or not winning any bid at all, respectively. Either scenario is undesired, so designing an optimal bidding strategy is one of the most important tasks in RTB advertising. While there are many studies about RTB strategies, it is not the case for studies about price settlement process of guaranteed inventories.

Finally, ad scheduling involves when to show the ads (i.e. timing) and how often to show the ad (i.e. frequency capping) to the target audience (Choi et al. 2019). Regarding ad timing, Sharp (2013, 424-425) discusses that advertisers can place the ads in a continuous manner or in bursts. While each option has its advantages and disadvantages, the author supports pacing the ad regularly throughout the year rather than cramping the ad impressions within a short period, because the first approach helps advertisers to reach new potential buyers in the long term. The study of Sahni (2015) also supports this view. Next, regarding ad frequency, it refers to the maximum times that the target audience is exposed to an ad during a period (Sahni 2015). According to the author, the rule of thumb for optimal frequency capping is five per week. Importantly, the advertisers have more flexibility in controlling the ad timing and frequency when buying ad via RTB than when buying ad via guaranteed inventories (Choi et al. 2019). Because in guaranteed inventory deals, publishers are responsible for delivering all booked impressions, ad pacing and frequency per agreement while in RTB deals, advertisers directly execute the buying process.

\subsubsection{Campaign optimisation and evaluation}

This step involves with the continuous monitor of ad performance and takes timely action to adjust the creatives and media to ensure achieving campaign's KPIs. This step consists of two main tasks which are experimental design and ad attribution.

\section{Experimental design}

Online advertising requires continuous optimisation because the online advertising environment keeps changing rapidly, and the competitors also react to advertiser's strategy. The optimisation process includes designing experiments, analyse, and interpret the results, incorporating the learnings into the current process, and retesting (Choi et al. 2019). Advertisers can test alternatives of ad design, targeting types, timing, and frequency of an ad, and so on via the controlled experiment technique. A controlled experiment is also referred to as a randomised experiment, A/B test, split test, control/treatment test (Kohavi, Longbotham, Sommerfield \& Henne 2009). An experiment starts with recruiting two groups of people and randomly divides them into two groups called the control group and treatment group (Kohavi et al. 2009). Each group then will be shown an alternative version of what being tested (e.g. two versions of an ad, different frequency of the same ad). By default, the control group will be exposed 
to the "existing" ad version, and the treatment group will be shown a "new" ad version that needs evaluating. Finally, statistical tests will be conducted to confirm the causal effect between the ads and purchase will be formed or dismissed.

\section{Ad attribution}

Attribution is defined as the process of analysing which ad formats and media channels are effective at influencing purchase conversions. This process does not only help advertisers optimise their advertising campaigns, but also evaluate the ad effectiveness and budget allocation (Choi et al. 2019; Nisar \& Yeung 2018). Attribution models are necessary because a consumer path-to-purchase is complex and he/she can be exposed to the advertiser's different ad formats on different channels, so the models are useful for advertisers to understand which channels and creative work and which do not. As illustrated in Figure 7, there are two scenarios of a consumer path-to-purchase. The first scenario demonstrates a straightforward path-to-purchase, so the advertiser can conclude the display ads contributed 100 per cent to the purchase. In contrast, the second scenario demonstrates a multi-touchpoint path-to-purchase, which is challenging for the advertiser to conclude which touchpoints are more effective or less effective at influencing the consumer's purchase. So, attribution models are essential.

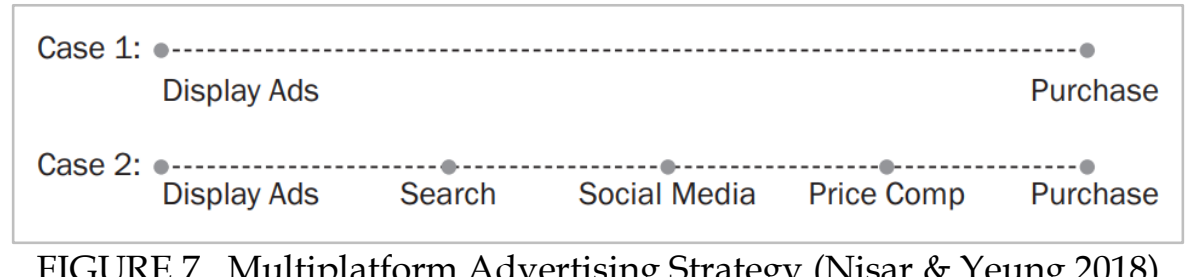

There are three popular attribution models which are last-click attribution, uniformly distributed attribution, position-based model, time-decay model, and statistics-based model. While the first three models are of ruled-based modelling assumptions, the last one skews towards data-driven and statistical method (Nisar \& Yeung 2018). The subsequent paragraphs briefly explain each model and its strengths and weaknesses.

The simplest attribution model is last-click attribution, which assumes that the purchase is 100 per cent contributed by the last touchpoint (Nisar \& Yeung 2018). Accordingly, this model dismisses the contribution of all touchpoints came before that last one. As a result, despite the simplicity of this model, it is scrutinised by many scholars for such a flawed assumption (Lewis et al. 2015; Nisar \& Yeung 2018). The authors warn that advertisers applying this attribution model will optimise their media budget suboptimally because the last click could not have happened without previous ad exposure. In other words, this attribution model overstates the causal effect of the last click and purchase. Still, this model is the most used by advertising practitioners (Lewis et al. 2015).

Next, uniformly distributed attribution, position-based model, and timedecay model are classified into multichannel attribution models. These models 
argue that each exposure plays a role in influencing the purchase. Therefore, all touchpoints should be given credits. The only difference among these models is the weights allocated for each touchpoint. Uniformly distributed attribution allocates equal weights for all touchpoints, assuming all touchpoints are equally important. The position-based model assumes that the first and the last touchpoints are the most important, so this model gives $80 \%$ credit to the first and the last touchpoints (i.e. each will be given $40 \%$ credit), and distributes the remaining $20 \%$ equally among middle touchpoints. Time-decay model assigns more credit to those touchpoints closer to the purchase, assuming these channels play a higher role in converting the potential buyers. (Nisar \& Yeung 2018.)

Although multichannel attribution models are more reasonable than the last-click attribution, these models are still of assumption nature. Therefore, those models can be used to calculate ad effectiveness rather than to correctly predict conversion events. Hence, statistics-based attribution models were introduced to predict conversions (Nisar \& Yeung 2018). Because these models are data-driven, they are perceived to be more advanced than the rule-based models. There have been more statistics-based attribution models developed and tested, but they are not widely applied in practice. While these models require large dataset and complicated methods, they do not yield reliable predictions as expected (Lewis et al. 2015). This partly explains why the statistics-based models have not been widely adopted in practice yet.

All in all, it appears that the ad attribution models are more suitable to evaluate ad impact of short-term direct response campaign than to evaluate ad impact of long-term brand-building campaigns. It is because the outcome of these models is to assign or predict which channels contribute more credit to the final purchases. Furthermore, because these models totally rely on users' online behavioural data, it is likely that the models miss offline purchase data. Hence, ad attribution models should be more effective at evaluating advertising impact for brands operating online only and eCommerce than hybrid stores or brick-andmortar stores.

\subsection{Impact of programmatic advertising on the advertising process}

\subsubsection{New online advertising process}

Even though there are many studies on programmatic advertising topic, there is limited research on how programmatic advertising impacts the advertising process from an advertiser's perspective. Indeed, at the time of writing this thesis, there was only one published paper, by Qin and Jiang (2019), on this topic.

Qin and Jiang observed the programmatic advertising process in Chinese internet companies such as Alibaba, Baidu, Weibo.com (China's Twitter) and Dianping.com (China's Yelp). The authors conclude that the advertising process under programmatic impact possesses four characteristics which are data-based, 
tool-based, synchronised and highly efficient. First, the data-based characteristic implies that data play crucial roles in the process. Second, the tool-based characteristic is because programmatic advertising relies heavily on tools and algorithms (e.g. tools to record consumers' online activities, tools to analyse the data and generate insights, tools to carry out real-time bidding, and so on). The authors go one step further when they argued that the future advertising process would be "more dependent on data and algorithms than manpower" (Qin \& Jiang 2019, 344). In other words, the programmatic advertising process is less labour intensive than the traditional process. Also, thanks to the capabilities of the algorithm to analyse data and make real-time decision in a millisecond, the programmatic advertising process is synchronised. Finally, because the algorithms keep taking in new data and learning from that to improve the overall ads and campaign performance, the whole advertising process is highly efficient.

Qin and Jiang (2019) also propose the new advertising process, as illustrated in figure 8 . The new advertising is shortened and includes only four steps which are consumer insight discovery, targeted ad creation, media planning and buying, and ad impact evaluation. According to the authors, while the traditional advertising process could take up to six months from the insight discovery to the ad evaluation stage, the new process can happen within seconds. The infrastructure of programmatic advertising allows these steps to happen in real-time and nearly parallel with each other. Furthermore, because programmatic advertising is both data and technology-driven, it also generates personalised at scale.

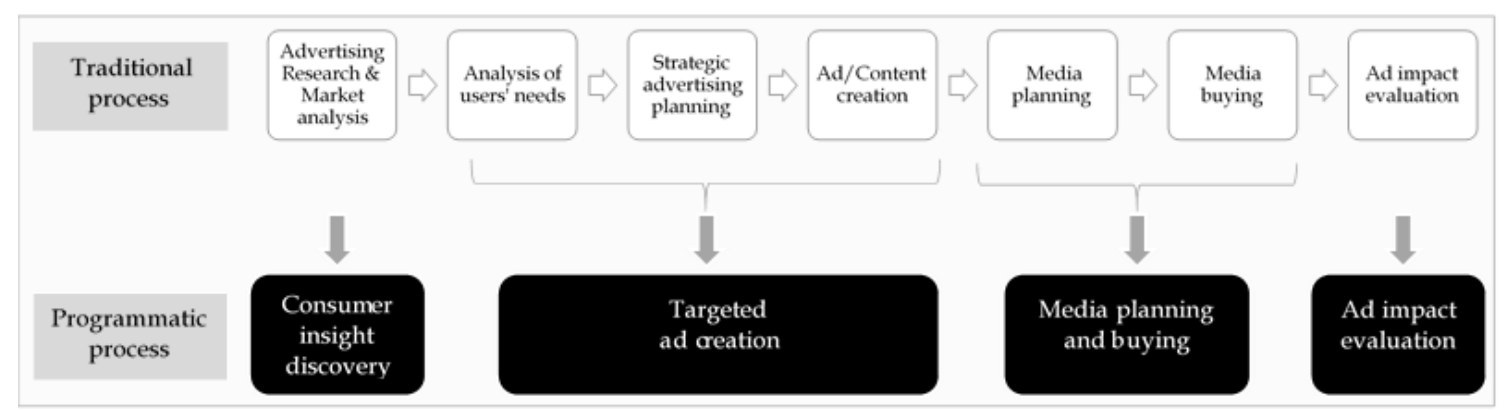

FIGURE 8 The transition from tradition advertising process to programmatic advertising process (Qin \& Jiang 2019)

Consumer insight discovery is defined as a process to build consumers' digital profiles including "their gender, age, origin, hobbies, purchasing power, and recent consumption" by collecting and integrating data from first-party, second-party and third-party data (Qin \& Jiang 2019, 341-342). As explained in section 2.3, this process is conducted by DMPs. The holistic consumers' digital profile provides insights into the consumers' needs and wants more accurately and granularly than the traditional advertising research and market analysis.

However, Chen et al. (2019) argue that the traditional research approach (i.e. advertisers bought quantitative data sets) is not as effective as the new process in terms of richness, scale, and update frequencies. First, the panels of traditional research usually segment the audiences based on their easily identifiable 
attributes such as age and gender. At the same time, DMPs allows advertisers to segment users in various sophisticated ways. Additionally, traditional panels have small sample sizes while the DMPs of programmatic advertising can collect million data points of real online users. Finally, the traditional panel is static because they are usually updated on a yearly basis while the DMPs update data in real-time. The real-time factor is desirable because it helps advertisers understand consumers' needs and wants as they emerge, which is the starting point of generating personalised ads (Kietzmann, Paschen \& Treen 2018). Even though the mentioned advantages of DMPs are supported by Chen (2020, 299-308), the author argues that data collected by DMPs are quantitative, which lacks depth when compared to traditional qualitative methods such as observations and indepth interviews. Hence, qualitative data from traditional market research are also important for discovering customer insights.

Next, targeted ad (i.e. personalised ad) creation is the combination of three steps analysis of user needs, strategic advertising planning and ad creation (Qin \& Jiang 2019). According to the authors, the backend system can analyse the digital user- profiles to infer the patterns of their needs and wants. Then, several creative messages tailor-made to each user will be developed. After that, PCP will create the ads whose content is based on the creative idea and format is optimised based on the users' touchpoints. Kietzmann et al. (2018) add that thanks to the smart technologies, the system can learn the performance of the ads and continuously optimise the content to improve ad performance over time. Even though the target ad creation can be fully conducted by the system, advertisers are free to decide the degree of automation (Chen et al. 2019). In the lowautomation scenario, advertisers decide most of the ad content and let the system adapt to different ad placement sizes. In the high-automation scenario, the system will create the ads based on the creative components (e.g. design templates, ad copies, photos, and videos) fed into the system by the advertisers. So, the advertisers need to input various versions of each component so that the system can mix and match and generate different ads versions to test and fine-tune them.

Then, regarding media planning and buying of programmatic advertising, the advertisers no longer need to find the audience. Instead, the advertisers just need to specify their outcome metrics (e.g. sign-ups, clicks to the sales page, conversion) to the system (Lewis et al. 2015). Then, the system will rely on data and bidding rules to find a suitable target audience and show ads to them. Thanks to the automatic matching process, programmatic advertising reduces the targeting cost. That is, advertisers can precisely target relevant audience rather than wasting impressions on uninterested consumers.

Additionally, Qin and Jiang (2019) argue that media planning and buying will happen in parallel rather than linearly, and this process can be fully conducted by the system. The system can choose the where to display ads and how much to pay for an ad impression. Then, based on the performance of the ad, the system can re-allocate the budget among different ad formats and place- 
ment. IAB $(2019 b, 7)$ even claims that the system can do ad attribution "automatically and autonomously". This explains why the new media planning and buying process is more efficient than the traditional process.

Finally, the ad impact evaluation phase will happen faster, thanks to the system's ability to capture and compare real-time ad response against the campaign's objective (Qin \& Jiang 2019). The system can inform this ad response to ad creation and media planning and buying phase within a second. So, the optimisation process occurs faster, more efficient, and result-oriented (IAB 2019b; Schultz 2016).

\subsubsection{Challenges of programmatic advertising}

Even though programmatic advertising offers advantages which can potentially transform the online advertising process, it also possesses inherent weaknesses that make the advertising process less efficient and effective than it should be.

\section{Data privacy hinders consumers insight discovery phase by DMPs}

Per the above discussion, programmatic advertising is capable of collecting and integrating data from different sources and build a holistic users' online profiles which help advertisers to understand the consumers' needs and wants in realtime. Furthermore, the optimisation process of programmatic advertising also relies heavily on users' real-time response to the ad to infer the ad performance. In other words, without access to user's behavioural data, programmatic advertising losses its charm, because the system has no data input and feedback to generate relevant ad messages (Deng et al. 2019). However, the recent growth of users' awareness of online privacy and personal data protection has caused online user data increasingly difficult (Chen et al. 2019; Malthouse, Maslowska \& Franks 2018). The authors state that this personal data awareness is manifested at both the individual level and societal level. At the individual level, the savvy tech users have used a variety of applications such as a virtual private network (VPN), Do not track', 'limit app permissions' features, on smart devices, and so on to limit their data being collected. At the societal level, after several major data breach incidents, the European government release the European Union's General Data Protection Regulation (GDPR) in 2018, limiting web browsers from collecting personal data. Such privacy regulation reduces advertising effectiveness because it prevents advertisers from targeting the right audience with relevant ads (Goldfarb 2014).

\section{Low-quality DMPs and biased algorithms deter precision targeting}

Precision targeting is highly desirable because it enhances the advertising efficiency and effectiveness (Chen 2020, 299-308). Programmatic advertising can offer precision targeting at scale by leveraging data provided by DMPs and relying on the ad delivery algorithms to bid and optimise the ads. However, several studies demonstrate that both DMPs and ad delivery algorithms are subject to flaws, causing precision targeting ineffective. 
First, regarding the quality of DMPs, Neumann, Tucker, and Whitfield (2019) conducted field studies across nineteen DMPs in Australia and concluded that the quality of those DMPs varies significantly. One reason for this quality variations is caused by "quality differences in the buying technology of DSPs and their service managed by service teams" (Neumann et al. 2019, 349). Another reason is the data collected lacks accuracy and coverage (Sylvester \& Spaeth 2019). The authors suggest that data inaccuracies can be caused by self-reporting error or data collection faults. And, low data coverage refers to data only cover certain demographic or geographical groups, and so on. Finally, DMPs also includes data provided by data vendors who combine data from different sources via different data collection techniques whose accuracy and validity are hard to justify (Gertz \& McGlashan 2016, 63).

Next, regarding the ad delivery algorithms, studies by Lambrecht and Tucker (2019) and Ali et al. (2019) prove that the ad delivery algorithms are prone to biased targeting. For example, in one of the studies by Ali et al. (2019), the researchers observe that Facebook system automatically showed ads whose content related to male interests (e.g. bodybuilding) to male despite that the researchers did not specify which gender when setting up the experiment. Such practice happens without advertisers' acknowledgement and can cause undesired outcome in the long run. Specifically, the brand may want to target both genders equally, but it ends up attracting male consumers because of the biased algorithms. This is problematic if the advertiser does not understand the cause before concluding the product is more interested by male than female consumers, and then changes its brand strategy because of that. Gordon et al. (2019) add that biased algorithms are caused by digital platforms trying to optimise their revenue model. For example, if a publisher gains revenue from consumers' clicks, it will prioritise showing ads to those who more likely to click on an ad.

Furthermore, Lewis et al. (2015) conducted several experiments and raised concern about the optimisation algorithm. There can be scenarios in which the system seeks for the easy to convert audience who are going to buy the product regardless of seeing the ad or not, rather than try to optimise for additional converts. In the former scenario, it is unnecessary to expose the ad to potential buyers because they are going to make the purchases soon. In contrast, it is more necessary to show an ad to the audience in the latter scenario so that the advertisers can recruit additional conversions. However, the system fails to differentiate the two scenarios, and because it is cheaper to expose ad to users in the first scenario, the chance for this to happen is high. Therefore, advertisers need to be aware of this issue in the optimisation process. Lewis et al. (2015) recommend that the proper optimisation practice should prioritise incremental conversions rather than a pure focus on minimising bids and lower price conversions. 


\subsection{Summary of the literature review}

This chapter discusses the research literature related to the topic of interest. First, the definition and overview of online advertising where discussed to lay context for the study. In brief, online advertising includes paid online activities such as display advertising and paid search ads that brand conduct to promote its products. The fundamental difference between online advertising and offline advertising is online advertising allows advertisers to target their consumers precisely based on their demographic attributes (i.e. demographic targeting), contexts (i.e. contextual targeting), interests and behaviours (i.e. behavioural targeting).

Next, the literature review explains programmatic advertising which belongs to display advertising. Programmatic advertising leverages real-time data and technologies to precisely target the audience with personalised ads at scale. Even though data and technologies are the strengths of programmatic advertising, they are also weaknesses due to ineffective DMPs and biased ad delivery algorithms. Programmatic advertising consists of two components which are programmatic buying and programmatic creative. Programmatic buying is the audience that ensures the ad impressions are shown to the right audience regardless of the websites. And, programmatic creative helps advertisers generate personalised and contextualised ads at scale.

Unlike traditional online display ads, programmatic advertising involves a whole new ecosystem and a range of technologies fuelling the programmatic buying and creative. This poses the question of how programmatic advertising practices and the process would be. Therefore, the chapter moves on studying the involved steps in an advertising process, including (1) Setting campaign objectives and effectiveness metrics, (2) Campaign insights discovery, (3) Strategic advertising planning, (4) Message strategy, (5) Ads creation, (6) Media planning, (7) Media buying, and (8) Campaign optimisation and evaluation.

Finally, the literature review studies the impact of programmatic advertising on online advertising process about the theoretical concept of Qin and Jiang (2019). The authors propose that the advertising process will be compressed from eight steps to four steps including (1) Audience insight discovery, (2) Targeted ads creation, (3) Media planning and buying, (4) Ads impact evaluation. Additionally, the new process is a data-based, tool-based, synchronised, and efficient process. As the process is derived based on observation of China market only, studies on programmatic advertising at other markets are encouraged to gain diversified perspectives on the topic.

The following table (Table 1) outlines the key literature of this study. 
TABLE 1 Summary of key literature

\begin{tabular}{|c|c|c|c|c|}
\hline Authors & Year & Topic & Methods & Key findings \\
\hline Goldfarb & 2014 & $\begin{array}{l}\text { Online } \\
\text { advertising }\end{array}$ & $\begin{array}{l}\text { Literature } \\
\text { review }\end{array}$ & $\begin{array}{l}\text { The paper identifies the fundamental } \\
\text { difference between online and offline } \\
\text { advertising. It is precision targeting, a } \\
\text { unique attribute offered by online ad- } \\
\text { vertising, which results in significant } \\
\text { decrease in cost of targeting. Also, } \\
\text { through the discussion on various } \\
\text { online targeting models, the paper } \\
\text { stresses that understanding these un- } \\
\text { derlying targeting models is essential } \\
\text { to understanding the online advertis- } \\
\text { ing landscape. }\end{array}$ \\
\hline $\begin{array}{l}\text { Choi, } \\
\text { Mela, } \\
\text { Balseiro \& } \\
\text { Leary }\end{array}$ & 2019 & $\begin{array}{l}\text { Online display } \\
\text { advertising's } \\
\text { ecosystem }\end{array}$ & $\begin{array}{l}\text { Literature } \\
\text { review }\end{array}$ & $\begin{array}{l}\text { The paper provides a holistic under- } \\
\text { standing of online display advertising } \\
\text { ecosystem by identifying all players } \\
\text { (i.e. advertisers, publishers, and inter- } \\
\text { mediaries) involved in the ecosystem } \\
\text { as well as discussing each player's de- } \\
\text { cisions (e.g. pricing, ad scheduling) } \\
\text { when participating in the display ad } \\
\text { market. The paper also finds that both } \\
\text { advertisers and publishers prefer to } \\
\text { trade ads via both guaranteed and } \\
\text { auction-based channels because each } \\
\text { selling channel has its own strengths } \\
\text { and weaknesses. Lastly, the players' } \\
\text { decisions are influenced by the selling } \\
\text { channel choices. }\end{array}$ \\
\hline $\begin{array}{l}\text { Chen, Xie, } \\
\text { Dong \& } \\
\text { Wang }\end{array}$ & 2019 & $\begin{array}{l}\text { Programmatic } \\
\text { advertising }\end{array}$ & $\begin{array}{l}\text { Case } \\
\text { study }\end{array}$ & $\begin{array}{l}\text { The study proposes a new theoretical } \\
\text { framework of programmatic advertis- } \\
\text { ing to include both programmatic } \\
\text { buying and programmatic creative. } \\
\text { The authors argue that while pro- } \\
\text { grammatic creative is a new phenome- } \\
\text { non, it has significant impact on online } \\
\text { advertising process. Lastly, even } \\
\text { though programmatic creative auto- } \\
\text { mates the ad generation process, hu- } \\
\text { man effort is still demanded due to } \\
\text { the imperfect underlying technologies. }\end{array}$ \\
\hline
\end{tabular}

(Continues) 
Table 1 (continues)

Qin \& Jiang 2019 Programmatic Case study The study discusses two findings. advertising First, the process is shortened from process various steps (e.g. advertising research, analysis of users' needs, strategic advertising planning, ad creation, media planning, media buying, and ad impact evaluation) to only four steps (e.g. consumer insight discovery, targeted ad creation, media planning and buying, and ad impact evaluation), because some steps are combined and occurred in parallel. Second, the new advertising process possesses four characteristics which are data-based, tool-based, synchronised, and highly efficient). 


\section{METHODOLOGY}

This chapter describes the study's research strategy (Section 3.1), the data collection process (Section 3.2) and how the data were synthesised and analysed (Section 3.3). Finally, the chapter would be concluded with a flowchart summarising the methodological process of this study (Section 3.4).

\subsection{Research strategy}

In brief, the study design involves using case study research and abductive reasoning to answer the research questions.

\subsubsection{Case study as a research strategy}

Yin $(2009,18)$ defines case study as "an empirical inquiry that investigates a contemporary phenomenon in depth and within its real-life context, especially when the boundaries between phenomenon and context are not evident". In other words, a case study is preferable for an in-depth study of a phenomenon that is context-sensitive. Yet, the researcher cannot replicate the phenomena in the laboratory setting but have to examine the phenomenon in the real-world setting. Yin $(2009,2)$ explains that the case study is also suitable for answering research questions of "how" and "why". Especially when the study object is a contemporary phenomenon over which the researcher "has little or no control", a case study should be the prevailing choice.

All in all, the case study allows the researcher to gain a holistic and realworld perspective of a phenomenon, including organisational and managerial processes. For those reasons, the case study research is an appropriate strategy for this study because the study involves studying the programmatic advertising's planning and implementation process which is a real-life phenomenon and cannot be replicated in a lab environment. Also, the nature of the research questions "how" and "what" can be answered using a case study.

One common criticism of case study research, according to Yin $(2009,15-$ 16), is that one cannot statistically generalise the study results from a case study. While the author agrees that it is not possible to make a statistical generalisation of the case study's findings, it is reasonable to make analytical generalisation. That is, expanding the study results in a broader theory. Johnston, Leach and Liu (1999) also support this argument of Yin (2009) when asserting that it is both inappropriate and unrealistic to draw such statistical generalisation because case studies usually include context-sensitive data and variables. Hence, even though there could potentially be enough cases for such statistical generalisation, doing so will remove the findings out of their context, making the generalisation meaningless. Additionally, the statistical generalisation of case study findings is 
flawed because a case is not a sampling unit (Yin 2009, 38). Instead, Johnston et al. (1999) advise that one should focus on the strength of the case study that each case study offers an in-depth understanding of the phenomenon of interest.

Finally, regarding the reasoning approach, there are three reasoning types which are deductive, inductive, and abductive (Mantere \& Ketokivi 2013). The authors explain that any reasoning type has the same three core components, which are (1) rule, (2) explanation and (3) observation. And, the reasoning types differ from each other in terms of which components are accounting for the premise and which component is accounting for the conclusion. That is, deductive reasoning uses rule and explanation as premises to predict specific observation. In contrast, inductive reasoning uses observation and explanation as premises to infer the general rule. Then, abductive reasoning, the middle ground of deductive and inductive reasoning, uses rules and observation as premises, and the conclusion is the "best explanation from a set of competing for an explanation" (Mantere \& Ketokivi 2013, 81). The authors explain that in abductive reasoning, a researcher needs to bounce back and forth between theories and empirical data to gain a new perspective of the theories as well as the empirical data. Because this study aimed at using study results to enhance the prior findings of programmatic advertising and online advertising process rather than testing existing theory or building new theory, abductive reasoning was chosen.

\subsubsection{Case selection}

\section{Case study design}

The study employed the single case study design. According to Yin (2009, 46-53), there are single case studies and multiple case studies. Multiple case studies (i.e. studies including at least two cases) are more favoured than single case studies most of the time because they allow cross-case comparison, making the study results of multi-case studies more robust and compelling (Perry 1998; Johnston et al. 1999; Yin 2009, 46-53). However, there are five rationales supporting the use of single case study (Yin 2009, 46-53). Among which, the rationale of a revelatory case applies to this study. A revelatory case is usually used when a researcher "has an opportunity to observe and analyse a phenomenon previously inaccessible" to the academic inquiry (Yin 2009, 48). In this study, the selected case was online advertising process in Vietnam market. The case could be considered to be revelatory because there were limited information and research regarding the phenomenon in the market. And since the researcher happened to work in the advertising field in Vietnam previously, it was possible to contact the digital specialists in the country to interview them and collect data for this study. Also, the researcher's prior understanding of the market can contribute to the detailed description of the case study. Moreover, Yin (2009, 60-62) recognises the major disadvantage of multi-case studies design is that it requires intensive time and resources to conduct these case studies effectively. Accordingly, resources and time constraint also contributed to the single-case design decision of this study. 


\section{Case's context: Overview of Vietnam market's internet landscape}

Vietnam's internet penetration in January 2020 was $70 \%$ which was relatively high compared to the world's average of $59 \%$. The country's internet penetration also keeps growing fast year on year. There was an increase of $10 \%$ in the absolute Vietnamese internet users compared to the same period of last year, which made the market stand among the top ten markets with the largest absolute growth of internet users. Vietnamese internet users spent on average 6.5 hours per day on the internet, which was on par with a worldwide average. Two-third of total time spent was equally accounted by social media activities and videos watching. (WeAreSocial 2020.)

Google search, YouTube and Facebook are the top three most visited websites in Vietnam. Facebook and YouTube are also the top two social media platforms whose penetration are $90 \%$ and $89 \%$ respectively (WeAreSocial 2020). Substantial penetration makes YouTube and Facebook the ideal platforms for advertisers in this market. This explains why both Google and Facebook position Vietnam as the most important market in Southeast Asia (The Information 2019; Market Realist 2019). The rest websites in the top twenty websites, reported by WeAreSocial (2020), are mostly local news websites (e.g. kenh14.vn, vnexpress.net) and eCommerce websites (e.g. shoppe.vn, tiki.vn, lazada.vn).

Vietnam is a mobile-centric market. $97 \%$ of Vietnamese internet also access the internet via a mobile device, and half of the internet time spent per day was via mobile internet (WeAreSocial 2020). Indeed, 70\% of YouTube watch time was from mobile phones (MMA 2018), 79\% of internet users only access Facebook via a mobile device (WeAreSocial 2020). Mobile-centric trend fosters the growth of mobile advertising. While mobile advertising has many advantages such as granular data and location-based targeting, it also faces several limitations such as limited rich advertising formats, high possibility of ad blockage, technological compatibility issues with different mobile operating systems (MMA 2018).

Another challenge to online advertising is the consumer's concerns about digital privacy and online well-being. WeAreSocial (2020) reports that $43 \%$ of Vietnamese internet users used adblocking tool, and 56\% deleted cookies from a web browser monthly. Such habits can negatively affect the accuracy of advertisers' ads tracking activities, which in turns negatively affect the precision targeting per the previous discussion in section 2.5.2.

Lastly, in terms of digital advertising spend, the estimated number for 2019 was \$306 million, increased sharply 9\% compared to the prior year. The digital spend was allocated for search ads, display ads (i.e. banners, videos, and social ads), and classified ads as 38.5\%, 44.2\%, 17.3\%, respectively. Display ads did not only account for the highest digital spend, but it was also the only ad format having a two-digit growth in spending last year (WeAreSocial 2020). The ad spend patterns of Vietnam market is also consistent with the global ad spend discussed in the Introduction chapter. 


\subsection{Data collection}

\subsubsection{Interview as a data collection method}

Yin $(2009,106-109)$ endorses interview as the most important and essential source of data for a case study. Furthermore, interviews allow a researcher to interact with the study subjects directly, as well as ask them open-ended questions to gain an understanding of a specific topic, especially when the topic is complex or sensitive (Hair et al. 2016, 200-208). Bloomberg and Volpe (2008, 7374) add that interview is preferable than the other methods when a researcher needs to obtain the experience or viewpoints of a person. As the study aimed at understanding the digital specialists' perspective on programmatic advertising as well as their experience in utilising programmatic advertising in online advertising campaigns and so on, interview as a research method helped to achieve that objective.

Having that said, the study also acknowledges the disadvantages of personal interviews. First, the quality of interviews significantly depends on the interviewees' willingness and articulate capabilities when answering the interview questions (Bloomberg \& Volpe 2008, 82-84). Personal interviews are prone to response bias because of various reasons such as the interviewee having a biased viewpoint, or the interaction and relationship between the interviewer and interviewee affecting the neutrality of the answer (Johnston et al. 1999). Another downside is the interviewer is not skilful enough to conduct effective interviews and the interview questions are poorly constructed (Yin 2009, 67-73). Hence, action steps were taken during the interview planning and conducting phases to minimise these disadvantages so that the collected data are useful and unbiased.

Next, there are three different types of interviews which are structured, semi-structured and unstructured (Bryman \& Bell 2011, 467-473; Hair et al. 2016, 200-208). The authors explain that these types differ with each other in terms of flexibility. The flexibility is manifested through the way interview questions being asked. Unstructured is the most flexible, whilst structured is the most rigid interview type. Accordingly, unstructured interviews are similar to conversations in which the researcher will start with one fixed question and continue with follow-up questions corresponding to individual interviews. On the other hand, A structured interview is the least flexible because the interviewer will prepare a list of questions in advance and ensure that all interviewees will be asked the same questions in the same order. Semi-structured interview is a middle ground between structured and unstructured interviews. In semi-structured interviews, the researcher prepares an interview guide consisting of tentative questions of predefined topics, but the researcher can also ask follow-up questions to dig deeper. After considering the strengths and weaknesses of each type, the study chose to use semi-structured interviews because it balances between directionality and flexibility as Yin $(2009,106)$ proposes. 


\subsubsection{Recruiting study participants}

The study participants were recruited using purposive sampling. According to Bryman and Bell $(2011,442)$, purposive sampling allows the researcher to sample participants having knowledge or relevant understanding of the topic of interest. In other words, the participants should be recruited according to "predefined criteria relevant to a particular research objective" (Guest, Bunce \& Johnson 2006, 61). Hence, the participants in this study were selected based on two criteria. First, the respondents must have at least two to three years of experience in digital advertising. This criterion was to ensure they have an adequate understanding of of the online advertising process. Then, the study participants must have experience in planning and implementing programmatic ad campaign within the past year. Because the digital advertising landscape keeps involving, this criterion was to ensure their answers reflected the market situation.

Then, in terms of a number of interviews, there is no requirement for minimum interviews since the methodology's goal is to study and understand a phenomenon, so quality and depth rather than the quantity of the data is prioritised (Bloomberg \& Volpe 2008, 82-84). However, in the study of Guest et al. (2006) about how many interviews should be enough, the authors suggest that a researcher should aim at conducting from six to twelve interviews. Specifically, six interviews are the minimum threshold of discovering major themes and twelve interviews are the thresholds of theoretical saturation. Theoretical saturation is defined as "the point at which no new information or themes are observed in the data" (Guest et al. 2006, 59). Thus, this study used six to twelve interviews as the rule of thumb.

Finally, all potential participants were shortlisted based on the mentioned criteria. Then, the researcher contacted the potential respondents and invited them to participate in the study. All of them were sent and explained the background and purpose of the study (i.e. Research notification), as well as personal data protection complying with the General Data Protection Regulations (i.e. Privacy notice). Only those signed the Research consent form, which allowed the researcher to use interview content in the study were interviewed. While there were eight people contacted by the researcher, only seven people were willing to participate in the study. Eventually, because the major themes emerged after five interviews, and no new significant themes came up after that, the data gathering process was completed with seven interviews with seven respondents.

\subsubsection{Conducting semi-structured interviews}

The semi-structured interviews were conducted in the Vietnamese language from 29.02.2020 to 15.03.2020. The interviews were planned to last within 60 minutes; however, the actual interview durations varied from 45 minutes to 90 minutes. All interviews were conducted via Skype and audio recorded and were transcribed within a week after the interview completion. The interviewees were either from a client's in-house digital media team or from an agency's digital 
teams. Table 2 presents details of the interviews and interviewees. The data were anonymised, and pseudo names have been used to camouflage the true IDs of the respondents.

TABLE 2 Details of semi-structured interviews

\begin{tabular}{|c|c|c|c|c|c|}
\hline Respondent & Position & Organisation & Category & Date & Duration \\
\hline Sen & Digital specialist & Client & $\begin{array}{l}\text { Skincare and } \\
\text { toiletries }\end{array}$ & 29.02 & 1h 9 mins \\
\hline Nhị & $\begin{array}{l}\text { Digital group } \\
\text { head }\end{array}$ & Agency & $\begin{array}{l}\text { Oral and } \\
\text { dental care }\end{array}$ & 01.03 & 55mins \\
\hline Vàng & $\begin{array}{l}\text { Senior digital } \\
\text { specialist }\end{array}$ & Client & Smartphone & 01.03 & 59 mins \\
\hline Bông & $\begin{array}{l}\text { Associate } \\
\text { director (Digital) }\end{array}$ & Agency & $\begin{array}{c}\text { Dairy, } \\
\text { Confectionery }\end{array}$ & 07.03 & 1h 36mins \\
\hline Trắng & Digital specialist & Agency & Smartphone & 13.03 & $45 \mathrm{mins}$ \\
\hline Lá & Digital manager & Agency & $\begin{array}{l}\text { Banking, F\&B, } \\
\text { Transport \& } \\
\text { Food delivery, } \\
\text { Travelling }\end{array}$ & 14.03 & $58 \mathrm{mins}$ \\
\hline Xanh & $\begin{array}{l}\text { Senior digital } \\
\text { specialist }\end{array}$ & Client & Dairy & 15.03 & 1h $12 \mathrm{mins}$ \\
\hline
\end{tabular}

The interviews went well, and according to the interview guide. The respondents answered and discussed the questions willingly and openly. The questions in the interview guide were formulated based on the framework by Bryman and Bell $(2011,477)$. First, six predefined categories were formed based on the theoretical understanding as presented in the literature review. Then, initial interview questions were developed in a way that they could help answer the research questions. Next, one pilot interview was carried out to identify potential issues related to the questions. After that, the interview questions were reviewed and finalised accordingly. Please see appendix 2 for the interview guide.

In brief, all interviews started with a brief explanation about the study background and purpose to lay the foundation for the interviews. Then, the respondents were asked to share their background (e.g. years of experience in digital advertising and programmatic ads, job position, product category). Next, the respondents were asked warm-up questions such as explaining their understanding of programmatic advertising. Since the programmatic ad is the key concept of the study, it was important that the interviewer and interviewees' have the same understanding of programmatic advertising before delving further. After that, the interview continued with main questions grouped under six predefined categories which were (1) Campaign objective and effectiveness metrics, (2) Campaign insight discovery, (3) Customer segmentation and targeting, (4) Campaign planning, (5) Campaign implementation, (6) Campaign evaluation.

Lastly, as the interviews were conducted in Vietnamese, the original interview guide was in Vietnamese, and then translated to English for reference purpose. Back translation method was used to ensure the accuracy of the interview 
guide's translation. According to Craig and Douglas (2005, 256-257), backtranslation is a three-step procedure in which the questionnaire was first translated from the source language "by a bilingual translator who is a native speaker of the target language into which the translation is being done". Then, the translated version will be translated back into the source language by another bilingual person who is also a native speaker of the source language. Finally, two versions of the source language are compared to access to the quality of the translation. Accordingly, this study followed this three-step back-translation procedure. The source language and the translated language were Vietnamese and English, respectively.

\subsection{Data analysis}

The study used thematic analysis because the method has the advantage of flexibility compared to other methods as well as aligns with the abductive reasoning approach of the study. Thematic analysis is defined as a method "for identifying, analysing, and reporting patterns (themes) within data. It minimally organises and describes your data set in (rich) detail. However, it also (...) interprets various aspects of the research topic." (Boyatzis 1998, as cited in Braun \& Clarke 2006, 6). According to Braun and Clarke (2006), thematic analysis is one of the qualitative analytic methods, including grounded theory, discourse analysis, narrative analysis. All of which seeks to identify and describe patterns across qualitative data. Yet, while other methods require data to be analysed within a theoretical framework, thematic analysis allows a researcher to analyse the data more openly. Thus, thematic analysis is suitable for a studies that do not emphasise generating a full grounded-theory analysis. (Braun \& Clarke 2006.)

Braun and Clarke (2006) explain that thematic analysis includes six phases which are (1) familiarising with data, (2) generating initial codes, (3) searching for themes, (4) reviewing themes to ensure the themes are meaningful, significant, and not overlapped with each other, (5) defining and naming themes, and (6) producing the report. The data analysis process of this study followed all six phases of thematic analysis. First, the researcher listened to the recordings from one to two times before transcribing them. Then, initial codes were generated. Some of the codes were identified during the transcription process, while the others were generated after all transcriptions were done. The coding process also involves the data reduction step in which the researcher only kept relevant data and made them more comprehensive and easier to analyse (Hair et al.. 2016,303). After that, based on the codes, the main themes were identified, reviewed, and defined. The interview transcriptions were coded based on the researcher's theoretical understanding of the topic. Then the codes were mapped and grouped into different themes in a way that these themes could help to answer the research questions. Finally, each theme was identified and determined if there were adequate supporting empirical data, and the theme presented critical point about 
the research questions. Finally, the study results and implications were presented in chapters 4 and 5, respectively.

\subsection{Chapter summary}

Figure 9 outlines the methodological decisions of this study. In brief, the study employed a one-case study research design with abductive reasoning approach, which helps achieve the research objectives as well as answer the research questions. The study collected empirical data through seven semi-structured interviews, and the participants were recruited based on purposive sampling. Then, the data were analysed using thematic analysis.

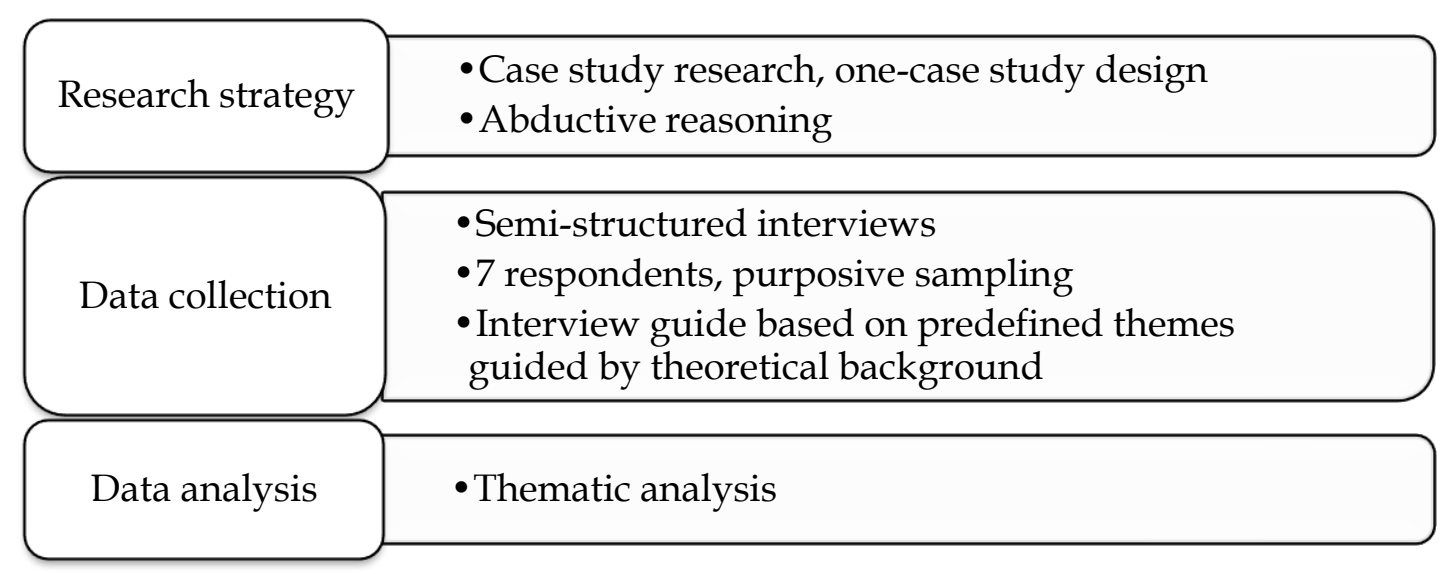

FIGURE 9 Research design of this study 


\section{STUDY RESULTS}

This chapter reports the findings of the empirical data collected from the seven semi-structured interviews. The findings are organised by the eight steps of advertising planning and implementation process. The purpose of this organisation is to help create the connection and consistency between the theoretical background and study results chapters. Thus, the findings will be grouped as follows:

Campaign objectives and effectiveness metrics

Campaign insight discovery

Strategic advertising planning

Creative strategy and ad creation

Media planning and media buying

Campaign optimisation and evaluation

Because the findings of two research questions are intertwined, it would be redundant to report the findings and supporting quotes of two research questions separately. Hence, the chapter is organised into two main parts. First, all the findings will be presented from section 4.1 to 4.6 . After that, section 4.7 will summarise and group the findings in a way that answer the research questions. The two research questions are as follows:

RQ1: How is programmatic advertising being used in online advertising campaigns in emerging markets?

RQ2: What is the planning and implementation process of programmatic advertising campaigns?

\subsection{Campaign objectives and effectiveness metrics}

\section{(1) Campaign objectives}

Generally, programmatic advertising is used for both long-term brand building campaigns and short-term direct response campaigns. While some advertisers were more experienced with programmatic advertising in terms of leveraging programmatic ads extensively and in a longer period, the others were new to the technology and still in the exploring phase. From the overall market perspective, programmatic advertising in Vietnam market seems to be in its developing stage.

Sen: "Our brand has used programmatic ads for both thematic and promotional campaigns. However, our team is still in the exploring phase of programmatic advertising, because at the moment, we only run programmatic ads via Facebook platforms. And since Facebook is a walled garden, a lot of promising benefits of programmatic ads are limited on the platform. We have plans for other DSPs like Google DV360. However, (...) alignments and process are needed to be established before we put full force in programmatic advertising." 
Nhị: "My client uses programmatic advertising for their thematic campaigns. The brand does not run any direct response campaigns in the local market (i.e. Vietnam market). We tested and allocated a proportion of budget to programmatic ad one and a half year ago. Then, this year 2020, we started to shift all digital advertising budget to programmatic ads."

Vàng: "Our brand used programmatic ads for one campaign around two years ago, but then stopped because it did not work. However, we gave it a try again early this year because the market seems to be more developed now. We also wanted to leverage the precision targeting advantage of a programmatic ad for our brand-building campaigns."

Bông: "Programmatic advertising was introduced in the Vietnam market around five years ago. However, only several top advertisers who are happened to be multi-international corporations seem to properly explore and exploit the technology, and they are ahead of the game. In contrast, the majority of advertisers seem just to start exploring and implementing the technology systematically from last year. Having that said, newcomers are catching up pretty fast. My accounts leverage programmatic ads for both thematic and promotional campaigns."

Trắng: "Programmatic ads have been used in all campaign objectives of brand A. However, it is worth highlighting that there are different ad platforms offering programmatic display ad solutions, and each platform has its pros and cons depending on the campaign objective. It also means that we employed different ad platforms for different campaign objectives."

Lá: "I manage different accounts, and different accounts leveraged programmatic ads in vastly different ways depending on their overall communication strategy and objectives. For instance, I have one banking client using programmatic ads to generate leads (i.e. credit card registration forms) for their sales team. The same situation with the travel booking service brand. This brand has used programmatic ads to generate conversions."

Xanh: "Our team mostly ran programmatic ads for promotional campaigns because of its hyper-targeting benefit and high ROI (...) Programmatic ads seem to be not very effective for thematic or brand-building campaigns, in my experience, because it has several limitations that make it not suitable for thematic campaigns."

\section{(2) Effectiveness metrics}

Empirical data suggest a consistent pattern of defining effectiveness metrics for each campaign objective across respondents. All respondents had experience in running programmatic ads for long-term brand building campaigns, and they shared that programmatic ads helped brands better plan and measured total reach and frequency of the campaigns. In contrast, only half of the respondents had experience with using programmatic advertising in short-term direct response campaigns, and they shared that the effectiveness metrics of direct response campaigns would be conversions. However, the definition of conversion was varied depending on the product categories as well as how deep the advertisers could follow the consumer's in their purchase funnel. For instance, the FMCG product category was usually of lower price and lower product involvement, so conversion was equal to purchase. In contrast, smartphones were usually of much higher price and higher involvement, so conversion was defined as a website visit. 
Sen: "The success metrics for thematic campaigns are the campaign's reach and average frequency. The success metric for promotional campaigns is purchase because we usually run campaigns on eCommerce platforms like Lazada and Shopee, allowing us to optimise sales."

Nhị: "Reach and frequency are the ultimate measurements of online display and video campaigns."

Vàng: "In addition to the campaign's reach and frequency performance, our team also track the ads' CTR. That is, how effectively the ads resulted in a click to the retailer websites. However, CTR is only secondary since our company distributes and sells products via retailers; our marketing communication effort focuses on brand building."

Trắng: "It goes without saying that thematic campaigns focus on generating brand awareness, translating into media metrics of reach and frequency. In contrast, direct response campaigns focus on generating visits to the brand's website so that the potential buyer can find out more information about the product."

Lá: "I have one banking client using programmatic ads to generate leads (i.e. credit card registration forms) for their sales team. The same situation with the travel booking service brand, this brand has used programmatic ads to generate conversions (i.e. successful bookings). Another client of mine, a food and beverage ( $F \mathcal{E} B$ ) company, has run several awareness campaigns via programmatic platforms (...), focusing on maximising reach and optimal frequency of the campaign."

\subsection{Campaign insights discovery}

The respondents stated that more powerful and sophisticated consumer insights were available due to more in-depth data collected through programmatic technologies. The programmatic technologies (e.g. DMP) enabled audience data to be collected and processed automatically and in real-time. Audience data were no longer limited to demographic traits, but also include the audience's interests, purchase intent (e.g. add-to-cart item data, in-market audiences), as well as the size of these audience groups. The data were useful for both formulating communication strategies and implementing online advertising campaigns.

Nhị: "Our agency network has our own DMP. This DMP can be plugged into DSPs such as Google DV360. It is not only used to collect the audience data for campaign optimisation, but it is also a powerful tool providing insights into the audiences in terms of their demographic information, interests, intention. The data also provide an estimate audience size. Let's say brand A wants to target audience with particular demographic traits and interests; our agency can use the tool to estimate the size of that audience group. This is to see whether the audience pool is large enough so that the campaign can be scaled and reach a meaningful number of people (...) Another advantage of DMP is the huge number of data points; millions of cookies are being collected, processed in real-time."

Bông: "We can layer and integrate different data sources into the DMP to build a more comprehensive audience profile. I know some companies like LightSpeed Data Solutions, or Eyeota 
offering sophisticated audience data such as spending patterns, in-market audiences for a specific product category. These data platforms and solutions add depth and layers to the audience profiles rather than pure demographic information like age or gender."

Even though the audience data could be collected and processed in real-time by the system, these data were not insights. It required the digital specialist who could interpret the data in the context of the client's brief to come up with meaningful and relevant insights for each campaign. Hence, it was undeniable that the programmatic technologies offered granular and sophisticated audience data, but these data needed to be analysed and put into context to become powerful insights. Otherwise, the potential of these audience data would be wasted.

Sen: "We use Facebook CPAS (i.e. collaborative performance advertising solution) for promotional campaigns, offering product bundles or discounts via eCommerce platforms such as Lazada and Shopee. Facebook CPAS connects the data of those e Commerce platforms with its data, resulting in a more holistic audience online profile. For instance, we can imply from the data which products were most interested in the consumers, how many users add the product to online carts but not yet purchase. This information is useful for the brand team and agency in optimising conversions."

Lá: "Programmatic advertising provides audience data after running a campaign, which does not only help the brand better understand their predefined target audience groups but also potentially helps brand identify or even change their target audience. I had such mind-blowing experience when worked with a pharmaceutical company (...) In one of their campaigns, we did not set up the targeting, but let the system optimise towards the metrics regardless of the target audience. There was the reason for that decision, but let's skip that part. Anyhow, at the end of the campaign, the data showed in addition to the predefined target audience, there was a significant percentage of another audience group also viewed and clicked the ads. The TVC view rate and CTR of this audience group were on par with the predefined one. This finding had a significant impact on the client's communication strategy formulation later on."

Additionally, the interview answers suggested that most respondents were not aware of the inaccuracy of DMP's audience data. This weakness was discussed in the literature, yet the industry seems to be negligible of the issue. Particularly, when being probed about the trustworthy and accuracy of the audience data provided by DMP, only one respondent was aware and concerned about the issue.

Sen: "My team and I have doubts about how DMPs and programmatic technologies in general, in terms of how they collect and process the data. We understand the general mechanism, but the actual process is somehow a black box in my opinion."

Xanh: "Surely the data from those platforms are trustworthy and more in-depth than advertiser's first-party data because those platforms integrate data from various sources and there are advanced technologies fuelling the process (...) I'm not saying that first-party data is not reliable. It is just not as reliable as the audience data provided by those platforms. Furthermore, the first-party data are limited and not especially useful for gaining audience insights."

Trắng: "We have never inquired or challenged about how those vendors and platforms collect and manage audience data. We just leverage the available data." 


\subsection{Strategic advertising planning}

According to the theoretical background, this step involves strategic planning for the whole online campaign, which may include different advertising forms such as search, display, email marketing and so on. However, because this study focuses on display advertising, this section only includes findings related to strategic planning related to display advertising form. Accordingly, the empirical data suggests two decisions at this stage which are (1) whether to include programmatic ads in the campaign and (2) segmenting target audience groups. The first decision is considered to be strategic because it affects all decisions coming after.

\section{(1) Whether to include programmatic ads in an online campaign}

The strategic decision of whether to use programmatic ads in a campaign is driven by the advertisers weighing the cost and benefit of programmatic ads. The findings identify several advantages and disadvantages of programmatic ads.

\section{Advantages}

Programmatic advertising lets advertisers plan and measures the reach and frequency at the campaign level. And this is the exclusive benefit that only programmatic ad can offer. Previously, advertisers could not track and measure the reach performance of the whole campaign via the direct buy (e.g. display ads via ad network inventories). That is, if a display campaign involves running different ad formats (i.e. videos, banners) on different device types (i.e. personal computers, mobile, tablets) through an ad network, it is impossible to measure the reach performance post-campaign. However, the programmatic platforms overcome this limitation, allowing brands to track and measure their campaign performance across ad formats, channels, and devices. As a result, programmatic ads improve the campaigns' efficiency as advertisers have better control over ad impressions' distribution.

Nhị: "The most significant benefit of programmatic advertising, especially for brand building and awareness campaigns, is that we can combine the reach and cap frequency at the campaign level. We can cap ad frequency across formats, channels, and devices. Hence, impressions of waste is eliminated. This was not possible in the past when running ads via ad networks. Ad networks are only capable of frequency capping for the same ad formats, the same devices, and the websites within that ad network."

Bông: "The most common reason for brands to shift from ad networks to programmatic advertising is that programmatic DSPs let brands implement campaigns across platforms and devices, regardless it is a website or a mobile application, and they can consolidate the reach performance across platforms and devices to give a final reach figure for the whole campaign. This is the most important advantage of programmatic, in my opinion, especially in terms of campaign efficiency."

Lá: "Running campaigns via DSP allows de-duplicating reach and capping frequency for the whole campaign, rather than individual ad network or device." 
Xanh: "Programmatic advertising is more advanced than the ad network because it allows our team to control the campaign reach and frequency. We know the actual reach postcampaign, and we can cap frequency per user regardless of the device they use or the websites they visit. This makes advertising campaigns much more efficient now than in the past."

Another perceived advantage of programmatic advertising is its precision targeting. This advantage is significantly valuable in the high-involvement product categories such as luxury products, cars, insurances and so on. It was difficult and inefficient to find and reach the target audience in these categories previously by the contextual targeting approach in which the advertisers placed their ads in several limited websites having relevant content with the product. However, the contextual targeting strategy could be inefficient and ineffective because not all potential would browse those websites and be exposed to the ads. In contrast, programmatic advertising is fuelled with audience data. It follows audience buying approach, so the ads will be shown to the right target audience regardless of the placements, which increase the potential reach of the campaign.

Vàng: "We want to leverage the precision targeting advantage of a programmatic ad for our brand-building (i.e. a smartphone brand) campaigns."

Lá: "The top-of-mind keyword when mentioning programmatic advertising is audience buying. Audience buying means the systems will automatically optimise to ensure that the brand's message can reach the right audience, and the message is also relevant to their intention. Programmatic advertising differs from direct buy advertising in terms of direct buy advertising with contextual targeting would buy ad impressions on websites assuming that the website content would be read by the audience and the brand's message on that website would reach the audience as a result. That assumption may be true or maybe not. To illustrate, a travelling company would choose to display ads on travel websites. Yes, there is a high chance that all people browsing the websites were interested in travelling, but what about those were also interested in travelling but were not on the website? Wouldn't the brand miss those people? Then, programmatic ads came as a solution helping brands reach the right people (...), and whatever websites a user was on, as long as that user was in the target group, the brand's ad would be displayed to the person. Programmatic ads help to extend the campaign's reach, especially for those luxury products which have only a few dedicated websites offering relevant content for contextual targeting advertising."

The programmatic technologies not only targeted the right target audience thanks to the utilisation of real-time audience data but could also personalised so that the ad content was relevant to the audience. Finally, the system could also adapt the ads to different sizes based on the initial creative template input. This did not only help to save repetitive creative resizing effort but also helped to extend the campaign reach because there were more ad inventories with various ad sizes available.

Sen: "The dynamic creative customises the banners depending on the products that the users previously (...) Furthermore, we could access the audience data and segment three groups: bought (1), add-to-cart not yet bought (2), just viewed the products (3). The system is capable 
of showing the customised banner to each group. For instance, showing the banners with discount codes to nudge the second group to buy."

Trắng: "For instance, when we input the creative into DV360 and let the system optimise the creative, the system can automatically adjust the size to fit with different ad placement. We no longer need to manually resize the banners. Also, the campaign's reach can be potentially extended because flexible ad sizes mean the brand's ads can be shown on more ad placement (...) For other cases, the systems can play and plug different locations in the ad copy to make the ad relevant to the audience at that location."

The final advantage, also mentioned by most respondents, is the granular and sophisticated targeting offered by programmatic advertising. Since this advantage is closely related to the audience segmentation, the findings will be reported in the next section (2) Segmenting target audience and targeting strategy.

\section{Disadvantages}

Despite the mentioned advantages, the inventory limitations have hindered the extensive use of programmatic advertising, especially for the long-term brandbuilding campaigns. The data suggest two major ad inventories limitations which were limited premium inventories on local websites (i.e. ad inventories on top local news websites) and limited advertising formats (i.e. eye-catching and large size banners such as expandable banners, mastheads). The first limitation was caused by local publishers preferring to sell their high-quality inventories (e.g. ad slots on the homepage) via traditional guaranteed contracts to via programmatic channels.

Vàng: "The programmatic ad inventory is limited. Major publishers like Admirco, Adtima prefers to sell their high-quality inventory such as placements of top websites like kenh14.vn, vnexpress.vn or zing.vn through direct contracts to through SSP and ad exchange. Therefore, it is difficult or even impossible to book these ad slots via programmatic buying. So, we still need to split the budget between programmatic and ad network even though that reduces the efficiency of the campaign."

Bông: "The Vietnamese publishers still prefer selling inventories through direct contracts, so the inventories left for programmatic is quite limited, and the quality of these inventories are not as good as those sold via direct contracts. In extreme cases, the publishers will only list the remnant inventories on SSPs. So, if brands are serious enough about their communication campaigns and insist on implementing the campaigns via programmatic, they have no choice but to negotiate exclusive deals. For example, programmatic guaranteed (PG) deals or preferred deals if brands want guaranteed inventories, or private marketplace (PMP) deals if brands favour bidding. The names also suggest the prices of these deals; guaranteed inventories are more expensive than bidding inventories. Note that these deals are tailormade based on brand's brief."

The second limitation was caused by the technological limitation as programmatic ads can only accommodate standard IAB banners. These two limitations discouraged advertisers from running programmatic ads, especially for brand's awareness campaigns. These campaigns aimed at maximising brands awareness, 
which meant that the ads must be displayed at mass websites with high reach, and with eye-catching ad formats to attract the target audience's attention. While the former limitation could be partly solved thanks to various programmatic advertising deals (e.g. programmatic guaranteed deals, preferred deals) in which advertisers/ agencies and the publishers negotiated an exclusive inventory package including high-quality ad placement, the latter one remained unsolved in short-term. Therefore, brands had to allocate a proportion of the budget for direct buy advertising campaigns if they wanted to include impactful ad formats in the campaigns. This could result in campaign inefficiency because there are potent reach and frequency duplication between programmatic ads and direct buy ads.

Nhị: "(...) limited ad formats is a critical issue of programmatic ads because we usually want to book eye-catching and large size banners for the (launching) campaigns. And you can say that standard banners are not as effective at attracting the target audience's eyeballs as other rich format banners. Furthermore, the ad inventory for videos is pretty limited. For example, if you want to air TVC on Google DV360 DSP, you have no choice but to negotiate specific deals with publishers to able to access to their video inventory via programmatic. And such deals often cost more than usual."

Trắng: "Previously I had to mix programmatic ads with direct buy ads in the campaigns because programmatic ad formats were limited to standard IAB formats only. That was annoying because such combination sacrificed the benefit of programmatic advertising. From the next campaigns, the client and our agency want to exploit programmatic ads more rigorously, so we will need to negotiate and work even more closely with the publishers and demand them to sync both premium inventory and impactful ad formats in the deals. I anticipate that there will be technological challenges because of format incompatibility. Regardless of the steep learning curve, we have no choice."

Lá: "Standard banners are the most popular inventory type of programmatic ads. Inventory for video is not as abundant as standard banners. Firstly, video inventories are already fewer than banner inventories, which means that video inventories are of high demand. Then, the publishers have no incentives to list their video inventories on SSP by default. They'd rather package them in exclusive and premium deals to maximise revenue (...) Because of such downside, I'd say the current programmatic ad inventory dos not match with the technologies and seems to hamper the potential of programmatic."

Xanh: "Programmatic inventories lack rich formats like page-takeover, and the placements are not usually at eye-catching positions on the websites. For example, if I wanted to buy a masthead on kenh14.on (i.e. a top popular news and lifestyle site), I had no choice but to book directly from them. So, there was always a combination of both programmatic and direct buy ads in the brand awareness campaigns, especially for the launching campaigns."

Another perceived disadvantage of programmatic ads is the additional fees like platform fees and data fees. The respondents said that data fees kept added up as the advertisers increase the targeting layers. In other words, the more granular and sophisticated targeting, the higher data fees were charged to the advertisers. Generally, the combination of platform fees and data fees would account for $10 \%$ to $15 \%$ of a display campaign's budget. On the the one hand, several respondents thought these additional fees were reasonable because the leveraging data helped 
to ensure the impressions were serve to the right target audience, reduced waste, and increase cost-efficiency. Hence, a $10 \%$ to $15 \%$ increase in cost is worthy.

Bông: "Yes, it is reasonable to pay those fees. You need to pay platform fees to use the DSP platform and its technologies, and data fees to leverage the data for targeting. I see no problem with that! Especially with the data fee, it's worth it. Let's say you go shopping for a particular brand at a store, wouldn't you feel more assured when knowing that all products in that store are verified, and there is no fake stuff in the store? Then, wouldn't it be fair to pay a relatively small fee compared to the product price for that verification? In the past, we also had third party audience tracking such as ComScore or Miaozhen The Bridge to measure how many intarget audiences was reached by the campaign. However, the tool was of "reporting" nature because by the time we had the information, the impressions were delivered, wastes occurred. In contrast, the data verification in programmatic happens before an impression being delivered, so potential waste is minimised."

Trắng: "Regarding the platform fee, I think it is justifiable because the platform provides the reach de-duplication and frequency capping which are two most important metrics for thematic campaigns. The solution is phenomenal because the industry longed for a combined reach and average frequency estimation for the whole campaign in such a long time. We tried different methods and approaches to address the concern but failed. Imagine how much more it would cost because of buying duplicated inventories. Thus, it's reasonable to pay for DSP."

Xanh: "Data fees are reasonable. Previously we relied on the audience of ad network which has been proven to be both limited and flawed. Limited in terms of ad networking, could only target age and gender. Flawed in terms of the information of ages and genders were mostly inferred based on the content they consumed. There were many times we wanted to target male consumers, yet the ads were exposed to female consumers."

On the other hand, other respondents shared that it was challenging to justify these additional fees as the incurred costs were high, yet the benefits of data fees were neither immediate visible nor directly proportionate with the costs. Especially in those companies that the marketing department needed to justify marketing spend with accounting department and procurement department, this disadvantage was even more pronounced, because it took time to explain the nuances of programmatic advertising to these departments as well as to prove the worth of those additional fees.

Vàng: "The data fees keep increasing as we add more targeting layers, for example, demographic layer, location layer, interest layer, and so on. Granular targeting sounds fancy, doesn't it, but it's ridiculously expensive, so we need to have a good plan and rationale for such granular targeting. Especially, our department has to explain and justify every marketing spend with both accounting and procurement team before having the plan approved, because our company is super cost-driven (...) You know, there were campaigns that we had to get them on-air as soon as possible, there was no time luxury to explain or discuss back and forth with those departments. All in all, there was little incentive to run programmatic campaigns in such an environment because we had to spend an enormous amount of time and effort to explain things to different parties both before and after the campaigns. The burden of accountability was huge, yet the outcome was uncertain." 
Furthermore, sometimes the fees were merged with the ad impression costs, and the advertisers were only informed a combined CPM. This scenario usually happens when the programmatic plans are executed through an agency trading desk. "An Agency Trading Desk is a team within an ad agency that executes online media buying as a managed service" (Tubemogul 2020). Such practice gave the impression of non-transparency to the advertisers.

Sen: "It usually cost more when we bought ad inventory through programmatic than traditional direct buy. Let's say if I bought video ad inventory directly from YouTube, it would cost 150 d compared to 200d if I bought the very same inventory from the agency trading desk A. It was unclear to me why there was such increment in cost, so I preferred direct buy from YouTube because that agency trading desk also bought inventory from YouTube at the end of the day. Then, it doesn't make sense to include that intermediary in the process and incur an extra cost. Another reason which I think more important is the benefit of the higher cost is vague, so hard to justify."

Nhi: "The fees like platform fees and data fees are headaches. Sometimes there will be another fee such as tech types as well, but it is case by case. The issue with these fees is that we were not aware of these fees previously (...) 10\% to 15\% budget must be allocated to cover these fees, meaning the committed KPIs will be decreased because the budget remains unchanged. Furthermore, the benefits of paying these fees are vague. I mean we can only evaluate the cost versus benefit after implementing (...) In terms of fees transparency, the fee structure was clear in the case of DV360, but it was vague in the case of the agency trading desk A. I didn't know how they came up with the cost, everything was added up together in the cost."

The final drawback of programmatic advertising is the advertisers' mindset that they must be able to see and exposed to whenever they wanted to check the ads. Otherwise, they would be likely to conclude programmatic advertising to be ineffective or prone to fraudulent. Such a mindset stemmed from the habit of seeing ads when they bought ads via fixed duration booking and ad network, which were channel buying. However, programmatic advertising is not channel buying; rather, it is audience buying. Hence, only the right target audience would be exposed to the ads. Furthermore, the data suggest that there could be various factors affecting whether an ad is displayed, for example, the bid price. It could be inferred from the interview answers that this mindset was partly stemmed from the lack of a thorough understanding of programmatic advertising.

Nhị: "The most common complaint when running programmatic ads was that the client did not see their ads during the campaign period. While this is understandable from our perspective because programmatic is audience buying and not channel buying, so only the right audience can see the ads. And a lot of time, the client personnel was not in the target group. Or even when the client personnel are in the target group, it is unlikely for them to see the ads because there are thousands of ad placements that the ads could be potentially shown. There are also other influencing factors such as campaign budget, campaign pacing, bid price and so on (...) While these notes were communicated clearly and repetitively to clients, not all clients accept this fact and insist on seeing their ads to feel assured."

Vàng: "My big boss and the sales team would inquire us if they didn't see the brand's advertising during the campaign. They just could not comprehend the idea that the company spent 
money on an advertising campaign, but they could not see the ads. As a result, they tend to conclude that programmatic ads are not effective, and it is wasteful to run programmatic campaigns. This explains why we also need to spend a little budget on CPD (i.e. fixed period booking for banners) just to reassure the sales team."

Lá: "One of the reasons hindering the development of programmatic ads in Vietnam is the mindset that one must see the ads after one paying for it like in the case of fixed duration ads or ad network. That mindset is inappropriate in the context of programmatic buying because programmatic buying means audience buying. So, it is normal that someone out of the target group was not exposed to the ads. Or even one is in the target group and wandering around the websites to check the ads, the chance of seeing those ads is slim. Because usually they'd go to top websites and sections, and as I explained previously, high chance that the ad placements are not sold via programmatic environment. Thus, the client just did not see their ads."

Because of these limitations, most respondents shared that many online display campaigns included both programmatic and direct buy ads to balance out the costs and benefits of programmatic advertising. Then, it comes to the decision on the budget split between programmatic and direct buy ads, which will be reported under the section 4.5 Media planning and buying.

\section{(2) Segmenting target audience groups and targeting strategy}

First, regarding audience segmentation, the majority of respondents shared that programmatic advertising allowed advertisers to segment target audience more granularly and more sophisticatedly. The audience groups no longer are segmented based on their demographic characteristics only, instead, advertisers could target audiences based on their interests or behaviours, or further, divide the desired audience group into subgroups for ad personalisation purpose.

Sen: "For the previous Facebook CPAS campaign, a promotional campaign on eCommerce platforms like Lazada and Shopee (...). First, we let the ad be exposed to the predefined target audience, let's say female from 18 to 25 years old. After 2-3 days after the campaign started, we could access the audience data (e.g. which products have they viewed, which products did they put into the cart but did not pay) on these platforms. Then, we divided the initial target audience group into two sub-groups, group one included those viewed the products but did not add any product to cart, group two included those added products to cart but did not buy."

Vàng: "The next reason for choosing programmatic advertising was because it allowed us to target deeper and with more layers than traditional direct buy. Like in the past, when we bought media space via an ad network, the targeting was very general like placements in lifestyle or entertainment sections of a website. But programmatic advertising has changed the game. For example, in one of the previous campaigns, we were able to segment and target those people owning a smartphone device for more than two years (...)".

Trắng: “(...) segmenting and targeting the consumers based on their household income range. Because the company has three product ranges high-end, mid-end and low-end, the client wanted to precisely advertise the affordable product to the right person. The audience, accordingly, was segmented into different household economic class, and different segments were served the relevant product models (...) The campaign was executed via Google DV360." 
However, one respondent argued that while it was possible for more sophisticated customer segmentation and targeting, the level of sophistication depends on how well the digital specialists' skilfulness at leveraging the audience data.

Bông: "Yes, the customer segmentation can be more granular and sophisticated, yet it is not always as straightforward as it seems. For example, if a brand wants to target people with economic class $A B$, the data of economic class may not be readily available, so we need to infer this information from different data points such as the value of their current loans or the value of the banking transactions, etc. In brief, we still start with demographic data and then layer other audience data on top to narrow down the audience base and achieve as much precision as possible (...) The campaign was executed via an agency trading desk."

Next, regarding targeting strategy, the respondents said that programmatic advertising also came with a new targeting strategy which is lookalike audience targeting. According to the respondents, lookalike targeting was effective in expanding the campaign's reach with minimal effort. As long as there were "seed" audience profiles, the system could grow the initial audience pool at a fast pace.

Lá: "Lookalike targeting is a powerful targeting strategy, especially when the online audience portrait of the brand's desired customers is uncertain. One typical example of this is the driver recruitment campaign for a Transport and food delivery company. While the client briefed the target audience, let's say male from 18-25 years old with low income, this target audience was just too broad (...) Lookalike targeting helped us successfully recruit the drivers in leaps and bounds. The system was able to look for online users sharing similar characteristics online behaviours with those successful signups."

Xanh: "Lookalike targeting is both popular and effective nowadays. We can implement lookalike targeting for our campaigns via Facebook Lookalike Audiences or DV360's Similar Audiences. It helps expand the initial audience pool of the brand."

Vàng: "The application of lookalike targeting is extensive. For instance, we can upload the list of website visitors to the Facebook system and ask it to serve ads to new audience sharing similar traits with those visitors. Lookalike targeting also works with CRM data (e.g. customers' email address or phone numbers) and so on."

\subsection{Message strategy and ad creation}

The findings under this section mainly involve with (1) dynamic creative, and (2) planning and optimising dynamic creative in different campaign types.

\section{(1) Dynamic creative}

Based on the interview answers, dynamic creative is another name of programmatic creative. Dynamic ads are ads shown to a particular audience depending on their inferred interests or online behaviours. Dynamic ads can be either system-generated ads based on creative templates or systems resizing the ads to fit 
with different ad placements. The respondents stated that those system-generated either fully or partly were saving a significant of effort on the repetitive work such as resizing hundreds of banners, creating hundreds of ads by combining different creative elements to feed into the system for optimisation. In addition to saving time and effort, the second most mentioned benefit was that dynamic creative helped extended the campaign reach because the banners could fit onto various ad placements. The final advantage mentioned briefly by one respondent was the system could learn and improve based on the audience's behaviour towards the ads (e.g. clicks, video views, and so on), since the learning loop happened in real-time, this the creative optimisation was more efficient and effective. Despite the huge potential and advantages of dynamic creative, only four out of seven respondents had experience with dynamic creative. At the same time, the rest said that they were planning to experiment this feature soon.

Sen: "Facebook CPAS would automatically display or show the creative assets based on the tendency of the consumers. I just needed to input one banner template into the Facebook system; the system would generate different ad formats (e.g. Facebook carousel ad, slideshow ad, etc.) as long as the ads could reach the audience (...) Because Facebook CPAS connects with the product listing (i.e. catalogue) and audience data of eCommerce platform, the system can personalise the ads for each audience. For example, the ads would show a collection of previously viewed products by the audience to him/her or display the most frequently viewed product by that audience in the first position."

Bông: "The dynamic creative of Google DV360 can change the element of ads to make it relevant to the audience. For instance, we uploaded different creative elements to the system; then the system automatically generated the ads with a different combination of elements and at different sizes. The goal was to spread out the banners on as many placements as possible. Dynamic creative helped the brand gain significant exposure at an efficient cost. The system also learnt the performance of each banner variation so that the next generated banners be better."

Trắng: "For instance, when we input the creative into DV360 and let the system optimise the creative, the system can automatically adjust the size to fit with different ad placement. We no longer need to manually resize the banners. Also, the campaign's reach can be potentially extended because flexible ad sizes mean the brand's ads can be shown on more ad placement (...) For other cases, the systems can play and plug different locations in the ad copy to make the ad relevant to the audience at that location."

Nevertheless, the respondents recommended that brands should provide systems with abundant creative inputs to successfully leverage the strengths of dynamic creative. Too few creative inputs made it ineffective for the system to optimise because there would be limited materials for ad combinations.

Vàng: "We tried Facebook CPAS previously, but it didn't work. The key takeout from that campaign was that the catalogue was too limited, less than five items were listed for sales on the eCommerce platform because of several reasons. The system had no room for optimisation because there were too few items to show on the ads. Thus, we could not leverage the potential of system-generated ads." 
Bông: "If we were to leverage dynamic creative, that is, letting the system to automatically optimise the creative with various versions of system-generated ads; it'd help extend the testing of the campaign. A campaign's effectiveness could be increased, especially when there were multiple versions of ads copy and design being tested."

\section{(2) Planning and optimising dynamic creative in different campaign types}

The findings in this section were discussed in-depth by the only respondent, Sen, who had extensive experience with planning and implementing dynamic creative in both brand building and direct-response campaigns. On the other hand, the other respondents either not directly involved in the planning process or only had experience with the dynamic creative in direct-response campaigns. Hence, their answers were not as thorough and specific as Sen's. As a result, most of the direct quotes belong to Sen's because of their richness.

The planning and optimisation approaches for brand building campaigns versus direct response campaign show numerous differences. First, regarding the planning and production phase, brand-building campaigns required more rigid creative planning process than a promotional campaign, because the brand wanted to ensure all the branded creative assets deliver a meaningful and trustworthy brand message and brand image. Brand building campaigns also leveraged more types of creative assets (e.g. videos with different versions and length, a different set of banners with different messages and formats), so it took longer time to plan and produce these assets. Thus, most of the planning and production work would be directed to pre-campaign. On the other hand, direct-response campaigns may have their creatives to be adjusted depending on the campaign performance, so the planning and production work happened both before and during a campaign.

Sen: "The creative planning process of dynamic ads in promotional campaigns was more flexible because we want to leave room for later adjustment during the campaign. For promotional campaigns, we prepared 2-3 different templates, but only used one template first. Then depending on how the campaign rolled out, we would tweak the message on the second and third templates accordingly. In brief, we finalised the creative assets on the go."

Sen: "It would be different for thematic campaigns. Thematic campaigns usually aimed at building or maintaining brand awareness, we took a super careful and cautious approach when it came to thematic or brand-building campaigns (...) to ensure the compliance of brand guideline and so on (...). Also, thematic campaigns usually had more creative assets than promotional campaigns, long-form videos, short-form videos, banners with different formats."

Bông: "However, I observed that dynamic creative was mostly used in direct response campaigns (i.e. performance-based campaigns) rather than branding/thematic campaigns because the system would generate a vast amount of banners with various sizes which could potentially do harm to the brand image." 
Second, regarding the optimisation phase, the interview answers suggest that the creative optimisation process of brand building campaigns could be less intensive than direct response (i.e. performance-driven campaigns), because the most respondents said that they uploaded the creative assets to the systems once and let the systems do the optimisation. There were no new creative assets added during the campaigns. On the other hand, brands tended to refresh creatives (i.e. update creative assets) in performance-driven campaigns if the campaigns were not performing well. This explains why the planning and production phase of performance-driven campaigns were maintained throughout the campaigns.

Sen: "The creative optimisation process of the thematic campaign was not as real-time or
intensive as a promotional campaign. We did not introduce new assets at the mid of the cam-
paigns, rather we optimised the current assets, for example, by pausing the ineffective ones
after several days of observation. In contrast, the optimisation process of the promotional cam-
paign (especially those on eCommerce platforms) was intensive because the team only had a
limited of time to deliver the KPI, and we needed to monitor and take action fast (...)"

Nhị: "Thematic/branding campaign (...) all creative assets were uploaded to the systems once during the campaign set-up phase. No new assets were added during the campaign period. We did the optimisation based on whatever we had."

Trắng: "Another example was three creative sets (1), (2), (3) were uploaded to the system; then the system would test and show the most relevant sets to a different audience. The message of three sets was (1) high-resolution screen with long battery life, (2) camera for photos/selfies lover, (3) design of the phone (...). However, for those campaigns that banners' CTR was important, our team would monitor the CTR closely and refresh the creative assets (i.e. upload new creative sets) after ten days to avoid creative fatigue."

Finally, even though the creative optimisation process could be fully conducted by the systems, digital specialists' involvement could enhance this optimisation process. For example, Sen shared that the respondent's team planned and produced the creatives based on their understanding of the consumers' shopping habit on different eCommerce platforms, which resulted in better creative input for the systems. Or the digital specialist would play a supervisor role to ensure the dynamic ads functions properly.

Sen: "The creative planning process also considered the customer habits on different eCommerce platforms. For instance, the customer of Shopee eCommerce platform would normally buy the products right after putting them into the cart (...). So retargeting wasn't necessary. In contrast, customers of Lazada had the habit of adding products to cart. They would only complete the transactions on the promotion D-day when the discount codes were applied (...), so retargeting them with relevant messages (e.g. 'You added these products to cart, let's check out and reward yourself', discount codes, free shipping codes) was necessary."

Bông: "Our team would randomly check the placements where the ads were shown, and the ad sizes as well to ensure the placements were not next to sensitive or violent content as well as the ad sizes were not too tiny." 


\subsection{Media planning and media buying}

The findings under this section mainly involve with (1) budget split between programmatic versus direct buy ads, (2) programmatic inventory choices, (3) DSP choices, (4) campaign set up process.

\section{(1) Budget split between programmatic and direct buy buying ads}

Majority of respondents suggested that most of the campaigns still combine both programmatic buying and traditional direct buy because of various reasons reported in the previous findings. For example, they were booking ads with nonstandard IAB sizes or innovative formats through an ad network or direct buy since these inventories could not be bought via programmatic buying. Regarding the budget allocation between programmatic and direct buy, the respondents shared that there was no fixed budget split. However, it seems that in brand building campaigns, the common budget allocation would be around $60 \%$ to $70 \%$ of the budget for programmatic buying. In contrast, no fixed budget ratio was available in direct response campaigns.

Sen: "We still leverage advertising via ad network like Ambient ad network. The rough estimate budget split for ad network is around 20\% to $30 \%$, and the rest is for programmatic ads. There was some budget for an ad network, because, again, we want to diversify the ad formats and leverage the premium inventory which was not available through programmatic buying."

Bông: "The budget allocation for programmatic advertising, if it is included in an online campaign, would be significant, around $60 \%$ to $70 \%$. There are two common queries here. One, why not go all in $100 \%$ for programmatic advertising? Two, why not start with a $20 \%$ to $30 \%$ budget as a way to test the technology? For the first point, it is because the inventory of programmatic advertising is limited in terms of impactful banner formats, and so on (...) For the second point, as I mentioned previously, the strength of programmatic buying is consolidating the reach performance across platforms, devices, ad formats (i.e. banners and videos). In that sense, we'd want to buy as many media space through programmatic as possible to leverage this strength of the technology."

Trắng: "It depends on the campaign objectives and other factors, so we did not have a fixed percentage. For those thematic/branding campaigns, programmatic buying would account for more than $50 \%$ campaign's budget. Yet, we're aiming to consolidate everything via programmatic advertising in the next campaign to fully leverage the benefit of reach and frequency management across platforms. For direct response campaigns, again, no fixed percentage."

\section{(2) Programmatic inventory choices}

It seems that programmatic guaranteed inventories were the most preferred because these inventories have better quality than RTB inventories as most of the RTB inventories were remnant inventories that the publishers could not sell them via traditional direct buy. Furthermore, the respondents shared that they wanted to control the inventories input for brand safety and viewability purpose, which could only be achieved through programmatic guaranteed buying. Finally, programmatic guaranteed inventories ensured the delivery of booked impressions. 
Bông: "Publishers in Vietnam market prefers to sell their ad inventories through the traditional direct channel, and only leftover inventories are listed via programmatic RTB channel. Hence, if advertisers want to buy high-quality ad via programmatic, they have to negotiate specific deals with publishers. These deals are tailormade and exclusive for each advertiser."

Nhị: "DV360 offers several buying types such as IO buying, tag-guaranteed, preferred deals and so on. For those campaigns requiring ads to be displayed on top websites, premium inventory site list, programmatic guaranteed is the way to go."

Vàng: "We preferred programmatic guaranteed inventories over RTB because we often had trouble with the campaign's ad delivery when buying ad via RTB environment (...) Also, the RTB ads never appeared on top local news websites regardless of how high we bid."

However, programmatic guaranteed ads were more expensive than RTB, so the respondents shared that brands also combined programmatic guaranteed inventories with programmatic auction inventories. This reinforces the fact that programmatic guaranteed inventories were preferred when no budget constraint.

Nhị: "(...) However, in those campaigns that high-quality ad inventory was not strictly required, RTB buying is preferred because it was less costly and RTB inventories were more abundant than programmatic guaranteed."

Trắng: "sometimes we needed to mix programmatic guaranteed with PMP and RTB, to balance the cost of total campaigns, as programmatic guaranteed inventories were expensive. Yet, we set tight criteria for those RTB inventories to ensure brand safety."

\section{(3) DSP choices}

The data suggests that Google DV360 and Facebook ads manager were two popular and major DSPs in the Vietnam market. Both DV360 and Facebook ads manager had access to their exclusive ad inventories. For example, DV360 offered exclusive access to programmatic buying of YouTube inventory, while Facebook offered exclusive access to programmatic buying of Facebook and Instagram inventory. Hence, the majority of respondents shared that their companies or their clients used both DSPs to maximise the campaigns' exposure, except for one respondent whose company just leveraged programmatic advertising in the Facebook environment. Finally, except for the availability of inventories, there was no other reason for why and why not the respondents chose a DSP.

Sen: "Our team have just bought programmatic ads via Facebook so far. In that sense, Facebook ad manager is our DSP."

Bông: "Between DV360 and The Trade Desk, DV360 has been far more popular and in use than the other DSP because has Google brand name which is already very well-known with the market, so advertisers and brands are more open to onboarding DV360."

Trắng: "For brand-building campaign, we mostly use DV360, for performance or lead gen campaigns (i.e. direct response campaigns), we use prioritise Facebook dynamic ads and Google search especially Google dynamic search ads (...)" 
Lá: “(...) Facebook does not list its Facebook and Instagram ad inventories on other DSPs, therefore, the only way to access these inventories is to buy it via Facebook ads manager. Differ from Google DV360 selling inventories of both Google's platforms, including YouTube and other publishers, Facebook ads manager only sell ad inventories of Facebook and Instagram (...) Since YouTube and Facebook are within the top 5 websites in Vietnam, it is not unusual to operate on both DSPs in the campaign."

\section{(4) Programmatic campaign set up process}

The respondents shared several temporary concerned with programmatic buying campaigns. These concerns mainly stemmed from the fact that programmatic buying was in its developing phase in the market, so it took more time to set up the campaigns due to technical complexity as well as more time dedicated to the communications between the buy-side and sell-side. However, the respondents believed that these inefficiencies would disappear once the market got used to programmatic buying technology and process.

Nhị: "The communication process among the parties (i.e. client, agency, inventory seller, technical support of the DSPS). Each party hold a piece of information, so everything needs to be communicated in time and concisely so that everyone is on the same page. Also, programmatic advertising is complex and too different from the traditional buying for some clients and their boss, so we need to keep our communication as comprehensive and transparent as possible. In brief, more time and effort are dedicated to the communication process (...) I think that this situation will disappear as we advance in programmatic ads."

Bông: "Programmatic buying campaigns took 2-3 days more to set up the campaigns compared to the traditional direct buy. Mostly because we needed to deal with the inventory packages, check if the inventory successfully synced to the systems and so on. The setup process would be more complex if different inventory deals were included in the campaign. However, the process could be faster once it is well established and the team get used to it."

\subsection{Campaign optimisation and evaluation}

The findings under this section mainly involve with (1) Optimising programmatic ads and (2) Campaign evaluation.

\section{(1) Optimising programmatic ads}

Firstly, it appears that one common practice of optimising programmatic buying campaigns was to let the system freely and fully do the optimisation on its own for a short period at the beginning of the campaign. This period could be viewed as a learning period in which the system conducts various tests and learn about the audience feedback. This learning period could last from one day to one week, depending on the campaign length and different DSPs. For example, in the case of Sen, the respondent's team only allowed the learning period within one day. In contrast, other respondents allowed the system longer learning time. There were no conclusion on either the longer or shorter learning period, the better, or 
how many days would be enough. Regardless, the respondents generally agreed that leaving the campaign to the system for some time was critical.

Sen: "We let the system freely optimise for one day. Then we'd see which ads or ad groups were performing better (...) Based on our experience with Facebook and their statistics, one day is sufficient for the platform."

Nhị: "We let the system freely optimise for 3-4 days, even though we set certain rules like limiting the daily budget so that the system could not overspend."

Xanh: "This learning period is important because the system is in the exploration phase, trying out different options and learning from the audience feedback on the ads. Examples of the leanings are which placements are more effective, anything in common among the audiences clicked on this particular ad, etc. Hence, just leave some room for the system during the first 3-4 days or even a week, depending on the campaign length. Don't intervene too soon."

After the learning period, all respondents agreed with each other that they would intervene in the optimisation process because there could be technical problems causing the campaigns to be under-pacing. Thus, they were not confident that the system could effectively function without their supervision and guidance. For example, some critical metrics, especially campaign's reach, could not be optimised by all DSPs yet, so frequent monitor and adjustment were necessary (e.g. excluding certain placements to increase each or decrease the average frequency).

Sen: "Then, we'd intervene the optimisation of the systems like pause the lower-performing ads/ad groups or reallocate the budget among the ads/ad groups."

Nhị: "Our team still monitored campaign performance and took necessary action to ensure the KPI was achieved. We didn't let the system automatically optimised $100 \%$ (...) After 34 days, depending on the performance among ad sets or target audience groups would be reallocated depending on their performance. For example, if the campaign objective were website visit, we'd check which segment had a lower cost per section or which audience group could help scale up the campaign."

Bông: "Let's say optimisation for an awareness campaign where reach is the KPI. However, the system (i.e. DV360) cannot automatically optimise toward the reach metric yet, so human intervention is still required, for example, guiding/forcing the system to buy more or less inventory from this and that placement, increasing or decreasing the bid, and so on. We still leverage the technologies in terms of holistic and in-depth audience data to reach the right people, yet intervention is necessary."

Trắng: "We had this issue with PMP (i.e. private marketplace) deals when the system failed to bid and win any impressions due to technical problems (...) As a result, only a few impressions were delivered. We had to step in to solve the problem."

Lá: "Our intervention is still needed to monitor and react if unexpected things happen. We cannot leave 100\% optimisation to the systems; they are not at that level yet. And even if the systems are capable of doing everything on their own, digital specialists still need to aware of what is happening so that they can report everything transparently." 
Secondly, the data suggest that programmatic buying helped the optimisation process to be more efficient and effective. The respondents shared that DV360 could provide both predictive data (e.g. predicted ads viewability, brand safety) and a comprehensive Troubleshooter tool. On the the one hand, the predictive data helped digital specialists to set up the campaign faster and more thoroughly since they just needed to choose the desired options, and the system would optimise the campaign by the setup. On the other hand, the Troubleshooter tool seemed to help optimise campaign because it reported a thorough analysis of possible issues preventing the campaigns from performing.

Bông: "DV360 (...) Furthermore, the system has built-in predictive metrics (e.g. viewability of the ads, brand safety metrics) helping digital specialists to optimise the campaigns. In that sense, we can exclude those placements that have low viewability or exclude keywords to eliminate ads being shown on inappropriate or violate websites which pose a high risk of brand safety. The system can also report and screenshot those placements."

Trắng: "DV360 is useful for campaign monitoring and optimisation in terms of providing an analysis (i.e. the Troubleshooter of DV360) of the inventory deals so that we know possible reasons for why the campaign is underperforming. For example, why the inventory was underpaying, was it because of low bid, low frequency, etc. Then our team would have the basis to identify the root cause and come up with the solution."

\section{(2) Campaign evaluation}

Most respondents stated that there were two main differences in evaluating programmatic buying in brand building campaigns compared to the traditional direct buy. The most emphasised difference was DSPs helped consolidate the performance of different channels and platforms and report the KPIs at campaign level. Per reported in the prior findings, this benefit was exclusive to programmatic buying and the reason for brands to adopt programmatic buying for their campaigns in the first place. Another difference was the reported metrics (e.g. reach, frequency) are in-target by default. In other words, advertisers could know approximately how many target audiences were exposed to the campaign ads.

Xanh: "The evaluation would be at the campaign level for programmatic buying. This was not feasible if we bought media via traditional direct buy like an ad network, in which we could only evaluation the performance by placements, by devices or ad formats."

Lá: "We can measure the reach and frequency at the campaign level. And these reach and frequency are in-target reach and frequency by default. They are not some generic reach and frequency for a mass audience like traditional buying."

Vàng: "Yes, the reach is in-target reach and same for frequency. Programmatic buying helps bring online display advertising on par with TV advertising in the sense that now we can truly target and evaluate the campaign's in-target reach performance. To put it another way, we had no idea how many in-target audiences were exposed to the ads via direct buy."

Half of the respondents, however, argued that the benefit of full campaign's performance consolidation was still far from ideal because the ad inventories of 
YouTube and Facebook were traded exclusively on two different DSPs which were DV360 and Facebook Ads Manager, respectively. While some expressed the concern of significant duplication of ad impressions between YouTube and Facebook, the others did not find the issue as problematic.

Nhị: "Well, since we still need to buy ad impressions from YouTube and Facebook on different DSPs, the notion of consolidating reach and frequency across platforms, devices and ad formats are only half-way."

Sen: "To be honest, that's not exactly a problem for our team right now since Facebook and social ads are our focus at the moment. However, to my knowledge, the market research company, Decision Lab, have been developing a solution to address to the problem (...)"

Trắng: "I think it depends on the role of these two platforms in the online advertising campaigns. As I just mentioned, we leverage the two platforms for different objectives, DV360 for brand building campaigns, Facebook for performance campaigns. In that sense, there is no need to consolidate the reach between two platforms per se."

Lastly, access to audience data post-campaign and attributions were briefly discussed by two respondents. One respondent said that audience data postcampaign was valuable to evaluate whether the brand reached the right people as well as to enhance the brand's understanding of their audience's online portrait. Another respondent stated that the channels attributions were useful for evaluating the effectiveness of online channels in achieving the campaign's KPIs and for channel planning of future campaigns.

Lá: "When the campaign ended, we could analyse the audience data of different subgroups (i.e. by demographic traits, by interests, etc.) to see which one had better engagement with the ads (i.e. video view rates, banner clicks, etc.). Like I just shared by now about the case of a pharmaceutical company discovered interesting findings of the audience data post-campaign."

Xanh: "We can access to audience's overall media path post-campaign, for example, which were the top-visited websites, the contribution of these websites toward achieving campaign's objective, and so on. Brands can leverage this information in channel planning in future campaigns. These paths can shed light on the consumer's path to purchase of the category."

\subsection{Chapter summary}

\subsubsection{Study results for RQ1}

\section{How is programmatic advertising being used in online advertising campaigns in emerging markets?}

Overall, programmatic ads are used in both long-term brand building campaigns and short-term direct response campaigns, even though the data suggests that 
programmatic advertising is being used more in long-term brand building campaigns than short-term direct response campaigns. Different campaign objectives have distinctive effectiveness metrics. The effectiveness metrics of long-term brand building campaigns are reach and frequency, while those of short-term direct response campaigns are conversions. Different short-term direct response campaigns would define conversions differently, for example, website visits, form registrations, or purchases.

Programmatic advertising offers several exclusive advantages that foster its adoption in the market. The first advantage is the sophisticated and granular audience segmentation. This advantage is possible thanks to the underlying programmatic technologies together with holistic audience's online profile. Sophisticated audience segmentation implies that advertisers can segment the desired target audience into different subgroups and serve the relevant to each group. On the other hand, granular audience segmentation suggests that advertisers can layer various audience attributes to narrow the audience group and achieve precision targeting. Examples of audience attributes are demographic attributes, location attributes, interest attributes, online behaviour attributes and so on. The spectrum goes from broad demographic traits to specific online behaviours.

The second advantage is the lookalike audience targeting. When lookalike audience targeting option is employed in an online campaign, the DSP will automatically find a new audience who have similar online profiles with the brand's existing target audience. This targeting technique not only extends the campaign's reach but also increase the campaign's conversions in the case of shortterm direct response campaigns.

The final advantage is programmatic buying can consolidate the performance of different channels and devices and report the KPIs at the campaign level. This consolidation not only improves advertising efficiency (i.e. reduce the ad impression duplication across channels and devices), but also lets advertisers evaluate the campaign holistically (i.e. advertisers can evaluate advertising effectiveness at campaign level instead of channel level).

Despite the exclusive advantages, there are three issues with programmatic advertising. The first issue is the incurring of additional fees, such as platform fees and data fees. The advertisers will be charged platform fee when they implement programmatic ads via DSPs. Similarly, advertisers will be charged data fee when they leverage the audience data in targeting. The more data layers, the higher the data fees. There are controversial opinions among the respondents regarding whether the incurred fees are reasonable as these fees cost at least $10 \%$ to $15 \%$ of the media budget.

The next issue is many advertisers do not understand the audience buying the concept of programmatic advertising. Hence, they expect to see their ads during the campaign period; otherwise, they tend to conclude programmatic advertising to be ineffective.

The third issue of programmatic advertising is related to ad inventories. First, the banner ad inventories available for programmatic buying are subject to limited sizes and formats. That is, most of the programmatic banner ads are of 
IAB standard sizes, so if a brand wants to convey its message through a rich format banner (e.g. an expandable non-IAB standard), there is a high chance that the brand can only deliver that message via direct buy. The next obstacle is that many local publishers owning premium ad inventories (i.e. ad placements with high reach and high viewability) are reluctant to sell these ad impressions via programmatic channels. Instead, they prefer to sell these inventories through traditional direct contracts. If advertisers insist on buying these ad placements via programmatic buying, they can negotiate deals (e.g. programmatic guaranteed deals, preferred deals, or private market deals) which are more expensive and time-consuming to implement. Nevertheless, the respondents shared that these deals are limited, and many premium ad placements are still inaccessible through programmatic buying. Lastly, ad inventories on YouTube and Facebook, top two advertising platforms in Vietnam, are sold exclusively on two DSPs which are Google DV360 and Facebook ad manager, respectively. This fragmentation deters the benefit that programmatic advertising can consolidate ad performance across channels.

These limitations make it not feasible to plan and implement campaigns with $100 \%$ programmatic advertising. Thus, the respondents shared that all advertising campaigns combine both programmatic and direct buy ads to overcome the temporary limitations of programmatic advertising.

\subsubsection{Study results for $R Q 2$}

What is the planning and implementation process of programmatic advertising campaigns?

In general, the new planning and implementation process of programmatic advertising also includes eight steps as previously. The eight steps are (1) Setting campaign objectives and effectiveness metrics, (2) Campaign insights discovery, (3) Strategic advertising planning, (4) Message strategy, (5) Ads creation, (6) Media planning, (7) Media buying, and (8) Campaign optimisation and evaluation. However, there are three remarks about the new process. First, the new process is no longer linear. Next, the new process is more data-driven. Lastly, while many tasks in the new process are automatically conducted by the programmatic systems, the role of digital specialists remain critical. It is worth mentioning that while these remarks are applicable for the planning and implementation process of both long-term brand building and short-term direct response campaigns, these remarks appear to be more significant for the former. Figure 10 and 11 outline the new advertising process for both campaign types.

The first remark is that the new advertising process is non-linear. It is especially true for short-term direct response campaigns. First, there can be more than one step can happen at the same time, thanks to the underlying programmatic technologies. The DSP would create the ads containing the personalised message and match the size of the ad placement simultaneously in real-time, so the ad creation and the media buying steps happen concurrently. Then, the campaign 
evaluation step is iterated periodically during the campaign period rather than post-campaign, which forms the constant loop from step 2 to step 6 throughout the campaign. At the tactical level, the DSPs would evaluate the effectiveness of each ad version and ad placement based on the target audience's feedback on the ad. The systems, then, make necessary changes to improve the campaign performance. At the planning level, digital specialists would monitor the campaign performance. If there are any new learning or insights emerged from the evaluation process, the digital specialists will make necessary changes to the creative message, audience segmentation, budget allocation among audience subgroups, ad groups and media channels. From this perspective, the advertising process of short-term direct response campaigns appears to be more flexible and adaptive than one of long-term brand building campaigns because the planning and implementation steps interlace with each other throughout the campaign.

On the other hand, the planning stage and implementation stage of longterm brand building campaigns are separated. It can be inferred from the interviews that the planning phase of brand-building campaigns happen before the campaigns start and remain unchanged during the campaign period. Other than that, the implementation phase of long-term brand building campaigns is similar to the one of short-term direct response campaigns.

The next remark, the programmatic advertising process is a data-driven process. First, all optimisation decisions made by the DSP are data-driven. For example, Google DV360 and Facebook ad managers either rely on their built-in audience data or third-party data sources (e.g. DMPs, data provided eCommerce platforms) to decide whether to show an ad to a specific audience and which ad message so forth. Then, the systems rely on the audience's responses of the ad to evaluate if that optimisation decision was effective. Second, the DSPs also offer reporting dashboards (e.g. predictive metrics, historical data) so that digital specialists can quickly access the campaign performance and make a necessary intervention to the systems' optimisation process. The data-driven approach reduces a significant amount of guesswork in the advertising process. Additionally, the available data post campaigns go beyond the traditional digital metrics such as impressions or clicks. Rather, the systems can track and report more comprehensive data such as attribution reports and campaign's audience data, which are valuable for deeper analysis of the campaign performance.

The final remark is programmatic advertising has introduced the automation element to the advertising process. It seems that the automation happens mostly at the optimisation steps (i.e. creative optimisation, bid optimisation, ad placement optimisation). Hence, the digital specialists' role during the implementation steps is to supervise the systems. Yet, the respondents shared that their intervention was still required; the systems were not perfect yet. Nevertheless, the role of digital specialists during an advertising campaign's planning phase remains significant and irreplaceable yet. Lastly, while programmatic advertising offers automation of several tasks, it also creates new tasks for the digital specialist. For instance, the specialists need to create more creative elements to feed the DSP systems so that the systems have more ad combination options for 
optimisation. Also, the specialists need to spend time communicating with different parties as the programmatic ecosystem involves more parties than the traditional direct buy, as well as dealing with the technical issues when setting up programmatic campaigns.

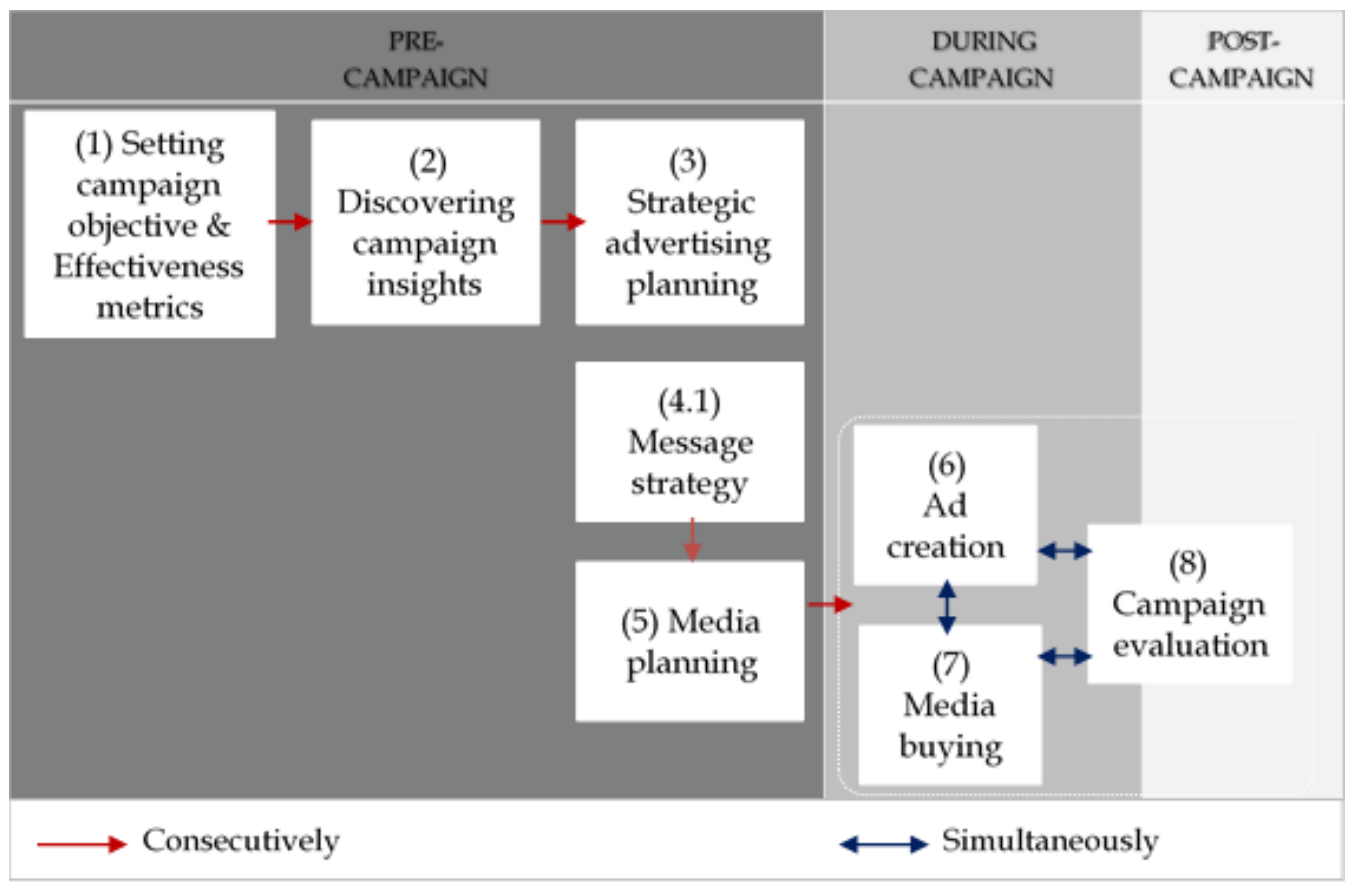

FIGURE 10 Programmatic advertising process of long-term brand building campaign

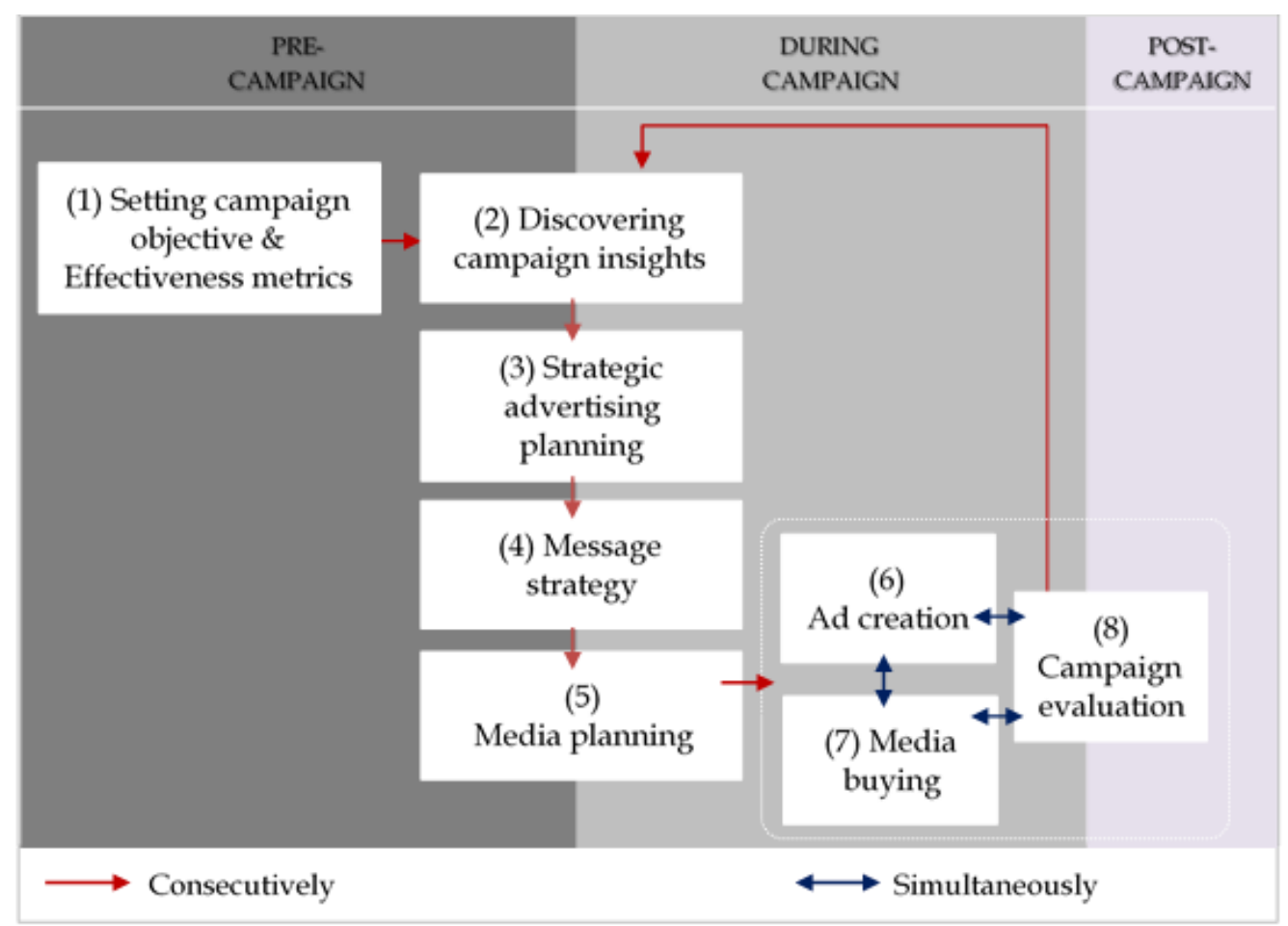

FIGURE 11 Programmatic advertising process of short-term direct response campaign 


\section{DISCUSSION}

This chapter starts by discussing both theoretical implications (Section 5.1) and managerial implications (Section 5.2) of this study. Then, the trustworthiness of the study will be evaluated according to four criteria which are credibility, transferability, dependability and confirmability (Section 5.3). Finally, the study will conclude by presenting the study limitations and proposing ideas for future research (Section 5.4).

\subsection{Theoretical implications}

By reviewing the research literature and analysing the study findings, several theoretical implications were identified. First, the study findings support the model of programmatic advertising by Chen et al. (2019) that programmatic advertising has two components which are programmatic buying and programmatic creative. While the former component is developed, the latter component is still developing. The development stage of two components was reflected through the experience of the study participants. All participants in the study had experience in implementing programmatic buying campaigns, but only a few had experience with programmatic creative. Furthermore, the discussion of programmatic buying was more thorough and in-depth than programmatic creative. For instance, programmatic buying was employed extensively in both long-term brand building and short-term direct response campaigns. The advanced deployment of programmatic buying was also manifested through the sophisticated customer segmentation, as well as the utilisation of lookalike audience targeting to extend the campaign's reach and conversions while addressing the issues of brand safety and viewability. Hence, it is reasonable to suggest that programmatic buying in the local market has reached its highest level, programmatic buying 3.0, according to the definition of Gertz and McGlashan $(2016,57)$.

In contrast, programmatic creative in the local market seems to be still in its developing stage because of two main reasons. First, it can be implied from the study's participants' answers that compared to programmatic buying, there were fewer campaigns implementing programmatic creative. Second, in terms of the platform infrastructure, Chen et al. (2019) state that creative programmatic platforms include includes programmatic creation platform (PCP) and content management platform (CMP). While PCP was mentioned and discussed by the study participants, CMP was not mentioned at all. The findings imply that CMP was not used in the market at the time when this study was conducted because all respondents implementing programmatic creative in their online campaigns had to manually design and upload the creative templates and components into the system. Thus, it is likely that CMP was not available in the market. Though 
the lack of CMP, in reality, can indicate the local market has not reached the technology's state-of-the-art, it seems that the model of programmatic advertising by Chen et al. (2019) needs modification to strengthen its explanatory power.

Next, the study findings of different types of programmatic buying transactions generally agree with the research literature. And the findings suggest that different programmatic inventory types can be combined in one campaign to optimise for the campaign budget and achieve the campaign's KPIs at the same time. That is, RTB programmatic buying is usually less costly than reserved programmatic inventory, but the quality of RTB inventories cannot be as high as reserved programmatic inventory. Hence, programmatic campaigns usually consist of different inventory deals. Furthermore, the study also contributes to programmatic buying's literature by pinpointing the additional motivation of advertisers when adopting programmatic buying for their campaigns. Prior studies state that the most significant benefit of programmatic buying is targeting the right people with the right message at the right time. However, the study findings show that the top reason for local advertisers and agencies using programmatic buying was its ability to consolidate the performance of different channels, which helped reduce ad impression duplication across media channels. Hence, the efficiency of programmatic buying not only because it serves the ads to the right person, but also because it can control and reduce ad duplication on the same person.

The next two theoretical implications concern with the planning and implementation process of programmatic advertising campaigns. The study supports the assertion by Qin and Jiang (2019) that the new process is data-based, tool-based, synchronised and highly efficient with two exceptions. The study findings found that different kinds of data (e.g. audience data, predictive data of the campaign metrics, campaign performance data) were used throughout the process to assist the campaign's planning and optimisation. Also, different tools and platforms were involved in the process. Then, the process is synchronised at the tactical level when the system automatically carries out a series of step (i.e. analysing audience data, choosing ad placement, generating personalised ads, completing ad transaction, and evaluating the ad performance) in real-time. However, there still lacks the synchronisation between the planning and implementation steps because planning steps were still conducted by digital specialists rather than the system. Lastly, in terms of efficiency, as discussed in the previous paragraph, programmatic buying is highly efficient, but the additional fees and biased algorithms challenge the efficiency of the technology. The implications of additional fees and biased algorithms will be discussed further in section 5.2.

Nevertheless, the study findings were not consistent with the four-step advertising process proposed by Qin and Jiang (2019). The case study suggests that there are two planning and implementation processes for the two campaign objective types and both of which are different from the one proposed by Qin and Jiang. The fundamental inconsistency between theoretical framework and study findings is the theoretical advertising process assumes the system can automatically conduct the whole advertising process. In contrast, this study findings suggest that the role of digital specialists remain essential throughout the 
process. The findings indicate that it is unreasonable to assume a fully automated advertising process because the system lacks context to conduct a comprehensive strategic ad planning step such as segmenting and prioritising audience groups, forming campaign's strategic message. Furthermore, because the CMP of programmatic creative was lacking, the digital specialists had to manually upload the creative elements into the system. Yet, were the CMP available in the local market, digital specialists would also be in need to censor the system generated ads to ensure brand guidelines. Likewise, media planning and buying steps also need intervening by digital specialists since there are media metrics that cannot be optimised by the systems yet. For example, DV360 cannot automatically optimise for reach and frequency metrics yet. Then, digital specialists are still responsible for evaluating the ad performance at campaign level since the current fragmented inventory landscape of local market (i.e. local advertisers and agencies leveraged two DSPs which were Facebook ad manager and DV360 in one campaign) causes challenges to a holistic ad attribution process. That is, each DSP can only perform the ad attribution on its platform, but not at the campaign level. All in all, the study argues that the theoretical advertising process by Qin and Jiang (2019) are too optimistic about programmatic advertising's capability.

Lastly, putting programmatic advertising in the broader context of online advertising, programmatic advertising has reinforced both strength and weakness of online advertising. In terms of strength, programmatic advertising with its lookalike targeting technique contributes strengthens the precision targeting capability of online advertising. In terms of weakness, programmatic advertising has not solved the ad measurement issue of online advertising. This study supports the research literature regarding ad impact evaluation per discussion in section 2.4.1 that online advertising is prone to measuring short-term behavioural metrics such as clicks and conversions. That is because programmatic advertising can offer advertisers even more readily available and abundant behavioural data in real-time. Even in the case of long-term brand building campaigns focusing on campaign's reach and frequency performance, these are still campaign-based metrics. There is still a disconnection between these metrics and the brand's longterm metrics such as brand awareness, brand consideration. In conclusion, even though programmatic advertising enhances the online advertising process, it has not addressed the fundamental issue of measuring online advertising effectiveness on long-term brand metrics.

\subsection{Managerial implications}

The study also provides implications which help companies better manage their programmatic advertising campaigns.

First, the study identifies two different planning and implementation processes of programmatic advertising, depending on the campaign objectives. For those campaigns aiming at long-term brand building, the advertising process is 
more straightforward because the planning phase and the implementation phase are separated. That is, the campaign's overall strategies, including customer segments, targeting strategy, creative strategy, media mix remains unchanged throughout the campaign. And, all the decisions during the implementation stage follows the predefined strategies. In contrast, the process for short-term direct response campaigns is more adaptive in the sense that the planning and implementation phases are integrated. And, the study findings suggest that the strategies, especially customer groups, targeting and even creative message, are subject to change during the campaign implementation phase.

Regarding the change in the target groups, it can be implied from the study findings that the advertisers want to prioritise ad spend on those who have the higher potential make a conversion (e.g. make a purchase, register a form) soon to achieve the campaign's KPI. Acknowledging the two processes helps advertisers manage the campaigns more effectively in terms of allocating reasonable time and resources at different stages of the processes. For instance, the process for long-term brand building campaigns can require more time and effort at the planning phase than the implementation phase. On the other hand, shortterm direct response campaigns require the continuous dedication of time and effort at both phases.

The differences between the two process can be explained by the nature of the two campaign types. Short-term direct response campaigns are performancedriven and demand immediate result. In contrast, long-term brand building campaigns aim at the long-term impacts such as changing consumers' perception or behaviour towards the brand. This explanation implies that even though programmatic advertising technologies have somehow changed the advertising process, it is not the sole contributor. The advertisers also play a significant role in shaping the processes the way they are. For instance, the programmatic mechanism works exactly the same in both processes; the audience data and campaign performance data are also collected and available in real-time in both processes. However, it is the digital specialists to decide how to leverage the mechanism in a way that suitable to the campaign's objective, and how and when to utilise these data to effectively plan and optimise the campaign. In that sense, programmatic advertising can help to enhance the advertising campaign performance and the efficiency of advertising spend. Yet, the enhancement level essentially depends on the in-depth understanding and expertise of the digital specialists regarding programmatic advertising specifically and online advertising generally. In other words, adopting programmatic advertising (i.e. shifting budget from traditional direct buy to programmatic buying, and leveraging dynamic ads) just because it has the promising advantage (i.e. deliver the right message to the right person at the right time) without a thorough understanding of the technologies and careful preparation could result in great expectation gap.

The findings from the case study also indicate two main reasons for this expectation gap. First, it is the justification of additional fees (e.g. platform fee, data fee, tech fee) incurred when executing programmatic advertising. As these fees are costly and vary depending on the depth of targeting layers, different 
DMPs, and the sophistication of involved technologies when integrating different intermediates in the programmatic ecosystem, it is critical that advertisers and agencies are well-aware of these fees while planning the campaigns. Additionally, as the data fees keep increasing as more targeting layers are added, the digital specialists need to justify the optimal point between cost and benefit of the additional targeting layers. Furthermore, while the issue of non-transparency fee was not mentioned in this case study, it was discussed in the research literature. Hence, advertisers and agencies should also be aware of this issue in practice. Second, it is the complicated nature of programmatic technologies. The most common issue from the case study was the incompatibility among the platforms, which interrupted the delivery of ad impressions. Moreover, complicated technologies also required more time and technical expertise to set up the programmatic campaigns. This emphasises that digital specialists not only need to be skilful at operating the DSPs but also need to have a systematic understanding of different platforms in the programmatic ecosystem and their working mechanism so that they can execute the campaigns effectively and efficiently.

Next, the case study finds the gap between the practice and theory, which could potentially lead to ineffective implementation of programmatic advertising campaign. First, it is the accuracy and coverage of audience data mentioned by Neumann et al. (2019) and Sylvester and Spaeth (2019). The authors suggest that there is a high chance that those third-party audience data lacks accuracy and coverage because of a variety of reasons such as self-reporting faults, data collection techniques faults, and so on. Second, it is the biased ad delivery and optimisation algorithms discussed by several researchers (i.e. Ali et al. 2019; Gordon et al. 2019; Lambrecht \& Tucker 2019; Lewis et al. 2015). In one instance, the algorithms automatically prioritise showing to one customer segment over the others because of their inherent biases. Those biased algorithms can cause misleading campaign results and evaluation. In the other instance, the algorithms can display the ads to those buyers who would make a conversion regardless of seeing the ads or not. So, the impressions are wasted without earning the additional advertiser conversions. However, both issues seem to be unaware by the digital specialists in the market, which is alarming because audience data and system algorithms are fundamentals of precision targeting of programmatic buying.

Hence, it is suggested that the advertisers and agencies should first acknowledge these issues and take gradual actions to address them. Regarding the accuracy of audience data, advertisers and agencies should start inquiring into the audience data collection and verification process of data vendors. The insights into the process will contribute to the decision of whether to pay data fees to layer additional audience data in the campaigns. Furthermore, if it is possible, systematic assessment of these third-party audience data sources should be conducted. Next, regarding the biased algorithms, it seems that operation of the algorithms is out of digital specialists' control, so there is a low chance for digital specialists to intervene in the systems and mitigate the biases. Having that said, digital specialists should still be mindful of the biased algorithms issue when interpreting the campaign's data, evaluating the campaign performance, and take 
strategic actions based on those data. The fact that the respondents in this study mentioned that the audience data results post-campaign could be used to redefine a brand's target audience underlines this suggestion.

Finally, the study findings suggest that even though programmatic advertising offers automation in the implementation steps (e.g. automatically choose the right ad placement to serve ads, automatically generate personalised ads at large scale), the workload does not necessarily reduce. Digital specialists still need to supervise the system to intervene timely. As explained previously, the technologies are still developing, and technical issues can occur during the campaign period. Nevertheless, too much human intervention is not encouraged because the research literature and the case study's findings imply that the algorithms of programmatic technology can operate and improve based on its feedback loop. Hence, the role of digital specialists should skew towards supervising and guiding the system instead of doing its job. Also, there is an increase in workload concerns with generating more creative templates and components used in dynamic creative so that the systems have resources to create different combinations of ad templates and creative components. This is important as the core of programmatic creative is to create personalised ads at scale, implying that the system needs a significant amount of creative element input to customise ads relevant to a different audience in different contexts. In other words, lack of creative component inputs hinders the strength of dynamic creative. In conclusion, the automation offered by programmatic technology should be viewed as an extension of digital specialists which helps them to better plan and implement online campaigns rather than to replace them.

\subsection{Evaluating the study}

This section aims to evaluate the quality of the study. Yin $(2009,42-45)$ mentions a framework including four tests to evaluate access to the quality of a case study research. The four tests are construct validity, internal validity, external validity, and reliability. However, the author also acknowledges the challenges of applying these four tests to judge the quality of a case study, because validity and reliability deal with objective measurement and causal relationships which are typically obtained through a quantitative study rather than qualitative study. Also, the fact that a case study cannot be replicated in the laboratory environment reinforces the challenge of accessing the study results based on validity and reality criteria. Indeed, Bryman and Bell (2011, 395-399) confirm that the concepts of validity and reliability are borrowed concepts from quantitative studies, and they are not reasonable criteria for evaluating the qualitative study. Instead, the authors suggest that qualitative should be accessed based on the study's trustworthiness which includes four tests, credibility, transferability, dependability, and confirmability (Guba and Lincoln 1994, as cited in Bryman \& Bell 2011, 395-399). 
Credibility refers to whether the study findings accurately reflected the respondents' opinions and perspectives. Two techniques to test credibility are data triangulation and respondent validation. The former technique involves using more than one data source to cross-check the findings and seek potential inconsistencies in the findings. The latter technique involves asking the respondents to review the study findings to ensure the findings are consistent with their perspectives (Bloomberg \& Volpe 2008, 77-78; Bryman \& Bell 2011, 395-399). Accordingly, this study is deemed to be credible because the data were collected from interviews with experienced digital specialists from different organisations and product segments of both client-side and agency side. Also, the findings were reviewed by the respondents who agreed the findings were consistent with the interview answers.

Transferability indicates the depth of the context description and defines the scope of the study results. In other words, the more specific and detailed the research context, the better it is for readers to decide if the study results are applicable (i.e. transferable) to other cases with similar context. (Bloomberg \& Volpe 2008, 77-78; Bryman \& Bell 2011, 395-399). The case's context was also described in the methodology chapter accordingly. Furthermore, since transferability is different from generalisation, the scope for this study results are limited within the programmatic advertising of the examined market.

Dependability concerns with whether the study design and data collection and analysis process were explained with adequate details so that other researchers can replicate the study or audit the research procedure if they wish to (Bloomberg \& Volpe 2008, 77-78; Bryman \& Bell 2011,395-399). Chapter 3 of this study documented the research procedures and rationales in great details. Appendix 2 also provided the interview guide which stipulates the pre-defined interview themes and interview questions. In that sense, the study procedure can be repeated and should obtain comparable findings.

Confirmability deals with the objectivity of data analysis and interpretation. That is, the study results are impartial and free from the researcher's bias (Bloomberg \& Volpe 2008, 77-78; Bryman \& Bell 2011, 395-399). It is reasonable to assume the confirmability of this study as the researcher has no financial incentive to manipulate the study findings. Furthermore, the data analysis and interpretation process were conducted diligently to minimise personal bias or theoretical preference. Also, the findings included direct quotes from the respondents as supporting evidence. Lastly, the study findings were reviewed and confirmed by the respondents.

In conclusion, the evaluation shows that the study is reasonably trustworthy according to four assessment criteria which are credibility, transferability, dependability, and confirmability. 


\subsection{Limitations of the study and ideas for future research}

The study is subject to the common critique of a case study research. That is, the study findings are limited to the investigated case only. In that sense, the scope of study findings would be mainly applicable for advertisers in the Vietnam market. However, as previously discussed, the value of a case study research does not lie in generalisation, but to gain an in-depth understanding of a phenomenon. Hence, the findings should be read in line with the case context to be meaningful. Another limitation concerns the differences between the thesis's language (i.e. English) and the interview language (i.e. Vietnamese). While translation gap was inevitable, a back-translation process was conducted to minimise translation gap.

Next, the thesis proposes three ideas for future research. First, as the research was conducted from the perspective of the buy-side represented by the digital specialists from advertisers and agencies, future research from the perspective of sell-side such as publishers would give a more holistic understanding on the phenomenon. This study findings suggest that the planning and implementation process of programmatic advertising has been significantly influenced by the quality and availability of ad inventory, implying the importance of publishers in the programmatic ecosystem. Yet, little is known about how the publishers plan and price their inventories for different inventory types (e.g. traditional direct buy, programmatic guaranteed inventories, RTB inventories). Hence, the research on the publishers' revenue models should be relevant and valuable.

Second, both literature review and study findings indicate the gap of programmatic creative in theory and in practice. Also, while conducting the literature review, the study finds that there are limited research papers on the topic, especially the intermediaries and platforms of programmatic creative and their working mechanisms. Further research about this component of programmatic advertising will not only result in a holistic understanding of the topic in theory, but also help accelerate the development of programmatic creative in practice.

Lastly, the study proposes future research to study the long-term impact of programmatic advertising on brandings such as brand attitudes and brand equity. Chen et al. (2019) and $\mathrm{Li}$ (2019) argue that while the effect of programmatic advertising is evident in short-term direct campaigns, its long-term impact on the brand is unclear. Indeed, the study also supports this argument because all respondents in the study shared that either their companies or their clients conducted any research measuring programmatic advertising effectiveness on brands. Such a study is essential for two reasons. First, programmatic advertising promotes different targeting practice (i.e. micro-targeting and large-scale personalised ads) with the traditional mass targeting. Though, there are few studies proving that micro-targeting and personalised ads are more effective at longterm brand building compared to the traditional mass targeting. Second, programmatic advertising contains black boxes such as biases in ad delivery and optimisation algorithms of programmatic advertising, which could potentially harm brands in the long-term. 


\section{REFERENCES}

Agrawal, N., Najafi-Asadolahi, S. \& Smith, S. A. 2020. Optimization of operational decisions in digital advertising: A literature review. In S. Ray \& S. Yin (Eds.) Channel Strategies and Marketing Mix in a Connected World. Cham, Switzerland: Springer, 99-146.

Ali, M., Sapiezynski, P., Bogen, M., Korolova, A., Mislove, A. \& Rieke, A. 2019. Discrimination through optimization. Proceedings of the ACM on HumanComputer Interaction 3, 1-30.

Balseiro, S. R., Feldman, J., Mirrokni, V. \& Muthukrishnan, S. 2014. Yield optimization of display advertising with ad exchange. Management Science 60(12), 2886-2907.

BCG. 2018. A guaranteed opportunity in programmatic advertising. [Referred 21.04.2020] Available at: <URL: https:/ / www.bcg.com/publications/2018/guaranteed-opportunity-programmatic-advertising.aspx>

Bloomberg, L. D. \& Volpe, M. 2008. Completing your qualitative dissertation: A roadmap from beginning to end. Thousand Oaks, CA: SAGE.

Braun, M. \& Moe, W. W. 2013. Online display advertising: Modeling the effects of multiple creatives and individual impression histories. Marketing Science 32(5), 753-767.

Braun, V. \& Clarke, V. 2006. Using thematic analysis in psychology. Qualitative Research in Psychology 3(2), 77-101.

Bruce, N. I., Murthi, B.P.S. \& Rao, R. C. 2017. A dynamic model for digital advertising: The effects of creative format, message content, and targeting on engagement. Journal of Marketing Research 54(2), 202-218.

Bryman, A. \& Bell, E. 2011. Business research methods. 3rd edition. New York: Oxford University Press.

Cai, H., Ren, K., Zhang, W., Malialis, K., Wang, J., Yu, Y. \& Guo, D. 2017. Realtime bidding by reinforcement learning in display advertising. Proceedings of the Tenth ACM International Conference on Web Search and Data Mining. New York: Association for Computing Machinery, 661-670.

Campaign US. 2019. 8 in 10 industry pros say brand safety issues have improved. [Referred 16.02.2020] Available at: <URL: https:/ / www.campaignlive.com/article/8-10-industry-pros-say-brand-safety-issues-improved/1525321>

Craig, C. \& Douglas, S. P. 2005. International marketing research. $3^{\text {rd }}$ edition. West Sussex: John Wiley \& Sons.

Chaffey, D. \& Ellis-Chadwick, F. 2016. Digital marketing. $6^{\text {th }}$ edition. Harlow: Pearson.

Chen, G., Xie, P., Dong, J. \& Wang T. 2019. Understanding programmatic creative: The role of AI. Journal of Advertising 48(4), 347-355.

Chen, S. 2020. The emerging trend of accurate advertising communication in the era of big data - The case of programmatic, targeted advertising. In J. S. Pan, 
J. Li, P. W. Tsai \& L. Jain (Eds.) Advances in Intelligent Information Hiding and Multimedia Signal Processing. Smart Innovation, Systems and Technologies 156. Singapore: Springer, 299-308.

Chen, Y. J. 2017. Optimal dynamic auctions for display advertising. Operations Research 65(4), 897-913.

Choi, H. \& Mela, C. 2019. Display advertising pricing in exchange markets. Working paper.

Choi, H., Mela, C., Balseiro, S. R. \& Leary, A. 2019. Online display advertising markets: A literature review and future directions. Columbia Business School Research Paper 18-1.

De Pelsmacker, P., Geuens, M. \& Van den Bergh, J. 2017. Marketing communications: A European perspective, $6^{\text {th }}$ edition. Harlow, UK: Pearson Education.

Deng, S., Tan, C. W., Wang, W. \& Pan, Y. 2019. Smart generation system of personalized advertising copy and its application to advertising practice and research. Journal of Advertising 48(4), 356-365.

Digiday. 2017. Digital ad concerns have an unlikely winner: Emerging markets. [Referred 21.04.2020] Available at: <URL: https:/ / digiday.com/?p=251945>

Disruptor Daily. 2017. The history of programmatic advertising: Everything you need to know. [Referred 15.02.2020] Available at: <URL:

https:/ / www.disruptordaily.com/the-history-of-programmatic-advertising-everything-you-need-to-know / >

Drèze, X. \& Hussherr, F. X. 2003. Internet advertising: Is anybody watching? Journal of Interactive Marketing 17(4), 8-23.

Estrada-Jiménez, J., Parra-Arnau, J., Rodríguez-Hoyos, A. \& Forné, J. 2017. Online advertising: analysis of privacy threats and protection approaches. Computer Communications 100, 32-51.

Evans, D. 2009. The online advertising industry: Economics, evolution, and privacy. The Journal of Economic Perspectives 23(3), 37-60.

Gertz, O. \& McGlashan, D. 2016. Consumer-centric programmatic advertising. In O. Busch (Ed.) Programmatic Advertising: The Successful Transformation to Automated, Data-Driven Marketing in Real Time. Switzerland: Springer, $55-73$.

Ghose, A. \& Yang, S. 2009. An empirical analysis of search engine advertising: Sponsored search in electronic markets. Management Science 55(10), 16051622.

Goldfarb, A. 2014. What is different about online advertising. Review of Industrial Organization 44(2), 115-129.

Goldfarb, A. \& Tucker, C. 2011. Online display advertising: Targeting and obtrusiveness. Marketing Science 30(3), 389-404.

Goldfarb, A. \& Tucker, C. 2015. Standardization and the effectiveness of online advertising. Management Science 61(11), 2707-2719.

Gordon, B. R., Jerath, K., Katona, Z., Narayanan, S., Shin, J. \& Wilbur, K. C. 2019. Inefficiencies in digital advertising markets. SSRN Electronic. 
Guest, G., Bunce, A. \& Johnson, L. 2006. How many interviews are enough? An experiment with data saturation and variability. Field Methods 18(1), 59-82.

Ha, L. 2008. Online advertising research in advertising journals: A review. Journal of Current Issues \& Research in Advertising 30(1), 31-48.

Hair, J. F. Jr., Celsi, M., Money, A., Samouel, P. \& Page, M. 2016. Essentials of business research methods. $3^{\text {rd }}$ edition. New York: Routledge.

IAB. 2014. Programmatic everywhere? Data, technology and the future of audience engagement. [Referred 18.01.2020] Available at: <URL:

https://www.iab.com/insights/programmatic-everywheredata-technology-and-the-future-of-audience-engagement/>

IAB. 2016. The programmatic supply chain. [Referred 19.01.2020] Available at: <URL: https://www.iab.com/wp-content/uploads/2016/03/Programmatic-Value-Layers-March-2016-FINALv2.pdf>

IAB. 2019a. IAB internet advertising revenue report. 2018 full year results. [Referred 30.01.2020] Available at: <URL: https:/ / www.iab.com/insights/2018-full-year-iab-internet-ad-revenue-report/>

IAB. 2019b. Artificial intelligence in marketing report. [Referred 18.01.2020] Available at: <URL: https:/ / www.iab.com/insights/iab-artificial-intelligence-in-marketing/>

IAB. 2020. Glossary of terminology. [Referred 30.01.2020] Available at: <URL: https://www.iab.com/insights/glossary-of-terminology/>

IAB UK. 2017. Guide to digital display advertising [Video file]. [Referred 09.03.2020] Available at: <URL: https:/ / youtu.be/efHVOWcNJZo>

IAB UK. 2019. UK viewability hits highest point ever. [Referred 16.02.2020] Available at: <URL: https:/ / www.iabuk.com/opinions/uk-viewabilityhits-highest-point-ever $>$

Johnson, G. A., Lewis, R. A. \& Nubbemeyer, E. I. 2017. The online display ad effectiveness funnel \& carryover: Lessons from 432 field experiments. SSRN Electronic.

Johnston, W. J., Leach, M. P. \& Liu, A. H. 1999. Theory testing using case studies in business-to-business research. Industrial Marketing Management 28(3), 201-213.

Kietzmann, J., Paschen, J. \& Treen, E. 2018. Artificial intelligence in advertising: How marketers can leverage artificial intelligence along the consumer journey. Journal of Advertising Research 58(3), 263-267.

Klapdor, S. 2013. Effectiveness of online marketing campaigns. An investigation into online multichannel and search engine advertising. Munich: Springer.

Kohavi, R., Longbotham, R., Sommerfield, D. \& Henne, R. M. 2009. Controlled experiments on the web: Survey and practical guide. Data mining and knowledge discovery 18(1), 140-181.

Kumar, V. \& Gupta, S. 2016. Conceptualizing the evolution and future of advertising. Journal of Advertising 45(3), 302-317.

Lambrecht, A. \& Tucker, C. 2013. When does retargeting work? Information specificity in online advertising. Journal of Marketing Research 50(5), 561-576. 
Lambrecht, A. \& Tucker, C. 2019. Algorithmic bias? An empirical study of apparent gender-based discrimination in the display of stem career ads. Management Science 65(7), 2966-2981.

Lewis, R., Rao, J. M. \& Reiley, D. H. 2015. Measuring the effects of advertising: The digital frontier. In A. Goldfarb, S. M. Greenstein \& C. E. Tucker (Eds.) Bureau of Economic Research: Economic Analysis of the Digital Economy. USA: University of Chicago Press, 191-218.

Li, H. 2017. Pre-conference session: Toward a new discipline of computational advertising. American Academy of Advertising, 4-6.

Li, H. 2019. Special section introduction: Artificial intelligence and advertising. Journal of Advertising 48(4), 333-337.

Malthouse, E. C., Maslowska, E. \& Franks, J. U. 2018. Understanding programmatic $t v$ advertising. International Journal of Advertising 37(5), 769-784.

Manchanda, P., Dubé, J. P., Goh, K.Y. \& Chintagunta, P. K. 2006. The effect of banner advertising on internet purchasing. Journal of Marketing Research 43(1), 98-108.

Mantere, S. \& Ketokivi, M. 2013. Reasoning in organization science. Academy of Management Review 38(1), 70-89.

Market Realist. 2019. Why the Vietnamese market is important for Facebook. [Referred 15.04.2020] Available at: <URL: https:/ / marketrealist.com/2019/01/why-the-vietnamese-market-is-important-for-facebook>

Mediacom. 2018. Automated output, human input: The secrets of effective programmatic creative. [Referred 15.02.2020] Available at: < URL: https://www.mediacom.com/en/think/blog/2018/automated-outputhuman-input-the-secrets-of-effective-programmatic-creative>

Mopinion. 2019. Top 10 data management platforms: An overview. [Referred 17.02.2020] Available at: <URL: https://mopinion.com/top-10-data-management-platforms-dmp/>

MMA. 2018. Mobile ecosystem \& sizing report - Vietnam 2017/8. [Referred 16.04.2020] Available at: <URL: http://vietnam.mmaglobal.com/wp-content/uploads/2018/11/mma_mobile_marketing_ecosystem_report_2017_-_vietnam_0.pdf>

Neumann, N., Tucker, C.E. \& Whitfield, T. 2019. How effective is third-party consumer profiling and audience delivery? Evidence from field studies. Marketing Science 38(6), 918-926.

Nisar, T. M \& Yeung, M. 2018. Attribution modeling in digital advertising. An empirical investigation of the impact of digital sales channels. Journal of Advertising Research 58(4), 399-413.

Palos-Sanchez, P., Saura, J. R. \& Martin-Velicia, F. 2019. A study of the effects of programmatic advertising on users' concerns about privacy overtime. Journal of Business Research 96, 61-72.

Perry, C. 1998. Processes of a case study methodology for postgraduate research in marketing. European Journal of Marketing 32(9/10), 785-802. 
Qin, R., Yuan, Y. \& Wang, F. Y. 2017. Exploring the optimal granularity for market segmentation in RTB advertising via computational experiment approach. Electronic Commerce Research and Applications 24, 68-83.

Qin, X. \& Jiang, Z. 2019. The impact of AI on the advertising process: the Chinese experience. Journal of Advertising 48(4), 338-346.

Sahni, N. S. 2015. Effect of temporal spacing between advertising exposures: Evidence from online field experiments. Quantitative Marketing and Economics 13(3), 203-247.

Sayedi, A. 2018. Real-time bidding in online display advertising. Marketing Science 37(4), 553-568.

Schultz, D. 2016. The future of advertising or whatever we're going to call it. Journal of Advertising 45(3), 276-285.

Sharp, B. 2013. Marketing: theory, evidence, practice. Australia: Oxford University Press.

Sven, W. \& Owens, C. 2016. The creative challenge: How to transform programmatic media to dynamic brand messaging. In O. Busch (Ed.) Programmatic Advertising: The Successful Transformation to Automated, Data-Driven Marketing in Real Time. Switzerland: Springer, 123-130.

Sylvester, A. K. \& Spaeth, J. 2019. Precise targeting foiled by imprecise data. Why weak data accuracy and coverage threaten advertising effectiveness. Journal of Advertising Research 59(2), 133-136.

Tellis, G. J. 2009. Generalizations about advertising effectiveness in markets. Journal of advertising research 49(2), 240-245.

The Information. 2019. Facebook and Google balance booming business with censorship pressure in Vietnam. [Referred 15.04.2020] Available at: <URL: https:// www.theinformation.com/articles/facebook-and-google-balancebooming-business-with-censorship-pressure-in-vietnam>

The Drum. 2019. Look at these advertising trends in emerging markets. [Referred 21.04.2020] Available at: <URL: https:/ / www.thedrum.com/profile/alf-insight/news/look-at-these-advertising-trends-in-emerging-markets>

Tinuiti. 2018. An in-depth look at Facebook dynamic creative ads. [Referred 15.02.2020] Available at: <URL: https://tinuiti.com/blog/paid-social/anin-depth-look-at-facebook-dynamic-creative-ads/>

Tubemogul. 2020. Ad glossary. [Referred 06.04.2020] Available at: <URL: https://www.tubemogul.com/glossary/>

Wang, J., Zhang, W. \& Yuan, S. 2017. Display advertising with real-time bidding (RTB) and behavioural targeting. Foundations and Trends ${ }^{\circledR}$ in Information Retrieval 11(4-5), 267-435.

WeAreSocial. 2020. Digital 2020: Vietnam. [Referred 15.04.2020] Available at: <URL: https:/ / datareportal.com/reports/digital-2020-vietnam>

Yang, Y., Yang, Y.C., Jansen, B.J. \& Lalmas, M. 2017. Computational advertising: A paradigm shift for advertising and marketing? IEEE Intelligent Systems 32(3), 3-6. 
Yin, R. K. 2009. Case study research: Design and methods. $4^{\text {th }}$ edition. Los Angeles: Sage.

Zhang, W., Yuan, S. \& Wang, J. 2014. Optimal real-time bidding for display advertising. Proceedings of the 20th ACM SIGKDD international conference on Knowledge Discovery and Data Mining. New York: Association for Computing Machinery, 1077-1086.

Zhu, Y. \& Wilbur, K. C. 2011. Hybrid advertising auctions. Marketing Science $30(2), 249-273$. 


\section{APPENDIX 1 FLOWCHART OF RTB PROCESS}

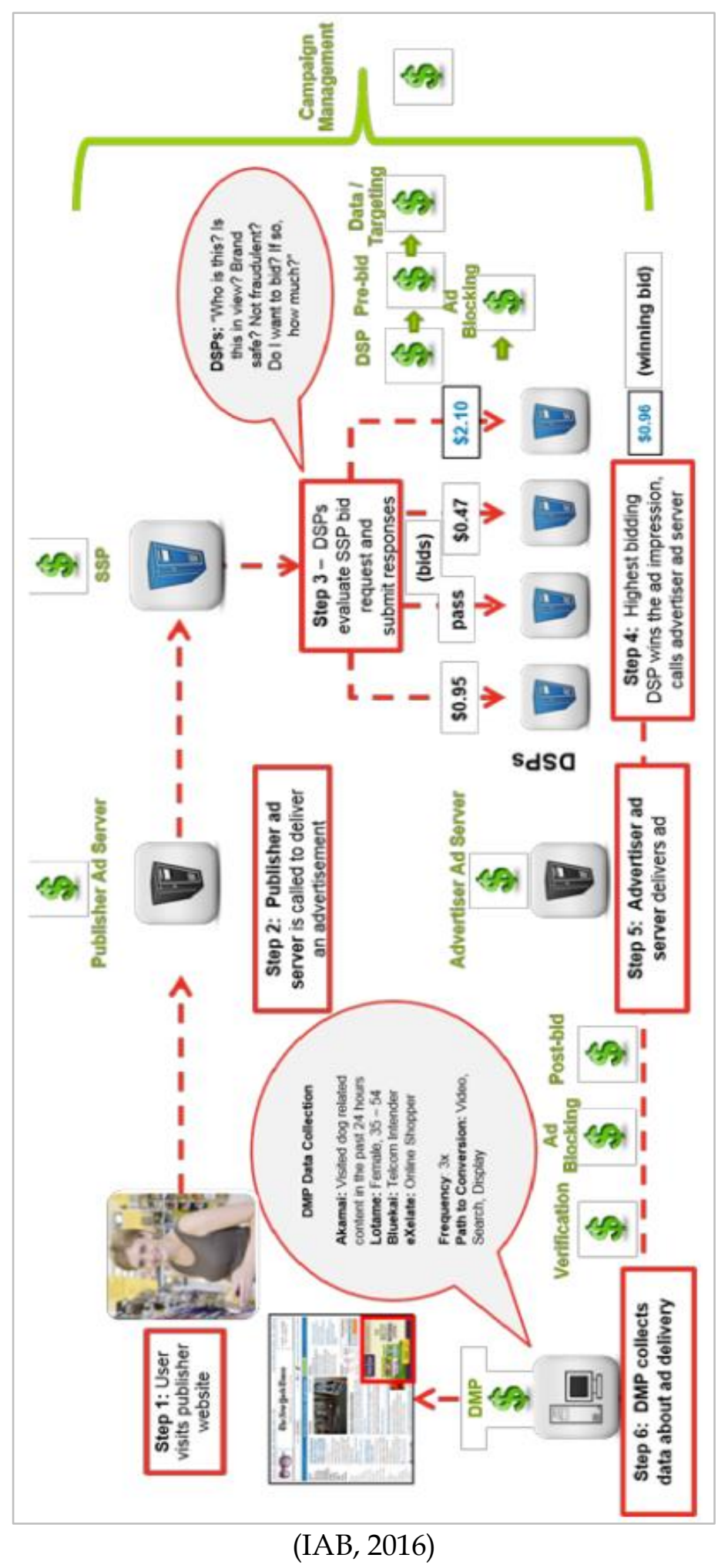




\section{APPENDIX 2 INTERVIEW GUIDE}

Part 1: Interviewee's background information:

1) Name, job title, organisation (Client vs. Agency)

2) Number of years working in digital advertising

3) Has experience in plan/execute programmatic ad in the past 12 months

\section{Part 2: Warm up questions}

1) How do you define programmatic advertising?

2) Could you briefly tell your experiences with programmatic ad campaigns? (e.g. number of campaigns, how often, etc.)

\section{Part 3: Categories and tentative questions}

(1) Campaign objective and effectiveness metrics

- Campaign objective: programmatic ads are usually used for which campaign objectives (e.g. brand awareness, consideration, promotion, lead gen, etc.)? Is there any specific objective that leverage programmatic advertising by default?

- What were the campaign metrics in correspondence to the objective?

(2) Campaign insight discovery

- How was this step conducted?

- Added value from programmatic ads?

(3) Customer segmentation and targeting

- How did you segment different audience groups for targeting?

- Purpose of audience segmentation? And, the objectives for each target audience group?

- Was there any involvement of data sources (e.g. CRM data, data collected from previous campaigns, leverage data from DMPs, other sources)?

$\circ$ If yes, how useful are these data sources? And, did these data sources are used separately or in combination?

- If no, why not use them?

- Pros and cons of each data sources?

- Segmenting audience for programmatic ad

(4) Campaign planning

- Did the campaign also include other online display formats?

- If yes, why? And can you tell the budget split between them?

- If no, why not? And, why did you choose programmatic display ads over other online ads (e.g. fixed duration, ad network, etc.)?

- Pros and cons of using programmatic ads 
- Planning approach between programmatic ads (In terms of strategy, data checking, new tasks or new parties involved, lead time, etc.)

\section{(5) Campaign implementation}

- Which platforms/ channels did you use in those campaigns (e.g. DV360, DoubleClick, Facebook, etc.)? Why is that?

- What kind of programmatic inventories did you buy (e.g. programmatic guaranteed inventory, preferred deal, private RTB, open RTB)? Why?

- What kind of creative assets did you use in those campaigns (e.g. video, standard banners, rich formats, dynamic creative, etc.)? Are there any formats are more preferred than the others?

- The implementation process between programmatic ads. In terms of:

- Creative optimisation, cost optimisation, metrics optimisation, etc.

- The use of data in the optimisation process

- Were there any tasks newly emerged or disappear due to using programmatic ads (e.g. data analysis, more communications involve...)

- The level of automation in the implementation process: fully automated (i.e. the system optimises the creatives, targeting, bid...) vs. partially automated (i.e. there is human intervention in the process)? When and where human intervention was required?

\section{(6) Campaign evaluation}

- Campaign evaluation of programmatic advertising and other online display ads? Did programmatic advertising help to solve certain measurement problems?

- The Results vs. Planned? And, any challenges hindering delivery of programmatic ad? How did/should you solve them?

- Cost-effectiveness of programmatic advertising

- Effectiveness of programmatic ad in terms of sales, market share, brand impact both long term and short term? 